Aus dem Department für Endokrinologie

(Prof. Dr. med. W. Wuttke)

der Medizinischen Fakultät der Universität Göttingen

Die Effekte von

Estradiol, Testosteron, Belamcanda chinensis und Cimicifuga racemosa auf die Expression von IGF-1

in Knochen und Leber von orchiektomierten Ratten

\author{
INAUGURAL-DISSERTATION \\ zur Erlangung des Doktorgrades \\ der Medizinischen Fakultät \\ der Georg-August-Universität zu Göttingen
}

vorgelegt von
Kamyar Emami
aus Teheran / Iran

Göttingen 2009 
Dekan: Prof. Dr. med. C. Frömmel

I. Berichterstatter: Prof. Dr. med. W. Wuttke

II. Berichterstatter / in:

III. Berichterstatter / in:

Tag der mündlichen Prüfung: 
Meiner Ehefrau und meinen Eltern gewidmet 
1. Einleitung und Zielsetzung $\quad 7$

2. Literaturübersicht 9

2. 1. Insulin-like Growth Factor 1 (IGF-1) 9

2. 1. 1. IGF-1-Rezeptor 10

2. 1. 2. IGF-Bindungsproteine (IGFBP) 11

2. 1. 3. Regulation der IGF-1-Synthese 12

2. 1. 4. Biologische Wirkungen 12

2. 1. 4. 1. Wachstumsstimulierende Wirkungen 13

2. 1. 4. 1. 1. Lokale Wirkungen von IGF-1 im Knochengewebe 14

2. 1. 4. 2. Metabolische Wirkungen 14

2. 1. 5. Kanzerogene Wirkungen 15

2. 2. Androgene 16

2. 2. 1. Biosynthese und Metabolismus 16

2. 2. 2. Wirkungsmechanismus 17

2. 2. 3. Biologische Wirkungen 17

2. 2. 3. 1. Knochengewebe 17

2. 2. 3. 2. Leber 19

2. 3. Partielles Androgendefizit des alternden Mannes (PADAM) 19

2. 3. 1. Substitutionstherapie mit Testosteron 21

2.4. Östrogene 22

2. 4. 1. Wirkungsmechanismus 22

2. 4. 2. Folgen des Östrogenmangels im Knochen 24

2. 5. Phytoöstrogene 25

2. 5. 1. Belamcanda chinensis (BC) 27

2. 5. 2. Cimicifuga racemosa (CR) 29

3. Material und Methoden 32

3. 1. Tierexperimente 32

3. 1. 1. Versuchstiere und Haltungsbedingungen 32

3. 1. 2. Orchiektomie 32

3. 1. 3. Durchführung der Tierversuche 32

3. 1. 4. Testsubstanzen 33 
3. 1. 5. Versuchsende 34

3. 2. Analytische Methoden 34

3. 2. 1. Präparation von Gewebeproben zur Bestimmung der 34 IGF-1-Konzentration

3. 2. 1. 1. Prinzip 34

3. 2. 1. 2. Durchführung 34

3. 2. 2. Radio-Immunoassay zur quantitativen Bestimmung von 35 Insulin-like Growth Factor 1 der Ratte (r-IGF-1)

3. 2. 2. 1. Prinzip des Radio-Immunoassays (RIA) 35

3. 2. 2. 2. Verwendete Substanzen 36

3. 2. 2. 3. Durchführung des RIA 37

3. 2. 3. Gesamtproteinbestimmung 38

3. 2. 3. 1. Versuchsprinzip 38

3. 2. 3. 2. Verwendete Substanzen 38

3. 2. 3. 3. Durchführung 39

3. 2. 4. TaqMan-Polymerase-Kettenreaktion 40

3. 2. 4. 1. Isolierung von Gesamt-RNA 40

3. 2. 4. 1. 1. Vorsichtsmaßnahmen im Umgang mit der RNA 40

3. 2. 4. 2. Reverse Transkription $\quad 40$

3. 2. 4. 3. Polymerase-Kettenreaktion (PCR) 41

3. 2. 4. 3.1. PCR-Primer 42

3. 2. 4. 4. TaqMan-PCR 43

3. 2. 4. 4. 1. Auswahl der Sonden für die TaqMan-PCR 44

3. 2. 4. 4. 2. Durchführung des TaqMan-PCR-Assays 45

3. 2. 4. 4. 3. ABI PRISM 7700 Sequence Detection System 45

3. 3. Statistische Auswertung 46

4. Ergebnisse $\quad 47$

4. 1. Knochen (Femur) 47

4. 1. 1. Genexpression von IGF-1 im Knochen 47

4. 1. 2. IGF-1-Konzentration bezogen auf das Volumen der 48 pufferhaltigen Probelösung im Knochen

4. 1. 3. IGF-1-Konzentration bezogen auf das Gesamtprotein im Knochen 49 
4. 1. 4. Einschätzung der Korrelation zwischen der Genexpression und der Proteinkonzentration (ng/ml) im Knochen

4. 1. 5. Einschätzung der Korrelation zwischen der Genexpression und der Proteinkonzentration (ng/mg) im Knochen

4. 2. Leber 52

4. 2. 1. Genexpression von IGF-1 in der Leber

4. 2. 2. IGF-1-Konzentration bezogen auf das Volumen der pufferhaltigen Probelösung in der Leber

4. 2. 3. IGF-1-Konzentration bezogen auf das Gesamtprotein in der Leber

4. 2. 4. Einschätzung der Korrelation zwischen der Genexpression und der Proteinkonzentration $(\mathrm{ng} / \mathrm{ml})$ in der Leber

4. 2. 5. Einschätzung der Korrelation zwischen der Genexpression und der Proteinkonzentration (ng/mg) in der Leber

5. Diskussion

6. Zusammenfassung

7. 1. Abkürzungverzeichnis 75

7. 2. Abbildungsverzeichnis 77

8. Literaturverzeichnis 


\section{Einleitung und Zielsetzung}

Im Gegensatz zu der abrupten Abnahme der Östrogene während der weiblichen Menopause verläuft der männliche Alterungsprozeß langsam und mit hoher individueller Variabilität. Der Begriff Partielles Androgendefizit des alternden Mannes (PADAM) beschreibt den Alterungsprozeß präziser und zutreffender als Begriffe wie männliches Klimakterium oder Andropause (Schill, 2001). Ab dem 60. Lebensjahr wird der altersassoziierte Rückgang des Testosteronspiegels in Männern statistisch relevant, da die endogene Androgenproduktion nachläßt (Vermeulen, 1988). Der Hypogonadismus im Mann kann neben sexuellen Dysfunktionen und psychovegetativen Beschwerden, Abnahme der Muskelmasse sowie Anämie insbesondere zur Osteoporose führen. Albright und Reifenstein berichteten früh über eine Osteoporose-Entwicklung in Eunuchen (Albright und Reifenstein, 1948). Die Osteoporose kann mit diffusen Knochenschmerzen und erhöhter Frakturgefährdung einhergehen (Schill, 2001). Statistisch tritt jede dritte Hüftfraktur bei Männern auf, und mehr als $11 \%$ der männlichen Bevölkerung im Alter von über 50 Jahren erleiden diese Fraktur (Kastelan, 2007). Angesicht der zunehmenden Lebenserwartung der Bevölkerung, besonders in den Industrieländern, nehmen die Folgen des Partiellen Androgendefizits des alternden Mannes an Bedeutung zu. Eine Testosteronsubstitution hypogondaler Männer birgt gewisse Gefahren in sich. Die Entwicklung einer Polyzythämie (Hajjar et al., 1997) und insbesondere die Entstehung eines Prostatakarzinoms (Djavan und Marberger, 2002) können im Rahmen der Testosteronbehandlung auftreten, die regelmäßige Kontrollen des Blutbilds und des urologischen Status erforderlich machen. Allerdings ist die aktuelle Datenlage bezüglich der Vor- und Nachteile einer Langzeitbehandlung mit Testosteron sehr dürftig (Schill, 2001). Deshalb konzentriert sich die medizinische Forschung gegenwärtig auf alternative Therapiemöglichkeiten der Osteoporose bei Männern mit manifestem Androgenmangel. Dabei ist man auf die beiden Arzneipflanzen Belamcanda chinensis (BC) und Cimicifuga racemosa (CR), die in dieser experimentellen Arbeit verwendet werden, aufmerksam geworden. Für BC und die aus inrem Wurzelstock isolierten Isoflavone Tectoridin und Tectorigenin konnten in tierexperimentellen Untersuchungen an weiblichen ovarektomierten Ratten eine osteoprotektive Wirksamkeit und eine Aktivität als Selective Estrogen Receptor Modulator (SERM) nachgewiesen werden (Seidlova-Wuttke et al., 2000; Becker, 2002). Auch für $C R$, die seit langem in der Prophylaxe und Therapie 
postmenopausaler Beschwerden der Frau Verwendung findet, konnte in zahlreichen klinischen und tierexperimentellen Studien belegt werden, daß sie den Prozeß der Osteoporose aufhält (Viereck et al., 2005; Seidlova-Wuttke et al., 2003; Wuttke et al., 2002 b). Außerdem wurde für beide Arzneipflanzen eine inhibitorische Wirkung auf das Prostatakarzinom sowohl in vitro als auch in vivo beschrieben (Jarry et al., 2007; Thelen et al., 2005).

In dieser experimentellen Arbeit wurden männliche orchiektomierte (orx) Ratten verwendet, die ein etabliertes und vereinfachtes Modell für die endokrinologischen Verhältnisse im hypogonadalen Mann darstellen (Stürmer et al., 2006; Franklin M et al., 2006). In dieser Studie beschäftigten wir uns mit der Analyse von Insulin-like Growth Factor 1 (IGF-1) in Knochen (Femur) und Leber der orchiektomierten Ratten, die mit Estradiol 17-beta, Testosteron und Extrakten aus BC und CR vorbehandelt worden waren. IGF-1 nimmt bekanntermaßen eine bedeutende Rolle im Knochenmetabolismus und im Pathomechanismus der Osteoporose ein und ist ein Marker des Knochenaufbaus (Kies und Höflich, 1995; Rosen und Donahue, 1998). Dabei ist die Leber als Hauptbildungsort der IGFs, von der diese in die Blutbahn gelangen und ihre endokrine Wirkungen entfalten, ein interessantes Untersuchungsobjekt. Außerdem wird das zirkulierende IGF-1 mit der Entstehung von Malignomen und mit einer Abnahme der Lebenserwartung in Verbindung gebracht (Campagnoli et al., 1994; McCarty, 2004). 


\section{Literaturübersicht}

\section{1. Insulin-like Growth Factor 1 (IGF-1)}

Man konnte für eine lange Zeit die Diskrepanz zwischen der Wirkung des hypophysären Wachstumshormons (growth hormone: $\mathrm{GH}$ ) in vivo und in vitro nicht erklären. In vivo stimulierte das GH die Chondro- und Myogenese und damit das somatische Wachstum. Wurde das GH Knorpel- bzw. Muskelinkubaten zugefügt, konnte eine derartige Wirkung nicht gezeigt werden (Wuttke, 2000 b). Salmon und Daughaday veröffentlichten 1956 ihre Hypothese, daß es einen Vermittler (Somatomedin) zwischen dem Wachstumshormon und seiner wachstumsstimulierenden Wirkung geben müsse (Salmon und Daughaday, 1957). Anschließend wurden die beiden Somatomedine zunächst unter verschiedenen Synonymen identifiziert, sequenziert und kloniert. Es handelt sich um Wachstumsfaktoren und Peptide, die in ihrer Aminosäuresequenz (45-prozentige Homologie zum Proinsulin) und Wirkung dem Insulin ähneln und zusammen mit Proinsulin und Relaxin eine Familie von homologen Peptidhormonen bilden. Man nennt die Somatomedine daher auch Insulin-ähnliche Wachstumsfaktoren (Insulinlike Growth Factors, IGF-1 und IGF-2). IGF-1 ist ein monomeres Polypeptid mit 70 Aminosäuren, dessen Sekundärstruktur durch drei Disulfidbrücken zusammmengehalten wird. Die Molmasse beträgt 7649 Dalton. Das Gen für das menschliche IGF-1 liegt auf dem Chromosom 12. Es gibt einige Varianten des IGF-1, die durch das posttranskriptionale alternative Splicing entstehen (Kiess und Höflich, 1995).

Hauptbildungsort der IGFs ist die Leber, von wo sie in die Blutbahn abgegeben werden (endokrine Wirkung). Allerdings werden die IGFs in vielen anderen Geweben exprimiert, wo sie als lokale Wachstumsfaktoren parakrin bzw. autokrin wirken (Birkhäuser, 2000).

Das IGF-System besteht aus den drei Rezeptoren: IGF-1-Rezeptor, IGF-2-Rezeptor und Insulinrezeptor und den drei Liganden: IGF-1, IGF-2 und Insulin. Es gibt sechs IGF-Bindungsproteine (IGFBPs), die den Blutspiegel der IGFs regulieren und deren Wirkung modulieren (Baserga et al., 1997). Abbildung 1 zeigt die Verknüpfungen dieses Systems. 


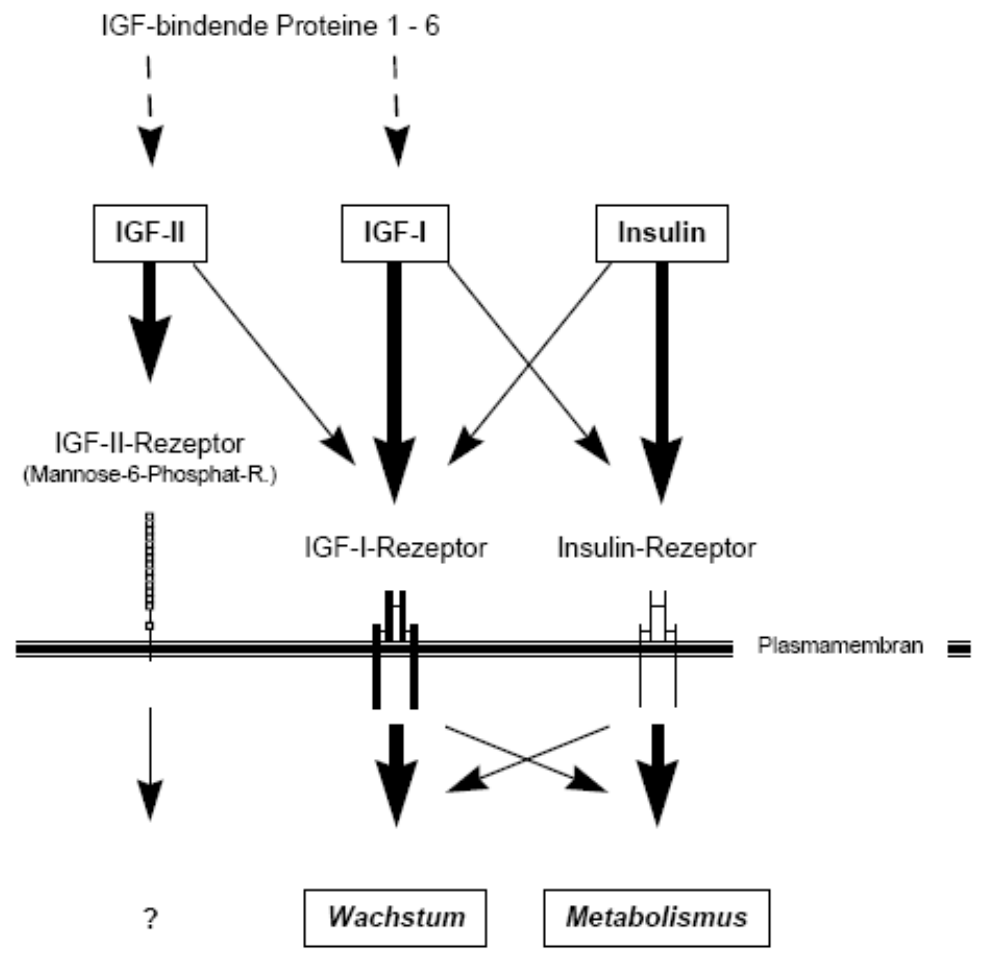

Abb. 1 : Das IGF-System [Vereinfachte Darstellung nach Rubin und Baserga, 1995, S. 319]

\section{1. 1. IGF-1-Rezeptor}

Wie andere Wachstumsfaktoren sind die IGFs extrazelluläre Signalmoleküle, die an spezifische Zellmembranrezeptoren binden. Der IGF-1-Rezeptor oder Typ-1-IGFRezeptor ist im IGF-System der bedeutsamste Rezeptor für das proliferative Zellwachstum. Er kann durch alle drei Liganden aktiviert werden und ist ferner eine notwendige Struktur für die Signaltransduktion weiterer Wachstumsfaktoren, z.B. von Epidermal Growth Factor (EGF) und Platelet derived Growth Factor (PDGF) (Baserga et al., 1997). Der IGF-1-Rezeptor (Abbildung 2), der zu der Familie der Tyrosin-Kinase-Rezeptoren gehört, ist ein heterotetrameres Glykoprotein, bestehend aus zwei extrazellulären $\alpha$ - und zwei transmembranösen $\beta$-Untereinheiten. Er hat bei einer 70-prozentigen Homologie in der Aminosäuresequenz eine große Ähnlichkeit zum Insulinrezeptor. Die zytoplasmatischen Domänen des IGF-1-Rezeptors, die $\beta$ Untereinheiten, besitzen eine Tyrosinkinase-Aktivität (Petrides, 1998 a).

Entscheidend für die Signaltransduktion nach Ligandenbindung an die a-Untereinheit sind die Tyrosin-Autophosphorylierung des Rezeptors und die TyrosinPhosphorylierung zytoplasmatischer Substrate durch die intrinsische Tyrosinkinase 
im intrazellulären Abschnitt der $\beta$-Untereinheit (Rubin und Baserga, 1995). Zytoplasmatische Substrate sind u.a. Mitogen-Activated-Protein- (MAP-) Kinase und Phophatidyl-Inositol-3- (PI 3-) Kinase (Le Roith et al., 1995; Werner und Le Roith, 1997). In diesem Zusammenhang ist der Ras-Signaltransduktionsweg wichtig. Er führt über die Aktivierung des MAP-Kinase-Weges zu verschiedenen biologischen Aktivitäten, u.a. zur Regulierung der Genexpression (Stewart und Rotwein, 1996).

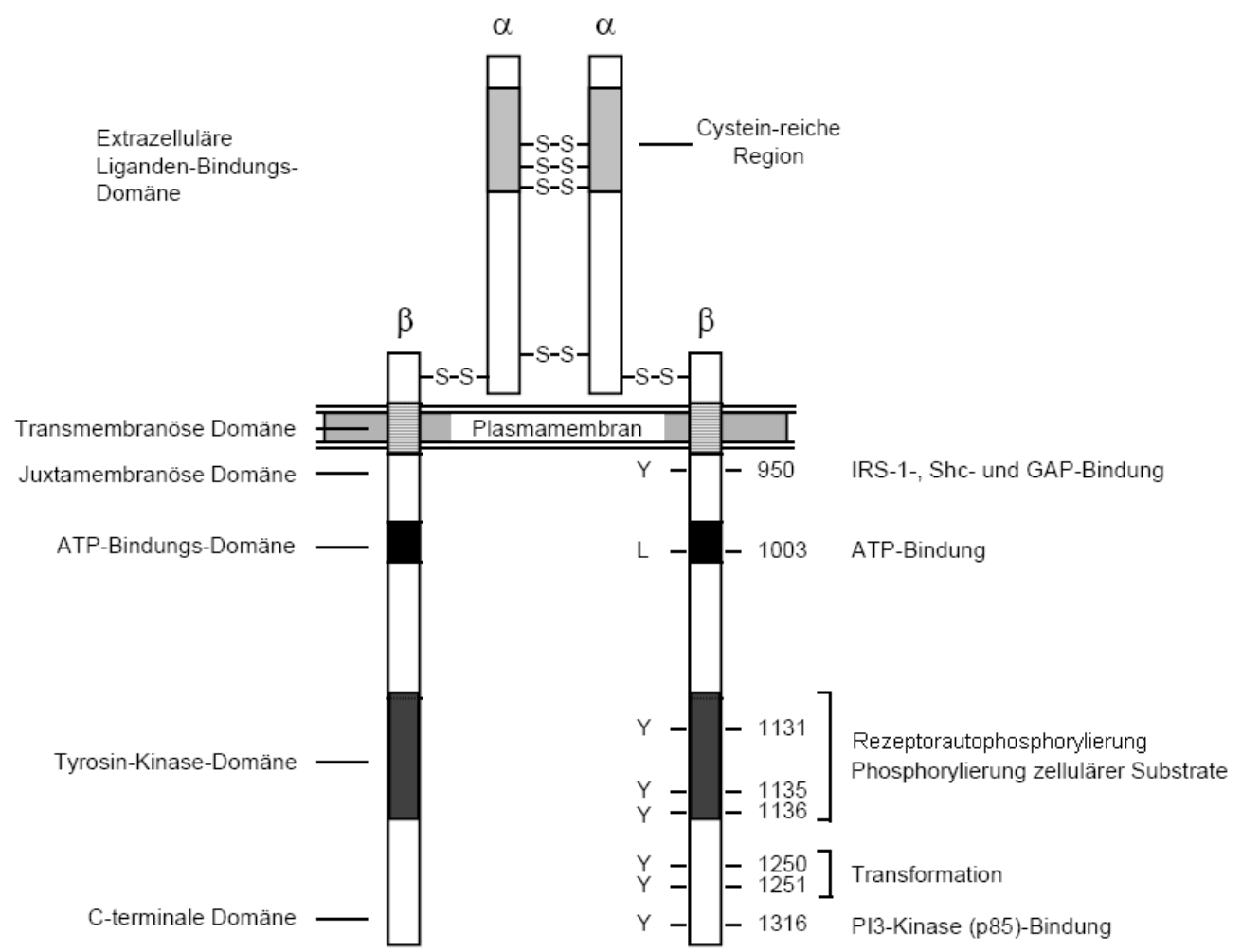

Abb. 2. : Der IGF-1-Rezeptor [nach Rubin und Baserga, 1995; Stewart und Rotwein, 1996; Sepp-Lorenzino, 1998]

\section{1. 2. IGF-Bindungsproteine (IGFBP)}

Etwa 90 Prozent der zirkulierenden IGFs werden an spezifische Transportproteine gebunden. Es handelt sich um hochaffine IGF-Bindungsproteine, wovon 6 Klassen (IGFBP 1-6) bis heute bekannt sind. Sie regulieren den Blutspiegel der IGFs und modulieren ihre Wirkung (Froesch et al., 1996).

IGF-Bindungsproteine erfüllen mehrere zum Teil gegensätzliche Funktionen: (1.) bilden sie ein Reservoir für die IGFs in der Zirkulation (insbesondere IGFBP-3); (2.) transportieren sie die gebundenen IGFs aus der Zirkulation durch die Kapillarschranke in das periphere Gewebe (IGFBP-1, -2 und -4); (3.) können sie die 
IGF-Wirkung entweder potenzieren oder inhibieren (Stewart und Rotwein, 1996). Die inhibitorische überwiegt dabei gegenüber der potenzierenden Wirkung, die nur für IGFBP-1, IGFBP-3 und IGFBP-5, abhängig von verschiedenen Mechanismen, beschrieben ist (Zapf, 1995).

Die IGFBPs verlängern die Halbwertszeit der IGFs (3-18 Stunden) im Plasma und im Gewebe (Dodt und Fehm, 2000). Nur die freien IGFs sind am lokalen Zielort biologisch wirksam. Die IGFBPs kommen in gewebsspezifischer Verteilung vor (Kiess und Höflich, 1995).

\section{1. 3. Regulation der IGF-1-Synthese}

GH stimuliert in vielen Geweben und insbesondere in der Leber die Expression des IGF-1-Gens und die Synthese und Sekretion des IGF-1-Peptids. Andere Hormone wie Östrogene und Wachstumsfaktoren fördern ebenfalls die Expression von IGF-1 (Kiess und Höflich, 1995). IGF-1 hat ein negatives Feedback auf die Wachstumshormonsekretion auf hypophysärer und mit der Freisetzung von Somatostatin auch auf hypothalamischer Ebene (Melmed, 1990).

Der Serumspiegel von IGF-1 ist altersabhängig und beträgt beim Erwachsenen 170 bis $350 \mathrm{ng} / \mathrm{ml}$. Die Konzentration von IGF-1 im Serum steigt von relativ niedrigen Werten um $50 \mathrm{ng} / \mathrm{ml}$ ab dem 4. Lebensjahr bis zu einem Maximum in der Pubertät an. Im Alter fallen die IGF-1-Konzentrationen wieder ab (Kiess und Höflich, 1995). Katabole Zustände wie Hungern, Tumorkachexie oder die Folge von Trauma oder Operation vermindern die IGF-1-Serumkonzentration dramatisch. $\mathrm{Zu}$ den Erkrankungen, die mit niedrigen IGF-1-Spiegeln einhergehen, sind insbesondere der Hypopituitarismus, schwere Lebererkrankungen, Nierenerkrankungen und der insulinabhängige Diabetes mellitus (IDDM) zu nennen (Kiess und Höflich, 1995). Bei der Akromegalie lassen sich dagegen hohe Serumkonzentrationen von IGF-1 messen.

\section{1. 4. Biologische Wirkungen}

Bei den biologischen Wirkungen von IGF-1 kann man orientierend die Wachstumsstimulation von metabolischen Wirkungen unterscheiden. Zum einen fördert IGF-1, als Vermittler des hypophysären GH, das Wachstum des Organismus. Zum anderen erfüllen die IGFs anabol-metabolische Aufgaben (Froesch et al., 1990). 
Allerdings entfalten die IGFs aufgrund ihres ubiquitären Vorkommens gewebsspezifisch verschiedene andere Wirkungen. Zum Beispiel ist IGF-1 intraovariell in die Östrogen- und Progesteronsynthese involviert (Birkhäuser, 2000 C).

\section{1. 4. 1. Wachstumsstimulierende Wirkungen}

IGF-1 wirkt - von Typ-1-IGF-Rezeptor ausgehend - hauptsächlich mitogen und ist für das proliferative Zellwachstum sehr wichtig (Baserga et al., 1997). Dies zeigten unter anderem Baserga und Mitarbeiter in Versuchen mit sogenannten R--Zellen, Mausembryo-Fibroblasten, deren IGF-1-Rezeptorgen gezielt zerstört wurde. Diese Zellen zeigten im Gegensatz zu Kontrollzellen (Wildtypzellen) mit IGF-1-Rezeptor kein Wachstum im serumfreien Medium mit zugesetzten Wachstumsfaktoren (IGF-1, IGF-2, PDGF, EGF). Zwar konnte ein Wachstum dieser R--Zellen in Medium mit 10\% Serum nachgewiesen werden, jedoch in geringerem Ausmaß als bei den Wildtypzellen. Dies zeigt, daß der IGF-1-Rezeptor zwar nicht für das Zellwachstum allgemein, aber für die optimale Wachstumsrate notwendig ist. Diese Studien belegten zudem eine wichtige Rolle des Typ-1-IGF-Rezeptors im Zellzyklus: bei R-Zellen waren alle Phasen des Zellzyklus verlängert (Sell et al., 1993).

Auch andere in-vitro-Studien, bei denen die IGF-1-Rezeptorfunktion durch AntisenseTechniken oder IGF-1-Analoga gehemmt wurde, führten zu geringerem Zellwachstum und unterstreichen so die Wichtigkeit dieses Rezeptors (Baserga et al., 1997). Zudem konnte gezeigt werden, daß auch PDGF und EGF, selbst bei Überexpression ihrer Rezeptoren, für die Signaltransduktion auf einen funktionsfähigen Typ-1-IGF-Rezeptor angewiesen sind (Rubin und Baserga, 1995). IGF-1 stimuliert die Aufnahme von Aminosäuren und Glukose durch die Zellen (Lodish et al., 1996).

Bei hypophysektomierten Versuchstieren führt die Gabe von IGF-1 auch ohne die Anwesenheit von GH zu einer Zunahme der Muskelmasse und einem deutlichen Längenwachstum. Die wachstumsstimulierende Wirkung von IGFs beruht auf dem direkten Effekt auf Osteoblasten, Chondroblasten und Fibroblasten mit der Stimulation der Synthese von DNS, RNS, Kollagen- und Nichtkollagenproteinen (Kiess und Höflich, 1995). 


\section{1. 4. 1. 1. Lokale Wirkungen von IGF-1 im Knochengewebe}

Die Leber synthetisiert als „hormonaktive Drüse“ GH-reguliert IGF-1, das in die Blutbahn gelangt und in der Peripherie wie auch in der Leber selbst seine metabolischen, wachstumsstimulierenden oder gewebsspezifischen Wirkungen entfaltet. IGF-1 wird auch in vielen anderen Geweben als lokaler Wachstumsfaktor synthetisiert. Im Knochengewebe wird IGF-1 von Osteoblasten gebildet. IGF-1 stimuliert die Proliferation und Differenzierung von Osteoblasten.

Scheinbar besteht eine Korrelation zwischen IGF-1-Konzentration und Knochenmineraldichte (bone mineral density: BMD). Mausinzuchtstämme mit extrem hoher und extrem niedriger Femur-BMD zeigten eine 30-prozentige Differenz von IGF-1-Konzentrationen im Serum und Knochen (Beamer et al., 1996). Individuen mit einem bestimmten homozygoten Polymorphismus in dem Mikrosatelliten CA-Repeat, eine Kilobase stromaufwärts des IGF-1-Gens, finden sich zweifach häufiger in Patientengruppen von Männern mit asymptomatischer Osteopenie bzw. idiopathischer Osteoporose (Rosen et al., 1998).

Osteoblasten älterer Individuen zeigen eine zunehmende Resistenz gegenüber IGF1 (Davis und Simmen, 1997). Mit zunehmendem Alter nehmen die IGF-1Konzentrationen sowohl im Serum als auch im Knochen ab, was teilweise von einer verminderten $\mathrm{GH}$-Sekretion abhängt. Ferner überwiegen im Alter scheinbar die Spiegeln von den inhibitorischen IGF-Bindungsproteinen (IGFBP) 4 und 6 gegenüber den stimulatorischen Bindungsproteinen 3 und 5, was zur verminderten Wirkung von IGF-1 beitragen kann (Rosen und Donahue, 1998). Diese Ergebnisse können zum Teil die altersabhängige Osteopenie bzw. Osteoporose erklären.

IGF-1 erhöht die Aktivität der knochenspezifischen alkalischen Phosphatase (AP) und vermindert den Abbau von Kollagen und Gesamtprotein im Knochengewebe (Lazkowski et al., 1994). Nach IGF-1-Infusionen konnte eine erhöhte m-RNAExpression von Prokollagen 1, AP und Osteopontin nachgewiesen werden (Wakisaka et al., 1998). Das Resultat ist eine Zunahme an Knochenmatrix.

\section{1. 4. 2. Metabolische Wirkungen}

IGF-1 kann sowohl über den IGF-1-Rezeptor als auch über den Insulinrezeptor anabol-metabolische Wirkungen entfalten. Jedoch sind diese im Vergleich zu den metabolischen Wirkungen des Insulins schwächer ausgeprägt (siehe Abbildung 1). 
Während der IGF-1-Rezeptor in seinem Aufbau dem Insulin-Rezeptor stark ähnelt, zeigen beide Rezeptoren in ihren physiologischen Auswirkungen größere Unterschiede. Zwar sind beide in der Lage, sowohl ähnliche metabolische als auch mitogene Mechanismen zu induzieren, dennoch wirkt der Typ-1-IGF-Rezeptor hauptsächlich mitogen, während der Insulin-Rezeptor in erster Linie metabolische Aktivitäten zeigt (Rubin und Baserga, 1995).

Die kontinuerliche Infusion von IGF-1 bewirkt eine Verminderung der Konzentration von Glukose und freien Fettsäuren im Plasma (Kiess und Höflich, 1995). IGF-1 stimuliert die Glukoseaufnahme durch die Zelle und die Glykogensynthese in der Leber (Lodish et al., 1996).

\section{1. 5. Kanzerogene Wirkungen}

Viele Onkogen-Proteine haben Strukturähnlichkeiten mit den an der Wachstumsregulation beteiligten Proteinen. Man nimmt deshalb an, daß Onkogene durch Mutationen aus diesen normalen für den Fortbestand einer Zelle notwendigen Genen, die Protoonkogene genannt werden, entstanden sind (Petrides, 1998 b).

Die IGFs und ihre Signaltransduktionswege spielen wie andere Wachstumsfaktoren auch für die Tumorprogression eine wichtige Rolle (Passarge, 2000). Die IGFs sind über den IGF-1-Rezeptor entscheidend für die Ausprägung und Aufrechterhaltung eines transformierten Phänotyps und somit für eine mögliche Tumorgenese. An R-Zellen-Mausembryo-Fibroblasten, deren IGF-1-Rezeptorgen gezielt zerstört wurde, konnte gezeigt werden, daß virale Onkogene nicht in der Lage sind, Zellen ohne den IGF-1-Rezeptor zu transformieren (Baserga et al., 1997). Umgekehrt konnte auch gezeigt werden, daß Zellen mit transformiertem Phänotyp durch Reduktion der IGF1-Rezeptordichte oder Funktionseinschränkung des Rezeptors einen nichttransformierten Phänotyp ausprägen können. Dies konnte sowohl für das "simian virus 40 large tumor antigen" (SV40T Ag) als auch für ras-Onkogen gezeigt werden (Sell et al., 1993).

Ferner konnte ein antiapoptotischer Effekt des IGF-1-Rezeptors beobachtet werden. Während verschiedene, zum Teil menschliche Tumorzellen gut in speziellen Diffusionskammern im subkutanen Gewebe von Ratten oder Mäusen wuchsen, unterlagen mit Antisense-RNA gegen den Typ-1-IGF-Rezeptor transfizierte, 
beziehungsweise mit Antisense-Oligodesoxynukleotiden gegen die IGF-1-RezeptorRNA inkubierte Zellen dem programmierten Zelltod (Baserga et al., 1997).

\section{2. Androgene}

Androgene sind Steroidhormone, deren häufigste und wichtigste Vertreter das Testosteron $(T)$ darstellt. Hauptbildungsort der Androgene beim Mann sind die Leydigzellen im Interstitium der Hoden. Die männlichen Sexualhormone werden in kleinen Mengen auch in der Nebennierenrinde und in den Ovarien produziert.

Etwa 4 bis $12 \mathrm{mg}$ (im Mittel $7 \mathrm{mg}$ ) T werden täglich in den Leydigzellen eines erwachsenen Mannes produziert und sezerniert (Petrides, 1998 a).

\section{2. 1. Biosynthese und Metabolismus}

Der Grundbaustein für die Steroidhormon-Synthese ist das Cholesterin. Im Zytoplasma ist Cholesterin, ein Molekül mit 27 Kohlenstoff-(C-) Atomen, in Form von Lipidtröpfchen gespeichert. Die limitierenden Schritte der Testosteron-Synthese sind der Transport von Cholesterin von der äußeren zur inneren Mitochondrienmembran durch das "steroidogenetic acute regulatory protein" (Kallen et al., 1998) und die LH (Luteinisierendes Hormon) -kontrollierte Umwandlung von Cholesterin zu Pregnenolon durch die Trennung der Seitenkette mittels Side chain cleaving enzyme (Birkhäuser, 2000 b). Pregnenolon (21 C-Atome) stellt das gemeinsame Intermediärprodukt bei der Synthese aller Steroidhormone dar. Pregnenolon wird im endoplasmatischen Retikulum auf dem $\Delta 4$ - bzw. $\Delta 5$-Syntheseweg über verschiedene Intermediärprodukte zu T weiterverarbeitet (Schopohl, 2000 a).

In einigen Zielorganen wird das zirkulierende $T$ intrazellulär durch die $5 \alpha$-Reduktase in Dihydrotestosteron (DHT), das eine zweieinhalbfach stärkere biologische Aktivität als T besitzt, umgewandelt (Petrides, 1998 a).

Ferner bilden Androgene die Vorstufe für die Östrogen-Synthese. Hierfür ist die Cytochrom-P450-abhängige Aromatase notwendig.

Die Halbwertszeit von T im Plasma beträgt 56 min. In der Zirkulation sind 98\% des T an Eiweiße gebunden. Das Sexualhormon-bindende Globulin (SHBG), das in der Leber gebildet wird, hat eine sehr hohe Bindungsaffinität und bindet $44 \%$ des $\mathrm{T}$. Albumin, das eine 100 -fach niedrigere Affinität als das SHBG besitzt, bindet $54 \%$ des T. Nur in freier Form sind Sexualhormone biologisch aktiv (Schopohl, 2000 a). 
Der Abbau von $\mathrm{T}$ erfolgt hauptsächlich in der Leber, aber auch in peripheren Geweben. Durch oxidative Prozesse wird $T$ in 17-Ketosteroide wie Androsteron umgewandelt und in freier Form oder als glukuronidierte bzw. sulfatierte Derivate im Urin ausgeschieden (Petrides, 1998 a).

\section{2. 2. Wirkungsmechanismus}

Die Androgene entfalten ihre Wirkung über einen intrazellulären Androgenrezeptor (AR), der zur Familie der steroidbindenden Hormonrezeptoren gehört. Das Gen des AR liegt auf dem X Chromosom. Bindet T bzw. DHT an den AR, so wandert der Hormon-Rezeptor-Komplex in den Zellkern und bindet dort an spezielle "androgen responsiv elements" der DNA. So werden androgenabhängige Gene aktiviert, durch deren Expression Proteine entstehen, die für die Androgenwirkungen notwendig sind (Hiort et al., 1998). Aber es gibt eine wachsende Zahl an Befunden, die zeigen, daß Androgene auch auf nichtgenomische Signalwege wirken können. Hierfür werden nicht nur intrazelluläre Steroidhormonrezeptoren, sondern auch spezifische unkonventionelle Membranrezeptoren eingesetzt. In einer Studie von Guo et al. (2002) führte $T$ zu einem schnellen Anstieg der intrazellulären Konzentration des freien Calciums in Makrophagen auf einem nichtgenomischen Signalweg.

\section{2. 3. Biologische Wirkungen}

\section{2. 3. 1. Knochengewebe}

Durch die vermehrte Bildung von Androgenen während der männlichen Pubertät kommt es initial zu einem Schub des Längenwachstums. Unter der vermehrten Androgenwirkung werden am Ende der Pubertät die Epiphysenfugen der langen Röhrenknochen verknöchert, so daß das Längenwachstum abgeschlossen wird.

Für die spätere Knochendichte ist es scheinbar wichtig, daß Androgene rechtzeitig während der Pubertät gebildet werden: Eine mangelnde oder fehlende Testosteronproduktion führt bei erwachsenen Männern mittelfristig zu einer schweren Osteoporose (Schopohl, 2000 b; Finkelstein et al., 1996). Albright und Reifenstein berichteten 1948 über eine Osteoporose-Entwicklung in Eunuchen. 
Im Knochengewebe verfügen nicht nur die Osteoblasten über AR. AR konnten auch in Osteozyten, hypertrophen Chondrozyten, mononukleären Zellen und dem Endothel der Blutgefäße des Knochenmarks nachgewiesen werden (Abu, 1997). Wie bei Östrogenen führt T zur Reduktion der Knochenresorption (Benz et al., 1991). Ein Großteil dieser Wirkung erfolgt indirekt durch Aromatisierung von T zu E2 (Falahati-Nini et al., 2000) und durch Senkung der Interleukin-6 Produktion, ähnlich wie es im weiblichen Geschlecht durch Östrogene der Fall ist.

Ebenso hat $\mathrm{T}$, wie Östrogene auch, die Eigenschaft, die Lebensspanne von Osteoblasten zu verlängern (Manolagas, 2000) und die Apoptoserate von Osteoklasten zu beeinflussen. Als weiterer Aspekt wird für T auch ein leichter Effekt auf die Osteoblastenproliferation beschrieben (Bucay et al., 1998; Kasperk et al., 1989).

In menschlichen Knochengewebe-Kulturen kann $\mathrm{T}$ in $\mathrm{DHT}$ umgewandelt werden, was nahe legt, daß DHT im Knochengewebe das aktive Androgen darstellt (Schill, 2001). Das Interessante an dem Metaboliten DHT ist, daß für inn mitogene Effekte bei Osteoblasten nachgewiesen werden konnten (Spelsberg et al., 1999). Des weiteren ist DHT in der Lage, die Aktivität der AP und die der Kollagen Typ-1 Synthetase zu regulieren (Hofbauer et al., 1998).

Wie bereits erwähnt, ist eine Metabolisierung von T zu E2 für die Androgenwirkung im Knochen unerläßlich. In einer Studie von Smith et al. wurde über einen Mann mit homozygoter Mutation im Östrogenrezeptor (ER)-Gen berichtet. Dieser Mann weist im Vergleich mit der Normalbevölkerung normale Testosteron-Serumspiegel auf, hat aber trotzdem eine Osteopenie, nicht geschlossene Epiphysenfugen und einen stark erhöhten Knochenumbau (Smith et al., 1994).

In zwei weiteren Studien wurde über zwei Männer berichtet, die eine homozygote Mutation im Aromatasegen aufwiesen, welches für die Metabolisierung von T zu E2 unabdinglich ist. Diese Männer zeigten eine verringerte BMD bei erhöhtem Knochenumbau. Die Spiegel für $\mathrm{T}$ waren auch hier im Normbereich. Einer der Männer erhielt eine Behandlung mit $\mathrm{T}$, die jedoch keinerlei signifikante Änderung des Knochenphänotyps zeigte. Dem anderen Mann wurde eine Therapie mit Östrogen zuteil, was zu einer signifikanten Erhöhung der BMD und einer Normalisierung des Knochenumbaus führte (Morishima et al., 1995; Carani et al., 1997).

Ferner werden Gene, die für die Osteoklastenbildung verantwortlich sind, durch die Sexualhormone in ihrer Aktivität herunterreguliert (Manolagas et al., 2002). 
Lokal aktive Zytokine und Wachstumsfaktoren wie verschiedene Prostaglandine (PG E1 und PG E2), Transforming Growth Factor $\beta$ (TGF $\beta$ ), knochen-morphogenetische Proteine (BMP) und IGF-1 spielen eine wichtige Rolle im Knochenmetabolismus (Lang, 2000). Eine Interaktion der Androgene mit diesen Substanzen ist denkbar. Androgene können auch den Knochenstoffwechsel beeinflussen, indem sie mit den Calciumhaushalt-regulierenden Hormonen wie Calcitonin interagieren (Schill, 2001).

\section{2. 3. 2. Leber}

In der Leber beeinflussen Sexualhormone die Proteinsynthese. Jedoch wirken Androgene und Östrogene häufig wie bei der Synthese von SHBG antagonistisch. Vereinzelte synergistische Effekte wie bei der Bildung von $\alpha 1$-Antitrypsin sind auch bekannt (Schopohl, 2000 a).

\section{3. Partielles Androgendefizit des alternden Mannes (PADAM)}

Angesichts der zunehmenden Lebenserwartung der Bevölkerung, insbesondere in den Inustrieländern, finden die Erfordernisse des alternden Mannes mehr Beachtung (Diczfalusy, 1998). Im Gegensatz zur rapiden Abnahme der Östrogene während der weiblichen Menopause (Runnenbaum et al., 1987), vollzieht sich der männliche Alterungsprozeß langsam und mit hoher individueller Variabilität.

Im Allgemeinen kommt es mit zunehmendem Alter zu einer Abnahme der intratestikulären und peripheren Androgenkonzentration. In Männern über 60 Jahren können verminderte Testosteronspiegel sich klinisch in Osteoporose, einer Abnahme der Muskelmasse und -kraft sowie in einer Reduktion der männlichen Behaarung und der Libido manifestieren (Schill, 2001).

Erst nach Beginn der siebten Lebensdekade wird eine alters-assoziierte Abnahme des T statistisch relevant (Vermeulen, 1988). In neueren Studien fallen die mittleren Gesamt-, aber auch die freien Testosteron-Plasmaspiegel bei gesunden Männern zwischen dem 25. und 75. Lebensjahr um 30\%. Dennoch gibt es hier eine starke interindividuelle Variabilität (Plas et al., 2001). Verschiedene Studien haben gezeigt, daß das Androgendefizit des alternden Mannes primär testikulären Ursprungs ist. Die Leydigzellen scheinen weniger empfänglich für die LH-Stimulation zu sein (Hartmann et al., 1985). Wahrscheinlich besteht ein verkleinerter Vorrat an $\mathrm{T}$ in den Hoden älterer Männer, der auf die verminderte Syntheseleistung der Leydigzellen schließen 
läßt. Ein gradueller Rückgang der Leydigzellzahl, die mit einer verminderten testikulären Perfusion einhergeht, kennzeichnet den männlichen Alterungsprozeß (Vermeulen, 1988). Im alternden Mann ereignen sich die LH-Pulse hoher Amplitude trotz der großen sekretorischen Reservekapazität der Hypophyse seltener. Somit sind die LH-Spiegel nicht hoch genug, um die Konzentration des freien T im Serum zu normalisieren (Wide, 1985). Auch die zirkadiane Testosteron-Rhythmik mit hohen Spiegeln am frühen Morgen ist im Alter aufgehoben, was die Folge eines verminderten LH-Rhythmus ist (Bremner et al., 1983; Vermeulen, 1990).

$T$ wird in der Zirkulation wegen seiner hydrophoben Natur an Plasmaproteine wie Albumin und dem hochaffinen SHBG gebunden. Nur ca. $2 \%$ des T wird in freier und folglich biologisch aktiver Form transportiert. Nach einem Alter von 70 Jahren steigt der Serumspiegel von SHBG an. Somit wird vermehrt T an SHBG gebunden, und der Anteil des freien und biologisch aktiven T nimmt ab (Baker et al., 1983). Der Grund dafür ist die zunehmende Umwandlung von Androgenen in Östrogene durch die gesteigerte Aromatase-Aktivität im vermehrt vorkommenden peripheren Fettgewebe des alternden Mannes. Eine Erhöhung des freien E2 im Serum führt zur vermehrten Synthese des SHBG (Schill, 2001).

Der Begriff des männlichen Klimakteriums wurde 1939 von Wermer verwendet. Er beschrieb Männer in oder jenseits der 5. Lebensdekade, die eine Reihe von psychovegetativen Symptomen wie Abnahme des Erinnerungsvermögens, Konzentrationsmangel, Müdigkeit, Nervosität oder verminderte Stressbewältigung beklagten. In Analogie zum weiblichen Klimakterium wurde auch beim Mann initial eine plötzliche Reduktion des T-Plasmaspiegels und eine rasche senile Rückbildung der Gonaden angenommen (Wermer, 1939). Spätere Studien belegten jedoch signifikante Unterschiede zwischen dem weiblichen und männlichen Alterungsprozeß. Eine allmähliche Abnahme des Androgenspiegels im Mann wird lediglich im hohen Alter beobachtet. Auch hinsichtlich der Spermatogenese gibt es breite interindividuelle Schwankungen. Intakte Keimzellen wurden sogar in über 80jährigen Männern gefunden. Keine der von Wermer beschriebenen Symptome des sog. "Klimakterium virile" hat eine statistisch signifikante Prävalenz bei Männern in der 5. oder 6. Lebensdekade (Schill, 2001). Auch eine Besserung der subjektiven Beschwerden durch die Gabe von Androgenderivaten kann auf die psychotrope Wirkung der Androgene zurückführt werden (Kaiser et al., 1978). Entsprechend existieren ein männliches Klimakterium nicht. Der Begriff Partielles Androgendefizit 
des alternden Mannes (PADAM) gibt diesen Sachverhalt korrekter und präziser wider (Schill, 2001).

\section{3. 1. Substitutionstherapie mit Testosteron}

Niedrige Serumkonzentrationen von Gesamttestosteron in über 60-jährigen Männern können von klinischen Symptomen wie sexuelle Dysfunktion und psychovegetativen Beschwerden, Osteoporose, Abnahme der Muskelmasse sowie Anämie begleitet werden. Jedoch bestehen geringfügige Kenntnisse darüber, welche Vorteile eine Androgensubstitution für die o.g. Beschwerden älterer Männer tatsächlich bringt und welche negative Wirkungen auf das Gefäßsystem, die hämatologischen Parameter und besonders auf die Prostata erwartet werden können (Schill, 2001).

Tenover et al. untersuchten in einer doppelblinden und Placebo-kontrollierten Studie die Wirkungen des Testosteronenanthats in einer kleinen Gruppe gesunder Männer zwischen 57 und 76 Jahren für die Dauer von 3 Monaten. Die wöchentliche Injektionen von $100 \mathrm{mg}$ Testosteronenanthat führten in allen Probanden zu erhöhten Serumkonzentrationen von sowohl Gesamttestosteron wie von freiem T. In einem Teil der Probanden zeigte sich ein Anstieg von Libido und Aggressivität in Geschäftstransaktionen. Andere berichteten über eine allgemeine Verbesserung des Wohlbefindens. In allen Probanden zeigte sich eine Zunahme des Körpergewichts, jedoch nicht des Körperfettanteils. Die Urinausscheidung von Hydroxyprolin, einem Marker der Knochenabsorption, ging zurück. Es wurden positive Wirkungen auf den Fettstoffwechsel und die hämatologischen Parameter beobachtet. Die T-Injektionen führten nicht zu einer signifikanten Veränderung der Prostatagröße und des Restharnvolumens. Jedoch wurde ein Anstieg des Prostata-spezifischen Antigens (PSA) in 30\% der Männer sogar 3 Monate nach Therapieende beobachtet (Tenover et al., 1990).

Hajjar et al. (1997) publizierten eine retrospektive Analyse über eine Langzeittherapie mit $T$ bei 45 älteren hypogonadalen Männern, die alle 2 Wochen 200 mg Testosteronenanthat bzw. -cypionat für mindestens 2 Jahre erhielten. Die Kontrollgruppe bestand aus 27 hypogonadalen Männern ohne Androgeneinnahme. Nach 2 Jahren zeigte sich lediglich ein signifikanter Anstieg des Hämatokrits in der Testosterongruppe. $24 \%$ der mit $\mathrm{T}$ behandelten Probanden entwickelten eine Polyzythämie, die eine passagere Therapieunterbrechung oder eine Phlebotomie erforderte. 
Im Gegensatz zu der Studie von Tenover et al. zeigten sich keine signifikanten Veränderungen in der Konzentration des PSA. Ferner gab es kein signifikanter Unterschied in der Total-Cholesterinkonzentration zwischen der $\mathrm{T}$ - und der Kontrollgruppe. Nach über 3 Jahren Behandlung zeigte sich keine Anhäufung von Angina pectoris, Myokardinfarkt oder Apoplex. Die Libido stieg unter Substitution dramatisch an. Über 84\% der Probanden vertrugen die Testosterontherapie gut.

Trotz dieser positiven Erfahrungen mit einer T-Langzeitbehandlung, die jedoch regelmäßige Blutbildkontrollen und urologische Untersuchungen erfordert, ist die Datenlage bezüglich der Vorteile und von unerwünschten Wirkungen einer Androgenbehandlung dürftig. Gegenwärtig wird eine T-Ersatztherapie im alternden Mann gemäß den Emphehlungen der Canadian Andropause Society nur bei manifestem Androgendefizit empfohlen (Tremblay und Morales, 1998).

\section{4. Östrogene}

Östrogene sind weibliche Geschlechtshormone, die insbesondere die sexuelle Differenzierung, die Ausprägung der sekundären Geschlechtsmerkmale und das sexuelle Verhaltensmuster der Frau steuern (Petrides, 1998 a). Auch beim Mann spielen Östrogene eine nicht unbedeutende Rolle. Das wichtigste und physiologisch am stärksten wirksame Östrogen ist das Estradiol 17-beta (E2). Bei der Frau stellen Follikelzellen der Ovarien den Hauptbildungsort der Östrogene vor der Menopause dar (Wuttke, 2000 a). Im männlichen Geschlecht setzen die Leydigzellen der Hoden den Hauptanteil der Östrogene in die Zirkulation frei (Schopohl, 2000 a).

\section{4. 1. Wirkungsmechanismus}

Bei den Östrogenen kann der genomische Wirkmechanismus von nichtgenomischen Effekten unterschieden werden. Nach dem klassischen Modell der genomischen Wirkung gelangen die Östrogene mit dem Blutstrom an ihre Wirkungsorte und dringen durch die Diffusion in die Zielzellen ein. Das Östrogen bindet im Zytoplasma an einen spezifischen intrazellulären Rezeptor, der zur Großfamilie der ZinkfingerSteroidrezeptoren, einer Klasse ligandenabhängiger Transkriptionsfaktoren, gehört (Beato und Klug, 2000). Bindet ein Ligand an einen solchen spezifischen Rezeptor, kommt es zur Konformationsänderung im Rezeptormolekül, wodurch eine Dimerisierung zweier Ligand-Rezeptor-Komplexe möglich wird (Döcke, 1994). Der 
aktivierte Östrogen-Rezeptor-Komplex transloziert in den Zellkern und bindet dort an palindromische DNA-Sequenzen der Zielgene, die sogenannten "estrogen responsive elements" (EREs) (Kumar und Chambon, 1988). Diese befinden sich meist in der Promotorregion nahe dem Transkriptionsstart. Durch die Interaktion des Rezeptordimers mit dem ERE wird die Transkription der Zielgene reguliert, was zu einer veränderten Expression der von diesen Genen kodierten Proteinen führt (Mangelsdorf et al. 1995, Beato et al. 1995, Beato und Klug, 2000).

Die Wirkung von Östrogenen wird auf molekularer Ebene durch Bindung an spezifische Rezeptoren, die Östrogenrezeptoren $\alpha$ und $\beta$ (ER $\alpha$ und ER $\beta$ ), vermittelt. Beide Rezeptoren haben eine ähnliche Affinität zu E2 (Kuiper et al., 1996).

ER $\alpha$ und ER $\beta$ sind auf unterschiedlichen Gewebetypen verteilt. ER $\beta$ ist scheinbar ein wichtiger Rezeptor im Knochen, kardiovaskulären System, zentralen Nervensystem, Urogenitalgewebe und in Immunzellen, während er häufig mit ER a koexprimiert wird (Byers et al. 1997; Kuiper et al., 1996; Mosselman et al, 1996; Couse et al. 1997; Gustafsson, 2000). Hierbei sind sie jedoch oft auf verschiedenen Zelltypen verteilt. ER $\alpha$ ist besonders in der Mamma, im Uterus und in der Leber der vorherrschende Rezeptor, was durch unterschiedliche Phänotypen in ER $\alpha$ - und ER $\beta$-knock-out- Mäusen sichtbar wurde (Couse et al., 1997; Couse und Korach 1999; Couse et al., 2000).

Die Existenz eines dritten ER, möglicherweise ER $\mathrm{\gamma}$, wird in Micropogonias undulatus, einem zur Familie der Sciaenidae gehörenden atlantischen Fisch, von Loomis und Thomas beschrieben (Loomis und Thomas, 1999).

Die genomischen und nichtgenomischen Effekte sind allen Steroidhormonen zuzuordnen. Die nichtgenomischen Wirkungen von Steroidhormonen zeichnen sich durch einen schnellen Wirkungseintritt von Sekunden bis wenige Minuten aus, während die genomischen Effekte sich erst nach Stunden bis wenigen Tagen entfalten (Selye, 1942). Nichtgenomische Effekte führen oft zur Bildung intrazellulärer second messenger und zu einer Veränderung der Aktivität von Mitogen-ActivatedProtein-Kinasen, Phosphatidyl-Inositol-3-Kinasen und dem Anstieg der intrazellulären Calciumkonzentration. Trotzdem können nichtgenomische Effekte Einfluß auf die Genexpression haben (Cato et al., 2002).

E2 kann sehr schnell die Konzentration intarzellulärer second messenger wie Calcium (Morley et al., 1992; Improta-Brears et al., 1999) und cAMP (Aronica et al., 1994; Gu und Moss, 1996) erhöhen. Ferner kann E2 die Mitogen-Activated-Protein- 
Kinase (Migliaccio et al., 1996), die Phospholipase C (Le Mellay et al., 1997; Ho und Liao, 2002) und die endotheliale NO-Synthetase (Goetz et al., 1999; Simoncini et al., 2002) aktivieren. Die neuen Erkenntnisse legen nahe, daß die genomischen und die nichtgenomischen Wirkungen der Östrogene untrennbar miteinander verbunden sind und sich gegenseitig beeinflussen.

\section{4. 2. Folgen des Östrogenmangels im Knochen}

Die Knochenmasse hängt von den Geschlechtshormonen ab. Unter ihrem Einfluß bildet der Knochen in der Pubertät eine Art zusätzliches Kompartiment. Die noch mögliche Zunahme der Knochenmasse ist mit spätestens 30 Jahren abgeschlossen. Das zusätzliche Kompartiment geht bei allen Frauen nach der Menopause verloren. Nur ein kleinerer Teil der Frauen entwickelt aber eine Osteoporose. Faktoren, die bei der Entwicklung der Osteoporose eine Rolle spielen, sind die ÖstrogenExpositionszeit (ungünstig bei später Menarche oder früher Menopause), körperliche Aktivität der Frau, Calcium- und Vitamin-D-Versorgung und genetische Faktoren (Ziegler, 2000). Das Risiko einer Fraktur in der Postmenopause hängt vom Knochenkapital bei Menopauseneintritt ab. Vor der Menopause beträgt der physiologische jährliche Knochenverlust ca. $0.7 \%$, danach steigt er über 10 bis 15 Jahre für den trabekulären Knochen auf 5\%, für das gesamte Skelett auf 1 bis $1.5 \%$ an, um anschließend auf die senile Abbaurate abzusinken. Ein Östrogenmangel kann bereits bei einer jungen Frau mit primärer oder sekundärer Amenorrhoe eine hochgradige Osteopenie auslösen (Birkhäuser, 2000 d). Östrogen ist ein wichtiger Regulator des Knochenhaushalts. Nach der Menopause kommt es zu einem dramatischen Abfall der Östrogene. Daher erleiden Frauen dreimal mehr osteoporotische Frakturen als Männer. Der postmenopausale Mangel an den Sexualsteroiden führt $\mathrm{zu}$ einem beschleunigten Knochenumsatz und einem Nettoverlust an Knochenmasse (Boschitsch, 1998).

Östrogene hemmen die Knochenresorption über direkte und indirekte Mechanismen. Sie reduzieren direkt die Aktivität der Osteoklasten über deren autokrine Regulation, indem sie das Verhältnis der von diesen Zellen produzierten Isoformen des Transforming Growth Factor $ß$ (TGF-ß) modulieren (Robinson et al., 1996). TGF- $\beta$ führt zur Bildung von Osteoprotegerin (OPG), auch "osteoclastogenesis inhibiting factor" genannt (Giudice et al. 1993; Yakar et al. 1999). OPG ist ein löslicher, nichtmembranassoziierter Rezeptor, der zur Tumor Necrosis Factor (TNF)- 
Rezeptorfamilie gehört (Zanker und Swaine, 2000). Er schützt die Knochensubstanz vor dem Abbau, indem er an receptor activator of nuclear factor-kappa-B ligand (RANKL) bindet und es blockiert, womit die Signalübertragung zwischen stromalen Osteoklasten und osteoklastären Vorläuferzellen unterbrochen wird (Yasuda et al., 1999). Darüberhinaus fördern Östrogene die Apoptose der Osteoklasten (Hughes et al., 1995).

Die indirekten Mechanismen der Resorptionshemmung werden über Osteoblasten vermittelt. Einerseits hemmen Östrogene die Produktion von Zytokinen wie Interleukin-1 (IL-1) und Interleukin-6 (IL-6) in den Osteoblasten. Dadurch wird die Differenzierung von osteoklastären Vorläuferzellen zu reifen Osteoklasten inhibiert (Pacifici et al., 1989). Andererseits stimulieren Östrogene in den Osteoblasten die Produktion von TGF-ß, welches insbesondere durch das RANKL / RANK / OPGZytokin-Netzwerk sowohl die Osteoklasten-Differenzierung als auch die Aktivität reifer Osteoklasten hemmt (Mundy, 1993).

Einen weiteren Beitrag zum Knochenaufbau leisten die Östrogene, indem sie die Bildung von 25(OH)D3 aus Cholekalziferol in der Leber stimulieren (Lang, 2000).

\section{5. Phytoöstrogene}

Östrogene üben an zahlreichen Organen ihre hormonelle Wirkungen aus. Durch die perimenopausale starke Abnahme dieses Steroides kommt es zu Ausfallserscheinungen wie vasomotorische Instabilität und Störungen des Allgemeinbefindens, Osteoporose sowie kardiovaskuläre Veränderungen. In der Behandlung und Vorbeugung menopausaler Beschwerden der Frau werden im Rahmen der klassischen Hormon-Ersatz-Therapie ("hormone replacement therapy", HRT) Östrogene synthetischer oder tierischer Herkunft angewandt. Wegen der Nachteile und Nebenwirkungen von HRT, die insbesondere mit einer erhöhten Inzidenz von Mamma- und Endometriumkarzinom einhergeht, stellen Ärzte und Patientinnen diese Behandlungsform immer mehr in Frage (Akhmedkhanov et al. 2001; Mahavni und Sood 2001).

Die medizinische Forschung konzentriert sich bei der Prophylaxe und Therapie periund postmenopausaler Beschwerden auf Substanzen, die gewebespezifisch und organselektiv ihre östrogenartige Wirkungen entfalten. Diese werden Selective Estrogen Receptor Modulators (SERMs) genannt. Ein ideales SERM übt erwünschte 
Effekte auf Knochen, kardiovaskuläres System, zentrales Nervensystem, Haut, Bindegewebe und Urogenitalsystem aus, ohne jedoch kanzerogene Wirkungen auf die Organe Mamma und Uterus zu entfalten (Birkhäuser, 2000 b).

Insbesondere in der Behandlung des Mammakarzinoms werden solche synthetische Antiöstrogene entwickelt, die neben den antiöstrogenen Effekten in der Brustdrüse teilweise agonistische Wirkungen haben, damit insbesondere die wünschenswerten östrogene Wirkungen nicht aufgehoben werden (Harper und Walpole, 1967). Ein bekannter Vertreter von diesen synthetischen SERMs ist das Tamoxifen. Es steigert die Knochendichte (Love et al., 1992; Marttunen et al., 1998), reduziert das LDLCholesterin (Bagdade et al., 1990) und senkt letale Koronarinfarkte (Kaufmann et al., 1997). Eine erhebliche Nebenwirkung von Tamoxifen ist jedoch das erhöhte Risiko für die Entstehung eines Endometriumkarzinoms (EBCTC-Group, 1996; Barakat, 1996; Barakat, 1998). Weitere häufige Nebenwirkungen sind eine erhöhte Thromboseneigung, Hitzewallungen und Depression (Robinson et al., 1996; Day et al., 1999).

Parallel zu der Entwicklung von SERMs durch die Pharmaindustrie wandte sich der Blick der Wissenschaft auf östrogenartige Substanzen pflanzlichen Ursprungs, die sogenannten Phytoöstrogene. Nachdem bekannt worden war, daß asiatische Frauen weitaus seltener als europäische oder amerikanische Frauen unter ihrem Klimakterium litten, wurde im Zusammenhang mit der unterschiedlichen Ernährungsweise dieser Gruppe die positive phytoöstrogene Potenz der Soja und inrer Inhaltsstoffe Genistein und Daidzein entdeckt (Anthony et al., 1998; Setchell et al., 2001). Die Phytoöstrogene können verschiedenen chemischen Stoffklassen zugeordnet werden. All diesen Stoffen gemeinsam ist eine chemische Struktur ähnlich der des Estradiols, welche es innen ermöglicht, an ER zu binden (Diel et al., 2000; Ferrara, 2000; Gehm et al., 1997; Kuiper et al., 1998 ; Nikov et al., 2000).

In der Behandlung und Vorbeugung menopausaler Beschwerden der Frau spielen Phytoöstrogene bereits eine wichtige Rolle.

In den Mittelpunkt des Interesses standen die isoflavonhaltigen Pflanzen Soja und Rotklee (Trifolium pratense). Die meisten klinischen Studien, die eine Mischung der Isoflavone beider Pflanzen anwandten, zeigten keine Verbesserung der klimakterischen Beschwerden postmenopausaler Frauen (St Germain et al., 2001; Fitzpatrick, 1999). Für die Isoflavone dieser Pflanzen konnte jedoch sowohl für ovarektomierte Ratten als auch für postmenopausale Frauen eine milde 
osteoprotektive Wirkung gezeigt werden (Fanti et al., 1998; Picherit et al., 2000; Alekel et al., 2000; Scheiber et al., 2001). In perimenopausalen Frauen der westlichen Kulturen zeigte die kontinuerliche Einnahme von Soja im Rahmen der Umstellung der Ernährung, daß die Dichte der Brust (McMichael-Phillips et al., 1998), die Flüssigkeitsproduktion der Brustdrüse und die Bildung von Progesteronrezeptoren (Petrakis et al., 1996) ansteigen. Diese Veränderungen sind Indikatoren für ein erhöhtes Risiko, ein Mammakarzinom zu entwickeln (Greendale et al., 1999; Petrakis, 1993). Naheliegend ist jedoch, daß eine Ernährung auf SojaBasis von Beginn des Lebens an und insbesondere während der Pubertät, Mammakarzinom-protektive Wirkungen entfaltet. Dieses Phänomen konnte in Nagetieren gezeigt werden (Lamartiniere, 2000) und scheint der Grund dafür zu sein, daß japanische Frauen, die ihr Proteinbedarf vom Beginn ihres Lebens an primär von Soja beziehen, weniger Brustkrebs entwickeln (Wuttke et al., 2002 a).

Ferner stimulieren hohe Dosen von Isoflavonen, insbesondere von Genistein, das uterine Gewicht und die Expression verschiedener östrogen-regulierten Gene im Uterus (Diel et al., 2001; Burdette et al., 2002). Nach den oben erwähnten experimentellen und klinischen Befunden scheinen Soja und Rotklee und deren untersuchten Isoflavone nicht das Kriterium eines idealen SERM zu erfüllen.

Daneben sind die beiden Pflanzen Belamcanda chinensis und Cimicifuga racemosa, deren Extrakte in dieser Studie verwendet wurden, immer mehr in den Mittelpunkt des Interesses gerückt.

\section{5. 1. Belamcanda chinensis (BC)}

BC oder "Leopardenblume" ist in China, Japan und Korea beheimatet und gehört zu den Iridaceen. Es wird in der traditionellen chinesischen Medizin u.a. zur Behandlung entzündlicher und gynäkologischer Erkrankungen eingesetzt. Pharmakologisch findet der geschnittene und getrocknete Wurzelstock (Rhizom), ein unter der Erdoberfläche wachsendes nährstoffspeicherndes Organ dieser krautigen Pflanze, Verwendung.

Als wirksame Bestandteile sind neben vielen anderen die Isoflavone Iridin, Tectoridin, Tectorigenin, Belamcandinin und Irigenin sowie Flavonoide, Ketone, Triterpene, Xanthone und Stilbene bekannt. In vitro erwies sich der Extrakt dieser Pflanze u.a. als antimykotisch und antiviral, in vivo zusätzlich als uterusrelaxierend und schleimlösend. Jedoch sind scheinbar die Zusammensetzungen der Inhaltsstoffe der 
Extrakte aus dem Rhizom der BC, abgesehen von den Hauptbestandteilen Tectoridin und Iridin, abhängig von der Herkunft der Pflanze (Wagner $\mathrm{H}$ et al., 1999).

Das aus dem Rhizom dieser Pflanze isolierte Isoflavon Tectorigenin konnte in vitro an die beiden Östrogenrezeptor (ER)-Subtypen ERa und ER $\beta$ binden. Ferner konnte die intravenöse Gabe von Tectorigenin an ovarektomierten Ratten die pulsatile hypophysäre LH-Sekretion, die in postmenopausalen Frauen mit dem Phänomen "Hot Flush" in Zusammenhang steht, hemmen. Die chronische Applikation eines Extrakts von Belamcanda chinensis an ovarektomierten Ratten hatte keine Auswirkung auf das uterine Gewicht und auf die Expression östrogen-regulierter Gene im Uterus. Zusätzlich zeigten sich keine mammotrophe Effekte an den Versuchstieren. Ferner kam es zu einem deutlichen Anstieg der BMD in der tibialen Metaphyse der Ratten (Seidlova-Wuttke et al., 2004).

In einer weiteren experimentellen Arbeit konnte an ovarektomierten Ratten gezeigt werden, daß sowohl der Extrakt aus BC, als auch die aus inm isolierten Isoflavone Tectoridin und Tectorigenin in der Lage waren, auf die Genexpression von Substanzen, die im Knochengewebe als Marker der Osteoblastenaktivität (IGF-1, TGF- $\beta$, Osteocalcin und OPG) sowie als Marker der Osteoklastenaktivität (Tartratresistente sauere Phosphatase) gelten, wie ein Östrogen zu wirken. Dagegen kam es nicht zu einer Dicken- bzw. Gewichtszunahme des Uterus. Im Gegensatz zu der Wirkung des Östrogens blieben das Endometrium und die uterine Genexpression des Wachstumsfaktors IGF-1 unbeeinflusst (Becker, 2002).

Somit scheinen die Inhaltsstoffe der BC, deren Extrakt in dieser Arbeit eingesetzt wurde, phytoöstrogene Wirkungen und eine SERM-Aktivität zu besitzen.

In einer experimentellen Studie wurden LNCaP-Zellen, die dem humanen Prostatakarzinom entstammen und androgensensitiv sind, den männlichen Nacktmäusen subkutan verabreicht. Unter einer Fütterung mit einem Extrakt aus BC wurde das Wachstum der subkutanen Tumore deutlich vermindert. Ferner wurden in der gleichen Studie LNCaP-Zellen in vitro mit dem BC-Extrakt, Tectorigenin oder anderen Isoflavonen aus BC behandelt. Dabei ließen sich eine Reduktion der Genexpression von Prostate-derived Ets transcription Factor (PDEF, einem CoAktivator des Androgenrezeptors), von PSA und von IGF-1-Rezeptor sowie eine Verminderung der Proteinexpression von PSA und IGF-1-Rezeptor feststellen. Diese Studie zeigte eine Hemmung der IGF-1-Rezeptor-vermittelten Proliferation von Prostatakarzinomzellen durch Tectorigenin und anderen Isoflavonen der 
Belamcanda chinensis (Thelen et al., 2005). Aufgrund der inhibitorischen Eigenschaft von $B C$ und dessen Isoflavonen gegenüber dem Prostatakarzinom scheint deren Einsatz in der antiosteoporotischen Therapie von hypogonadalen Männern von besonderem Interesse zu sein.

\section{5. 2. Cimicifuga racemosa (CR)}

Die Traubensilberkerze (Cimicifuga racemosa, engl.: Black cohosh) wird der Familie der Ranunculaceae (= Hahnenfußgewächse) zugeschrieben. Die natürliche Verbreitung umfaßt die gemäßigten Zonen der nördlichen Hemisphäre (USA, Kanada, Mittel- und Nordeuropa) bis Sibirien. CR ist eine krautige Staude, deren bis zu 2 m hoher, aufrechter Stängel aus einem dicht bewurzelten Rhizom erwächst. Im Frühsommer (Juni, Juli) sind die weißen Blüten in langen und schmalen Trauben geordnet. Die Blüten haben einen unangenehmen Geruch und sollen Insekten, insbesondere Wanzen, von der Pflanze fern halten. Diese Beobachtung verlieh der Pflanze den botanischen Namen: lat. cimex $=$ Wanze, lat. fuga $=$ Flucht $($ Blaschek, 1998).

Pharmakologisch wird das nach der Fruchtreife (im Herbst) gesammelte, getrocknete und geschnittene Rhizom verwendet, wobei die Pflanze mindestens zwei bis drei Jahre alt sein soll. Klinisch eingesetzt werden sowohl isopropanolisch-wässrige wie auch ethanolisch-wässrige Extrakte. Die empfohlene Tagesdosis beträgt $40 \mathrm{mg}$ Droge pro Tag (Kommission E Monographie Cimicifuga, 1989).

Die Inhaltsstoffe der Traubensilberkerze sind erst zu einem kleinen Teil untersucht. Bedeutend sind die Triterpenglykoside. Es kommen hauptsächlich die Xyloside Actein (Acetylacteol) und Cimifugosid (Cimigenol) sowie Deoxyacetylacteol und 27Deoxyactein vor. Ferner enthalten Extrakte aus der Cimicifuga racemosa phenolische Verbindungen. Beschrieben sind das Flavon Kämpferol sowie verschiedene Hydroxyzimtsäurederivate (Kaffeesäure, Ferulasäure, Isoferulasäure, Fukinolsäure und die Cimifugasäuren A, B, E, F) (Kruse, 2000).

Welche Inhaltstoffe auch Wirkstoffe sind, ist noch unklar. Pharmakologische Untersuchungen zeigen, daß die Triterpenglykoside eher dopaminerge Effekte aufweisen. So reduziert Cimicifuga-Extrakt in vitro sowohl die basale wie auch die TRH-stimulierte Prolaktinsekretion. Dieser Effekt kann durch die gleichzeitige Verabreichung von Haloperidol, einem Dopamin-D2/4-Rezeptor-Antagonisten, aufgehoben werden (Löhning, 1999). 
Ferner konnte gezeigt werden, daß unbekannte Bestandteile des CR-Extrakts BNO 1055 sowohl an das rekombinante Dopamin-D2-Rezeptorprotein binden als auch radioaktiv markiertes E2 von dessen Bindungsstellen im Zytosol des humanen Endometriums verdrängen. Eine Verdrängung des Tracers von dem rekombinaten $E R \alpha$ und ER $\beta$ konnte überraschenderweise jedoch nicht nachgewiesen werden. Chromatographisch ließen sich Bestandteile mit dopaminerger und östrogenartiger Aktivität des CR-Extrakts in zwei verschiedenen Fraktionen auftrennen (Jarry et al., 2002).

Bezüglich des östrogenartigen Effekts von Cimicifuga-Extrakten liegen zahlreiche Daten vor. In einer doppelblinden und Placebo-kontrollierten klinischen Studie reduzierte das Cimicifuga-racemosa-Präparat CR BNO 1055 die klimakterischen Beschwerden postmenopausaler Frauen genau so wirksam wie das eingesetzte konjugierte Östrogen und beeinflußte die Serummarker des Knochenmetabolismus (Cross laps und knochenspezifische alkalische Phosphatase) positiv. Ferner führte CR BNO 1055, das in Arzneimitteln wie Klimadynon oder Menofem auf dem Markt erhältlich ist, zu der wünschenswerten Vermehrung epithelialer Oberflächenzellen der Vagina. Im Gegensatz zu dem Östrogen beeinflußte CR BNO 1055 keineswegs die Dicke des Endometriums (Wuttke et al., 2002 b).

Einige Publikationen mit isopropanolischen und ethanolischen Extrakten zeigten keine östrogenagonistischen und somit proliferativen Effekte auf die Brustdrüse (Freudenstein und Bodinet, 1999; Nesselhut et al., 1993).

In ovarektomierten Ratten konnte die intravenöse Gabe von CR BNO 1055 ähnlich wie E2 den LH-Spiegel im Serum senken, womit die Wirkung auf die hypothalamohypophysäre Einheit beschrieben wurde. Die vermehrte pulsatile LH-Freisetzung aus der Hypophyse nach der Menopause korreliert in nicht ganz vollständig geklärter Weise mit Hitzewallungen postmenopausaler Frauen. Nach der dreimonatigen oralen Applikation von CR BNO 1055 konnte der osteoporotische Prozeß, der in der Messung der Knochenmineraldichte der tibilaen Metaphyse von ovarektomierten Ratten sichtbar wurde, aufgehalten werden, obwohl die osteoprotektive Wirkung von E2 deutlicher ausfiel. Im Gegensatz zu E2 zeigte CR BNO 1055 auf die Genexpression im Uterus und auf das uterine Gewicht keinerlei Wirkung (SeidlovaWuttke et al., 2003). Somit spricht die Datenlage für eine selektive und osteoprotektive Potenz des in dieser Arbeit eingesetzten Cimicifuga-racemosaExtrakts. 
In Bezug auf das Prostatakarzinom konnten einige experimentelle Studien mit CR sehr interessante Ergebnisse liefern. Sowohl der Cimicifuga-racemosa-Extrakt BNO 1055 als auch das Petasiphenon, ein Phenol, das aus diesem Extrakt isoliert worden war, konnten die Proliferation von LNCaP-Zellen, androgensensitiven humanen Prostatakarzinomzellen, in immungeschwächten Mäusen wie auch in vitro signifikant hemmen (Seidlova-Wuttke et al., 2006; Jarry et al., 2007). Hostanska et al. (2005) konnten darüberhinaus feststellen, daß ein isopropanolischer Extrakt von $\mathrm{CR}$ in vitro sowohl das Wachstum von LNCaP-Zellen als auch die Vermehrung von nicht androgensensitiven Prostatakarzinomzellen über die Induktion von Apoptose signifikant hemmt. Angesichts der letztgenannten Eigenschaften von $\mathrm{CR}$ gegenüber dem Prostatakarzinom, weckt diese Arzneipflanze ähnlich wie BC für die antiosteoporotische Therapie von hypogonadalen Männern Aufmerksamkeit.

Ziel dieser Arbeit war es, die Einflüsse von BC und CR auf die IGF-1-Expression im Knochen der orchiektomierten Ratten zu untersuchen, um deren osteoprotektive Wirksamkeit in einem Tiermodell, das sich auf den hypogonadalen Mann übertragen läßt, zu erforschen. Dabei sollten die osteoprotektive Wirkungen der beiden Arzneipflanzen mit denen von Estradiol und Testosteron verglichen werden. Zusätzlich wurde die IGF-1-Synthese in der Leber gemessen, die indirekt ein Maß für die Höhe des zirkulierenden IGF-1 und für dessen endokrine Wirksamkeit darstellt. Nicht zuletzt wurden in dieser Arbeit geeignete Methoden zur Messung der Genexpression und der Proteinkonzentration von IGF-1 vorgestellt. 


\section{Material und Methoden}

\section{1. Tierexperimente}

\section{1. 1. Versuchstiere und Haltungsbedingungen}

Die Tierexperimente wurden an männlichen Sprague-Dawley-Ratten aus dem Züchtungsinstitut Winkelmann, Bochum durchgeführt. Die Anzahl der Versuchstiere betrug 52. Im Alter von drei Monaten und mit einem durchschnittlichen Gewicht von $230 \pm 10 \mathrm{~g}$ wurden die Tiere in einer Gruppengröße von 6 Tieren pro Käfig gehalten. Der Raum, in dem die Tierkäfige aufbewahrt wurden, wurde zwischen 6 und $18 \mathrm{Uhr}$ beleuchtet und bei $23 \mathrm{Grad} \mathrm{C}^{\circ}$ konstant temperiert. Die Tiere erhielten sojafreies Pellet-Futter (V 1334-000, 10 mm Schnitt, Soest, Germany) und Trinkwasser ad libitum. Die Tierversuche wurden bei Vorlage einer Genehmigung der Bezirksregierung Braunschweig und unter der Aufsicht von Frau Dr. Seidlova-Wuttke durchgeführt (AZ 509.42502 / 01-2 98).

\section{1. 2. Orchiektomie}

Die Orchiektomie der männlichen Ratten erfolgte eine Woche nach der Ankunft der Tiere in Narkose mit Isofluran (Floren, Abott, Germany). Dabei wurde jede Ratte bis zum Einsetzen der Bewußtlosigkeit dem Ether ausgesetzt und darauffolgend durch die intraperitoneale Injektion der o.g. Substanz narkotisiert. Nach Desinfektion des Operationsgebiets wurde das Skrotum mit einem Skalpell durchtrennt und somit die Hoden entfernt. Die postoperative Analgesie wurde mittels Rimadyl (Pfizer, 0,4 ml s.c.) durchgeführt. Die Haltungsbedingungen der Tiere blieben nach dem operativen Eingriff unverändert.

\section{1. 3. Durchführung der Tierversuche}

Die Versuche erfolgten in einem Zeitraum von 10 Tagen zwischen 17.01. und 26.01.2000. Die kastrierten männlichen Ratten wurden auf 6 Gruppen von je 7 bis 10 Tieren verteilt. Jede Gruppe erhielt über den gesamten Versuchszeitraum nur eine ausgewählte Testsubstanz auf dem subkutanen (s.c.) Weg. Die Gruppe, die Cremophor $20 \%$ bekam, galt als die Kontrollgruppe. 
Zu Beginn der Versuche betrug das mittlere Körpergewicht aller Ratten 361g. Dabei war das mittlere Körpergewicht der einzelnen Gruppen folgendermaßen:

\begin{tabular}{|l|l|l|l|l|l|l|}
\hline Gruppe & 1 & 2 & 3 & 4 & 5 & 6 \\
\hline Mittleres Gewicht & $360 \mathrm{~g}$ & $366 \mathrm{~g}$ & $370 \mathrm{~g}$ & $346 \mathrm{~g}$ & $371 \mathrm{~g}$ & $347 \mathrm{~g}$ \\
\hline
\end{tabular}

\section{1. 4. Testsubstanzen}

Die Testsubstanzen, die täglich für 10 Tage in einem Bolus von $1 \mathrm{ml}$ s.c. den Versuchstieren appliziert wurden, entsprachen:

1. Cremophor $20 \%$ (für die Kontrollgruppe)

2. Estradiol $17-$ beta $3.5 \mu \mathrm{g} / \mathrm{ml}$

3. Estradiol 17 -beta $0.5 \mu \mathrm{g} / \mathrm{ml}$

4. Testosteron $3.5 \mathrm{mg} / \mathrm{ml}$

5. Extrakt aus dem Rhizom der Belamcanda chinensis $(62.5 \mathrm{mg} / \mathrm{ml})$ von Bionorica (BNO)

6. Extrakt aus dem Rhizom der Cimicifuga racemosa $(62.5 \mathrm{mg} / \mathrm{ml})$ von Bionorica (BNO)

\section{Versuchsprotokoll:}

\begin{tabular}{|l|l|l|l|l|}
\hline Behandelt mit: & $\begin{array}{l}\text { Nummer der } \\
\text { Ratten: }\end{array}$ & Dosis: & $\begin{array}{l}\text { Applikations- } \\
\text { menge: }\end{array}$ & $\begin{array}{l}\text { Tiergruppen } \\
\text { und Anzahl der } \\
\text { Tiere: }\end{array}$ \\
\hline Cremophor & Nr.: 1 bis 9 & $20 \%$ & $1 \mathrm{ml}$ Bolus & Gruppe 1: 9 \\
\hline Estradiol 17-beta & Nr.: 10 bis 19 & $3.5 \mu \mathrm{g} / \mathrm{ml}$ & $1 \mathrm{ml}$ Bolus & Gruppe 2: 10 \\
\hline Estradiol 17-beta & Nr.: 20 bis 29 & $0.5 \mu \mathrm{g} / \mathrm{ml}$ & $1 \mathrm{ml}$ Bolus & Gruppe 3: 10 \\
\hline Testosteron & Nr.: 30 bis 37 & $3.5 \mathrm{mg} / \mathrm{ml}$ & $1 \mathrm{ml}$ Bolus & Gruppe 4: 8 \\
\hline BC & Nr.: 38 bis 45 & $62.5 \mathrm{mg} / \mathrm{ml}$ & $1 \mathrm{ml}$ Bolus & Gruppe 5: 8 \\
\hline CR & Nr.: 46 bis 52 & $62.5 \mathrm{mg} / \mathrm{ml}$ & $1 \mathrm{ml}$ Bolus & Gruppe 6: 7 \\
\hline
\end{tabular}




\section{1. 5. Versuchsende}

Die Decapitatio der Ratten erfolgte 6 Stunden nach der letzten Applikation am 26.01.2000. Das durchschnittliche Körpergewicht der Tiere betrug zum Zeitpunkt der Decapitatio $349 \mathrm{~g}$. Das mittlere Körpergewicht der einzelnen Gruppen umfaßte zu diesem Zeitpunkt folgende Werte:

\begin{tabular}{|l|l|l|l|l|l|l|}
\hline Gruppe & 1 & 2 & 3 & 4 & 5 & 6 \\
\hline Mittleres Gewicht & $354 \mathrm{~g}$ & $357 \mathrm{~g}$ & $372 \mathrm{~g}$ & $356 \mathrm{~g}$ & $363 \mathrm{~g}$ & $328 \mathrm{~g}$ \\
& & & & & & \\
\hline
\end{tabular}

Unmittelbar danach wurden diverse Organe und Blut der Tiere für die Untersuchungen entnommen, entsprechend fixiert und zur weiteren Aufarbeitung tiefgekühlt bei $-80^{\circ} \mathrm{C}$ aufbewahrt. Für diese Dissertation haben wir die Organe Femur und Leber untersucht.

\section{2. Analytische Methoden}

\section{2. 1. Präparation von Gewebeproben zur Bestimmung der} IGF-1-Konzentration

\section{2. 1. 1. Prinzip}

Ziel der Präparation ist die Extraktion bestimmter Proteine aus den Gewebeproben durch einen speziellen Puffer. Die dem Tierversuch entnommenen Gewebeproben, in dieser Arbeit Femur- und Leberproben der Versuchsratten, wurden pulverisiert. In der Pulverform bieten die Gewebeproben dem Extraktionspuffer eine größere Oberfläche an und können sich gleichmäßig in dem Puffer verteilen. Um ein Auftauen der Proben zu verhindern, wurden diese bei $-20^{\circ} \mathrm{C}$ tiefgefroren aufbewahrt. Während des Vorgangs der Präparation wurden die Proben im flüssigen Stickstoff bzw. auf Eis gelagert.

\section{2. 1. 2. Durchführung}

Zuerst wurde das Gewicht der leeren Röhrchen (Mikro-Schraubröhre $1.5 \mathrm{ml}$ Firma Sarstedt) ermittelt. Die Gewebeproben wurden mit einem Mikro-Dismembrator (Firma B. Braun Biotech international) pulverisiert. Das Gewicht der mit Gewebepulver 
gefüllten Röhrchen wurde gemessen und die Gewichtsdifferenz und damit die Masse der Gewebeproben berechnet.

Der Extraktionspuffer, der aus einer Phosphatpuffer-Lösung (phosphat buffer solution: PBS) mit dem Zusatz eines Proteaseinhibitors, im Allgemeinen Mercaptoethanol, bestand, wurde in einem Verhältnis von $1 \mathrm{mg}$ Gewebe zu $10 \mu \mathrm{l}$ Puffer in die Röhrchen pipettiert.

Unter der Behandlung mit Ultraschallwellen (Firma Branson Sonic Power Company) wurde aus den weitgehend getrennten Phasen von Probe und Puffer ein Homogenat gebildet. Die Röhrchen wurden anschließend in einer Mikrozentrifuge (Firma Hettich Zentrifuge) weiterbehandelt. Der Überstand, der zur Bestimmung von IGF-1 in den verschiedenen Assays eingesetzt wurde, und das Sediment (Pellet) wurden getrennt tiefgefroren aufbewahrt.

\section{2. 2. Radio-Immunoassay zur quantitativen Bestimmung von Insulin-like Growth Factor 1 der Ratte (r-IGF-1)}

\section{2. 2. 1. Prinzip des Radio-Immunoassays (RIA)}

Der Radio-Immunoassay (RIA) ist ein in-vitro-Verfahren zur quantitativen Messung einer bestimmten Substanz (Antigen) auf der Basis einer Antigen-AntikörperReaktion. Dabei wird zusätzlich ein radioaktiv markiertes Antigen (Tracer) verwendet. Das in unbekannter Konzentration vorliegende Antigen, hier das IGF-1 der Probe, konkurriert mit dem in bekannter Konzentration vorliegenden und durch Jodid-125 radioaktiv markierten Tracer um die Bindungsstellen des Antikörpers. Mit Hilfe eines zweiten Antikörpers, der an den bestehenden Antigen-Antikörper-Komplex bindet und diesen zur Präzipitation bringt, kann das gebundene Antigen von dem freien Antigen getrennt werden. Nach Zentrifugation des Reaktionsmediums und Dekantieren des Überstands wird im Sediment die Radioaktivität gemessen. Es gilt die Aussage: je größer die Konzentration des zu bestimmenden Antigens in der Probe ist, desto weniger radioaktiver Tracer ist an den Antikörper gebunden worden und um so geringer ist die Immunkomplex-gebundene Radioaktivität. Es liegt somit eine umgekehrt-proportionale Beziehung zwischen den Antigen- (IGF-1) Konzentrationen der Proben und der Höhe ihrer radioaktiven Messungen vor. 
Die Bestimmung der Antigenkonzentrationen der Proben erfolgt mit Hilfe einer Standardkurve, die für jeden Assay neu erstellt werden muß. Dabei wird für bekannte Antigenkonzentrationen (Standards), die mit Tracer und Antikörper versetzt werden, die Anzahl der radioaktiven Zerfälle pro Minute ( $\mathrm{CpM}$ ) gemessen. Mit den Standards wird die Nachweisgrenze des Assays festgelegt. Durch die graphische semilogarithmische Darstellung von Standardkonzentrationen im Verhältnis zu ihren CpM ergibt sich die sigmoidal verlaufende Standardkurve. Durch die Standardkurve kann die gemessene Radioaktivität einer Probe ihrer Antigenkonzentration zugeordnet werden. Somit können die IGF-1-Konzentrationen der Proben bestimmt werden.

\section{2. 2. 2. Verwendete Substanzen}

Bei der Durchführung des RIA zur Bestimmung von r-IGF-1 wurde das RIA-Kit der Firma Diagnostic Systems Laboratories (Katalog-Nr. DSL 2900) verwendet.

Das RIA-Kit enthielt folgende Bestandteile:

1. Ratten-IGF-1-Antiserum: Ziege-Anti-Ratten-IGF-1-Serum in Proteinpuffer und Natriumazid (Konservierungsmittel)

2. 125-J-Ratten-IGF-1 (Tracer) mit einer Radioaktivität unter $185 \mathrm{kBq}$ in Proteinpuffer und Natriumazid

3. Präzipitierende Reagenz: Esel-Anti-Ziege Gammaglobulin mit Polyethylenglykol (PEG) und Natriumazid

4. Ratten-IGF-1-Standards: 6 Lösungen mit Ratten-IGF-1 in bekannten und unterschiedlichen Konzentrationen in proteinhaltigem Puffer und Konservierungsmittel (nicht quecksilberhaltig); Konzentrationswerte der Standards:

A: $0 \mathrm{ng} / \mathrm{ml}$, B: $150 \mathrm{ng} / \mathrm{ml}$, C: $300 \mathrm{ng} / \mathrm{ml}$, D: $600 \mathrm{ng} / \mathrm{ml}$, E: $1100 \mathrm{ng} / \mathrm{ml}, \mathrm{F}: 3500$ $\mathrm{ng} / \mathrm{ml}$ 
5. Ratten-IGF-1-Kontrollen: 2 Lösungen mit Ratten-IGF-1 bekannter Konzentrationen (Kontrolle 1: $425+/-125 \mathrm{ng} / \mathrm{ml}$, Kontrolle 2: $1100 \quad+/-300$ $\mathrm{ng} / \mathrm{ml}$ ) in Proteinpuffer und Konservierungsmittel (nicht quecksilberhaltig)

6. Proben jeweils von Femur oder Leber der Versuchsratten, die - wie unter 3.2.1. beschrieben - präpariert wurden.

\section{2. 2. 3. Durchführung des RIA}

Der lyophil getrocknete Inhalt der RIA-Kit-Reagenzien wurde in entsprechenden Mengen destillierten Wassers aufgelöst.

Der Versuch sah für die Messung der Proben eine Einfachbestimmung, für die Messung der Standards, der Kontrollen, der nicht-spezifischen Bindung (NSB) und der Totalaktivität (TA) eine Doppelbestimmung vor. Die Kontrollen überprüfen die Leistungsfähigkeit des Tests. Ihre Konzentrationen sind bekannt und liegen innerhalb der Nachweisgrenze. Die Kontrollen werden wie die Proben mit ihren unbekannten Konzentrationen behandelt. Die Messung der NSB stellt die Radioaktivität dar, die nach Zentrifugation und Dekantieren der Teströhrchen durch die verbliebenen freien oder unspezifisch gebundenen radioaktiven Tracer-Moleküle entsteht. Sie ist ein Korrekturparameter und wird am Ende von den Messwerten subtrahiert. Die TA stellt die maximal mögliche Radioaktivität dar, auf die sich die Messwerte prozentual beziehen lassen.

In die entsprechend beschrifteten Teströhrchen (Polypropylenröhrchen $12 \times 75 \mathrm{~mm}$ ) wurden jeweils $50 \mu \mathrm{l}$ der Proben, der Standards A-F und der Kontrollen pipettiert. Zur Bestimmung der NSB wurden $150 \mu \mathrm{l}$ des Standards A hinzugegeben. Die Röhrchen zur Messung der TA blieben leer.

Im nächsten Schritt wurden in jedes Röhrchen $100 \mu \mathrm{l}$ des radioaktiv markierten r-IGF-1 (Tracer) pipettiert. Gleich danach kamen in jedes Röhrchen, außer den NSBund TA- Röhrchen, $100 \mu \mathrm{l}$ r-IGF-1-Antiserum hinzu. Der Inhalt der Röhrchen wurde mit Hilfe des Vortex-Mixers durchmischt und dann für mindestens 3 Stunden (h) bei Raumtemperatur inkubiert.

Nach der Inkubation kamen in jedes Röhrchen, außer denen der TA-Bestimmung, $1000 \mu \mathrm{l}$ der Präzipitierenden Reagenz (2. Antikörper) hinzu. Nach kurzer Durchmischung schloß sich eine weitere Inkubation für 20 Minuten (min) bei 
Raumtemperatur an. Nach diesem Schritt wurde der Röhrcheninhalt (außer TARöhrchen) bei 3000 Umdrehungen pro Minute (UpM ) für 20 min gekühlt zentrifugiert (Cryofuge 5000, Firma Heraeus SEPATECH). Der Überstand (außer dem zur TABestimmung) wurde dekantiert und entsorgt. Die Radioaktivität im Sediment der Röhrchen wurde für 1 min im Gamma-Zähler (Fima Perkin Elmer Wallac GmbH) gemessen. Die Standardkurve und die r-IGF-1-Konzentrationen der Proben wurden vom Rechner berechnet und ausgedrückt.

\section{2. 3. Gesamtproteinbestimmung}

\section{2. 3. 1. Versuchsprinzip}

Eine sensitive Methode, die Konzentration von Proteinen in einer Lösung photometrisch zu bestimmen, ist die Methode nach Bradford (1976). Hier findet der Farbstoff Coomassie Brillant Blue G-250 in einem saueren Lösungsansatz (Farbreagenz) Anwendung. Die Farbreagenz besitzt eine rote Farbe und ein Absorptionsmaximum bei einer Wellenlänge von $470 \mathrm{~nm}$. Wird die Farbreagenz in eine proteinhaltige Lösung gegeben, so bindet sich der Farbstoff an das Protein. Bildet sich ein solcher Farbstoff-Protein-Komplex, dann ändert die Farbreagenz ihre Farbe zu blau und ihr Absorptionsverhalten mit einem Absorptionsmaximum, das nun bei $595 \mathrm{~nm}$ liegt. Zwischen der Absorptionsintensität der Farbreagenz bei der Wellenlänge $595 \mathrm{~nm}$ und der Proteinkonzentration der Lösung besteht eine proportionale Beziehung. Zur Ermittlung der Proteinkonzentrationen der Proben bei gemessener optischen Dichte bedarf es einer Standardkurve, die eine Zuordnung der Absorptionsintensität zu der Proteinkonzentration erlaubt. Die Standardkurve verläuft linear. Als Standardprotein findet bovines Gammaglobulin Anwendung.

\section{2. 3. 2. Verwendete Substanzen}

Zur Gesamtproteinbestimmung fand der Bio-Rad Protein-Assay Verwendung:

Die wässrige Farbreagenz (Bio Rad Cat-Nr. 500-006) enthielt den Farbstoff Coomassie Brillant Blue G-250 (0.01\% ), Phosphorsäure (1.6 molar) und Methanol (0.8 molar).

Der Proteinstandard 2 ( Bio Rad Cat-Nr. 500-0005 ) enthielt bovines Gammaglobulin. 


\section{2. 3. 3. Durchführung}

Die aufgetauten Probensedimente ( Pellets ) wurden für 2 Minuten bei 10000 UpM zentrifugiert.

Aus dem Proteinstandard der Ausgangskonzentration $1.45 \mathrm{mg} / \mathrm{ml}$ wurden 7 Standards ( ST) mit folgenden Konzentrationen hergestellt:

ST 1: $29 \mu \mathrm{g} /$ Tube, ST 2: $21.75 \mu \mathrm{g} /$ Tube, ST 3: $14.5 \mu \mathrm{g} / \mathrm{Tube}, \mathrm{ST} 4: 11.6 \mu \mathrm{g} / \mathrm{Tube}$, ST 5: $5.8 \mu \mathrm{g} /$ Tube, ST 6: $2.9 \mu \mathrm{g} /$ Tube, ST 7: $1.45 \mu \mathrm{g} /$ Tube $(1$ Tube $=10 \mu \mathrm{l})$. In dem Protein-Assay fand eine Mikrotiterplatte Anwendung. Es wurden in die entsprechenden Kavitäten der Platte $250 \mu \mathrm{l}$ der jewaligen Standards als Doppelbestimmung pipettiert. $1 \mu \mathrm{l}$ von den jewaligen Proben, verdünnt mit $249 \mu \mathrm{l}$ bidestillierten Wassers (Aqua bid.), wurden in andere Kavitäten hineingegeben. 2 weitere Plattenvertiefungen wurden mit $250 \mu$ l Aqua bid. als Leerwert für den Spektrophotometer gefüllt. Im nächsten Schritt wurden $50 \mu$ l der Farbreagenz in alle Kavitäten hinein pipettiert und die Lösungen in der Mikrotiterplatte durchmischt. Abschließend wurde die optische Dichte der Lösungen bei $595 \mathrm{~nm}$ im Spektrophotometer (Tecan Spectra, Firma SLT Labinstruments) gemessen. Die Standardkurve, die optische Dichte und die Proteinkonzentrationen ( in der Einheit: $\mu g /$ Tube ) der Proben wurden vom Rechner erstellt und ausgedrückt.

\section{Das Pipettierschema der Mikrotiterplatte:}

\begin{tabular}{|l|l|l|l|l|l|l|l|l|l|}
\hline & $\mathbf{1}$ & $\mathbf{2}$ & $\mathbf{3}$ & $\mathbf{4}$ & $\mathbf{5}$ & $\mathbf{6}$ & $\mathbf{7}$ & $\mathbf{8}$ & $\mathbf{9}$ \\
\hline $\mathbf{A}$ & ST 1 & ST 1 & 1 & 9 & 17 & 25 & 33 & 41 & 49 \\
\hline B & ST 2 & ST 2 & 2 & 10 & 18 & 26 & 34 & 42 & 50 \\
\hline C & ST 3 & ST 3 & 3 & 11 & 19 & 27 & 35 & 43 & 51 \\
\hline D & ST 4 & ST 4 & 4 & 12 & 20 & 28 & 36 & 44 & 52 \\
\hline E & ST 5 & ST 5 & 5 & 13 & 21 & 29 & 37 & 45 & \\
\hline F & ST 6 & ST 6 & 6 & 14 & 22 & 30 & 38 & 46 & \\
\hline $\mathbf{G}$ & ST 7 & ST 7 & 7 & 15 & 23 & 31 & 39 & 47 & \\
\hline H & LW & LW & 8 & 16 & 24 & 32 & 40 & 48 & \\
\hline
\end{tabular}

ST : Standard

$1-52$ : Proben

LW : Leerwert 


\section{2. 4. TaqMan-Polymerase-Ketten-Reaktion}

\section{2. 4. 1. Isolierung von Gesamt-RNA}

In diesem Arbeitsschritt wurde die Gesamt-RNA mit Hilfe spezieller Pufferlösungen aus den Gewebeproben isoliert, um in die TaqMan-Polymerase-Ketten-Reaktion (-PCR) eingesetzt zu werden.

Die einzelnen tiefgefrorenen Gewebefragmente wurden - wie unter 3.2.1. beschrieben - mit einem Mikro-Dismembrator (Firma B. Braun Biotech International) mechanisch zerkleinert, mit Lysepuffer versetzt und im Ultraschallbad homogenisiert. Die Präparation wurde mit Hilfe des RNeasy-Systems (Firma Qiagen, Hilden) durchgeführt und die RNA -Konzentration in einem Biophotometer (Firma Eppendorf) gemessen. Anschließend konnten die Proben direkt weiter verarbeitet oder bei $-70^{\circ}$ C gelagert werden.

\section{2. 4. 1. 1. Vorsichtsmaßnahmen im Umgang mit der RNA}

Damit die RNAse-Aktivität möglichst gering blieb, galten grundsätzlich folgende Maßnahmen für die Arbeit mit der RNA:

Alle Arbeitsschritte wurden mit Ethanol-desinfizierten Handschuhen, schnell und auf Eis (Ausnahme RNeasy) durchgeführt. Sämtliche Glasgefäße wurden bei $240^{\circ} \mathrm{C}$ $12 \mathrm{~h}$ sterilisiert, andere Materialien bei $120^{\circ} \mathrm{C}$ für 30 min autoklaviert. $0.1 \%$ Velcorin (Dimethylpyrocarbonat, Firma Bayer Leverkusen), das RNAsen durch kovalente Bindung inaktiviert, wurde allen verwendeten Lösungen zugefügt. Auch diese Lösungen wurden im Anschluß autoklaviert. Reagenzien wie Tris und Dithiothreitol (DTT), die durch Autoklavieren zerstört worden wären, wurden als RNAse-freie Lösungen eingesetzt.

\section{2. 4. 2. Reverse Transkription}

Die reverse Transkription bedeutet ein Umschreiben der RNA in die DNA. Nur die DNA kann im Rahmen der PCR sequenzspezifisch amplifiziert werden. Durch das Enzym reverse Transkriptase, eine RNA-abhängige DNA-Polymerase, wird mRNA in cDNA überschrieben. 
Um einen kurzen doppelsträngigen Startbereich für die reverse Transkriptase herzustellen, können sequenzspezifische Primer, "random"-Hexamere oder OligoPrimer eingesetzt werden.

Die reverse Transkription wurde mit dem SUPERSCRIPT TMPräamplifikationssystem der Firma GIBCO BRL durchgeführt. Das in diesem System verwendete Enzym besaß keine RNAse-Aktivität, so daß ein vorzeitiger Abbau der RNA während der Transkriptionsreaktion vermieden wurde. Diese Eigenschaft ist vor allem beim Arbeiten mit sehr geringen RNA-Mengen von Vorteil (Tse und Forget, 1990).

Folgende Reagenzien mit einem Reaktionsvolumen von $40 \mu$ fanden Anwendung:

$8 \mu \mathrm{l}$ Gesamt-RNA

$2 \mu l$ random-Hexamere

$14 \mu \mathrm{l}$ RNAse freies Wasser.

Dieser Ansatz wurde bei $22^{\circ} \mathrm{C}$ für 10 min inkubiert. Dann wurden weitere Komponenten zugefügt:

$8 \mu \mathrm{l} 5 \mathrm{x}$ Transkriptionspuffer

$4 \mu \mathrm{l} 0.1 \mathrm{M}$ DTT

$2 \mu \mathrm{l}$ Desoxyribonukleosid-Triphosphate (dNTP)-Mix (10mM)

$2 \mathrm{ml}$ der enzymhaltigen Lösung aus SUPERSCRIPT TM-Reverse Transkription

$1 \mu \mathrm{l}$ RNasin (40 IU/ml) (Firma PROMEGA, Madison, USA).

Im Thermocycler (Firma Biometra, Göttingen) erfolgten nun folgende Reaktionsschritte:

10 min Primer-Annealing bei $22^{\circ} \mathrm{C}$

50 min DNA-Strangsynthese bei $42^{\circ} \mathrm{C}$

10 min Denaturierung u.a. der reversen Transkriptase bei $95^{\circ} \mathrm{C}$.

Die Proben wurden auf Eis abgekühlt und nach kurzem Zentrifugieren sofort in die PCR eingesetzt oder bei $-70^{\circ} \mathrm{C}$ eingefroren.

\section{2. 4. 3. Polymerase-Kettenreaktion (PCR)}

Die PCR ermöglicht eine zügige und effektive Vervielfältigung (Amplifikation) selbst von kleinsten Mengen an DNA (Mullis et al., 1986). Hierbei werden DNAPolymerasen verwendet, die einen DNA-Einzelstrang in einen Doppelstrang 
verwandeln können, sofern ihnen ein kurzer, doppelsträngiger DNA-Bereich bereit gestellt wird. Im Vorfeld werden zwei Oligonukleotide (Primer) hergestellt, die komplementär zu den Randbereichen der zu amplifizierenden DNA-Region (Template) sind. Diese Primer hybridisieren an die komplementären Sequenzen der Template, und der entstehende doppelsträngige Bereich mit einem endständigen freien $3^{\prime}-\mathrm{OH}$ dient als Startpunkt für die DNA-Polymerase. Die entstandenen Doppelstränge werden durch Hitze in Einzelstränge getrennt, die erneut als Matrize für die Polymerase verfügbar sind. Durch die Wiederholung der Abfolge: DNADenaturierung, Hybridisierung der Primer und Polymerasereaktion kommt es bei jedem Schritt zu einer Verdopplung der Template-DNA. Dabei wird die thermostabile Taq-DNA-Polymerase (isoliert aus Thermus aquaticus) eingesetzt. Das Temperaturoptimum von diesem Enzym liegt bei $70^{\circ} \mathrm{C}$. Es ist kurzzeitig bis $95^{\circ} \mathrm{C}$ stabil und wird während der Hitzedenaturierung der Doppelstrang-DNA selbst nicht zerstört. Ferner zeichnet sich diese Polymerase durch eine hohe Leistungsstärke aus, so daß DNA-Fragmente von mehreren Kilobasen Länge vervielfältigt werden können.

Aufgrund der hohen Empfindsamkeit dieser Amplifikationsreaktion war darauf zu achten, daß die Arbeit mit PCR-Produkten streng räumlich getrennt vom sogenannten Prä-PCR-Bereich durchgeführt wurde, um Kontaminationen in den folgenden Reaktionen vorzubeugen. Deswegen war die Durchführung einer KontrollPCR ohne Template in jeder Versuchsreihe notwendig.

\section{2. 4. 3. 1. PCR-Primer}

Die Länge der Primer betrug ca. 20 bis 30 Basen. Der Guanin- und Cytosin (GC) -Gehalt für beide Primer war möglichst gleich und betrug nicht mehr als $60 \%$. Adenin- und Thymin- (AT) sowie GC-reiche Regionen und Strecken mit Polypurinen und Polypyrimidinen wurden vermieden. Die Primerpaare hatten keine komplementären Strukturen. Diese Maßgaben wurden mittels des Computerprogramms DNAsis (Pharmacia, Freiburg) für jedes Primerpaar überprüft. An die 5'-Enden der Primer wurden Schnittstellen für geeignete Endonukleasen angefügt, um ein direktes Klonieren der PCR-Produkte zu ermöglichen.

Die Synthese der Primer wurde von der Firma Biometra (Göttingen) durchgeführt. 
Die Aufreinigung der Primer erfolgte in mehreren Arbeitsschritten über NAP-5-Säulen (Qiagen). Die Konzentration der Primer wurde photometrisch bestimmt. Die Lagerung dieser erfolgte bei $-20^{\circ} \mathrm{C}$.

Folgende Primer wurden in dieser Arbeit eingesetzt:

sense-Primer: 5'-TGT CGT CTT CAC ATC TCT TCT ACC TG-3'

antisense-Primer: 5'-CCA CAC ACG AAC TGA AGA GCG T-3'.

\section{2. 4. 4. TaqMan-PCR}

Der TaqMan-PCR-Assay (Firma Applied Biosystems $\mathrm{GmbH}$, Weiterstadt) ist ein homogener Assay, der die sequenzspezifische Ampflikation der DNA und den simultanen Nachweis des PCR-Produkts in einem Reaktionsgefäß ermöglicht. Diese Methode beruht auf den Einsatz einer flurogenen Sonde sowie auf die 5'-3Exonuklease-Aktivität der AmpliTaq DNA-Polymerase.

Die Sonde ist ein Oligonukleotid (ca. 20-30 Basen), das am 5'-Ende mit einem fluoreszenten Reporterfarbstoff und am 3‘-Ende mit dem Quencherfarbstoff TAMRA (6-Carboxy-tetramethyl-rhodamin) verknüpft ist. Standardmäßig wird FAM (6Carboxy-Fluorescein) als Reporter eingesetzt. Allerdings können Derivate von 6Carboxy-Fluorescein auch verwendet werden. Das 3'-Ende der Sonde wird chemisch phophoryliert, um eine Extension der Sonde während der PCR zu vermeiden. Die Fluoreszenz des Reporterfarbstoffs wird wegen der räumlichen Nähe zum Quencher durch einen Fluoreszenz-Energietransfer (FET) unterdrückt, wenn die intakte Sonde bei einer Wellenlänge von $488 \mathrm{~nm}$ zur Fluoreszenz angeregt wird. Während der PCR bindet sich die Sonde sequenzspezifisch an den DNA-Matrizenstrang in unmittelbarer Nähe des Primers. In der Extensionsphase trifft die AmpliTaq DNAPolymerase auf die Sonde und beginnt diese zu verdrängen. Dabei entsteht eine $Y$ förmige Struktur des Enzyms, wodurch die 5‘-3‘-Exonuklease-Aktivität der DNAPolymerase aktiviert wird und die Sonde geschnitten wird. Kommt es zur Sondenhydrolyse, so wird die räumliche Nähe zwischen Reporter und Quencher unterbrochen und damit auch der FET aufgehoben. Nur sequenzspezifisch und damit stabil bindende Sondenmoleküle werden von der AmpliTaq DNA-Polymerase geschnitten. Nicht 100-prozentig bindende Sondenmoleküle werden verdrängt, noch bevor die Exonukleaseaktivität einsetzt. Somit steigt die Fluoreszenz des Reporterfarbstoffs proportional zur Akkumulation des PCR-Produkts an. 
Die Veränderung der Fluoreszenzen wird mit Hilfe des ABI PRISM 7700 Sequence Detectors (Firma PE Applied Biosystems $\mathrm{GmbH}$, Weiterstadt) im geschlossenen Reaktionsgefäß Zyklus für Zyklus erfaßt.

Die Berechnung einer Standardkurve ermöglicht die Quantifizierung der Fluoreszenzänderung. Die Produktmenge wächst in der PCR exponentiell, erreicht jedoch irgendwann ein Plateau. Die PCR läßt sich durch die folgende Gleichung mathematisch beschreiben:

$\mathrm{N}=$ No $x(1+E)^{\mathrm{n}}$

In dieser Gleichung sind: $\mathrm{N}=$ Menge des hergestellten Amplifikats No $=$ Startkopienzahl zu Beginn der PCR $E=$ Effizienz der PCR, z.B., falls $E=1$, dann wird pro Zyklus das PCR-Produkt verdoppelt. $\mathrm{n}=$ Zahl der Amplifikationszyklen

Zur Erstellung der Standardkurve wird diese Gleichung in ihre logarithmierte Form umgeschrieben: $\log N=\log N o+n \cdot \log (1+E)$.

Eine Standardkurve muß über mindestens 5 Standardstufen verfügen. In dieser Studie werden Standardkurven mit den Intervallen einer 1:10 Verdünnung verwendet.

\section{2. 4. 4. 1. Auswahl der Sonden für die TaqMan-PCR}

Einige Punkte wurden bei der Wahl der Sonde berücksichtigt:

1. Das 5'-Ende der Sonde befand sich in relativer Nähe des 3'-Endes des PCR-Primers.

2. Die Sondenlänge betrug 20-30 Basen.

3. Der GC-Gehalt war $40-60 \%$.

4. Am 5'-Ende der Sonde lag kein $G$.

5. Es lagen nie mehr als dreimal dieselbe Base hintereinander.

6. Sonde und PCR-Primer waren nicht komplementär zueinander.

7. Auffällige Sekundärstrukturen (z.B. hairpin-loops) wurden vermieden.

Die eingesetzten Sonden waren an ihrem $5^{\prime}$-Ende mit dem Farbstoff FAM (6Carboxy-Fluorescein) und an ihrem 3'-Ende mit dem Farbstoff TAMRA (6-Carboxytetramethyl-rhodamin) versehen. 
Folgende Sonde wurde in dieser Arbeit verwendet:

Sonde: 5'-FAM-TTA CCA GCT CGG CCA CAG CCG GAC-TAMRA3'.

\section{2. 4. 4. 2. Durchführung des TaqMan-PCR-Assays}

Für die TaqMan-PCR wurden bei einem Reaktionsvolumen von $25 \mu$ folgende Reagenzien benötigt:

$12,5 \mu \mathrm{l} 2 \mathrm{x}$ Puffer

2,5 $\mu$ l sense-Primer (300nM)

2,5 $\mu$ l antisense-Primer (300nM)

2,5 $\mu$ l Sonde $(225 \mathrm{nM})$

$3 \mu \mathrm{l}$ Ampuwa

$2 \mu l$ cDNA.

Diese Reagenzien wurden in eine 96-well Mikrotiterplatte (MicroAmp Optical 96well reaction plate, Firma PE Applied Biosystems, Weiterstadt) pipettiert, und die Platte mit optischen Deckeln (MicroAmp Optical caps, Firma PE Applied Biosystems, Weiterstadt) verschlossen.

Zur Analyse wurde die Microtiterplatte in das ABI PRISM 7700 Detection System überführt.

\section{2. 4. 4. 3. $A B I P R I S M 7700$ Sequence Detection System}

Das ABI PRISM 7700 Sequence Detection System (7700 SDS, Firma PE Applied Biosystems, Weiterstadt) besaß einen eingebauten Thermocycler, in welchem die Proben 40mal den folgenden Zyklus durchliefen.

Start:

2 Minuten $50^{\circ} \mathrm{C}$

10 Minuten $95^{\circ} \mathrm{C}$

Zyklus:

15 Sekunden $95^{\circ} \mathrm{C}$

1 Minute $60^{\circ} \mathrm{C}$.

Über den Reaktionsgefäßen der Microtiterplatte befand sich eine Linse, die den Strahl eines Argon-Lasers (488 nm) in die Gefäße weiterleitete, wodurch eine Fluoreszenzanregung erfolgen konnte. Die Fluoreszenzemission wurde über denselben optischen Leiter gemessen.

Die Steuerung des gesamten Systems leistete ein Power Macintosh 4400. 


\section{3. Statistische Auswertung}

Die Ergebnisse der RIA- und TaqMan-Analysen wurden mit GraphPad Prism (GraphPad Software), Version 3.0 für Windows (Microsoft) statistisch ausgewertet. Dabei wurde der Dunnett's Multiple Comparison Test mit einem Signifikanzniveau von $p \leq 0,05$ angewandt.

Die in Taqman-PCR für die Genexpression des IGF-1 gemessenen Werte, die als Rohdaten bezeichnet werden und die RNA-Menge wiedergeben, wurden prozentual auf die Mittelwerte von jeden der drei Aufarbeitungen der Kontrollguppe bezogen. Dabei wurden die Mittelwerte jeder Aufarbeitung der Kontrollgruppe dem Wert $100 \%$ gleichgesetzt. Ferner wurde für alle Prozentrelativierungen einer jeden Versuchsgruppe eine mittlere Prozentrelativierung mit zugehöriger Standardabweichung (SEM) berechnet. Die mittlere Prozentrelativierung mit der zugehörigen SEM einer jeden Versuchsgruppe wurden graphisch in Form von Säulendiagrammen dargestellt.

Die radioimmunologisch für die Proteinkonzentrationen des IGF-1 gemessenen Werte sind absolute Zahlen. Die in der RIA ermittelte IGF-1-Konzentration von jeder Probe bezieht sich auf das Volumen der pufferhaltigen Probelösung (mit der Einheit $\mathrm{ng} / \mathrm{ml}$ ). Die radioimmunologisch gemessenen IGF-1-Konzentrationen einer jeden Probe wurden aber auch auf die Masse des Gesamtproteins der entsprechenden Probe (mit der Einheit ng/mg) umgerechnet. Die Mittelwerte einer jeden Gruppe mit zugehöriger SEM wurden in der Säulengraphik dargestellt.

Für jeden untersuchten Parameter wurde eine Varianzanalyse mit Dunnett's Multiple Comparison Test durchgeführt. Als Referenzgruppe diente jeweils die Kontrolle (Cremophor-Gruppe). Abweichungen von der Kontrolle mit $p \leq 0,05$ wurden als signifikant gewertet und werden im Ergebnisteil mit dem Symbol " * "über der entsprechenden Säule im Graphen gekennzeichnet.

Ferner wurden für jedes Organ 2 Korrelationsgraphen dargestellt. Dabei ordneten wir die IGF-1-Konzentrationen der einzelnen Versuchstiere sowohl in $\mathrm{ng} / \mathrm{ml}$ als auch in ng/mg ihrer Genexpression, d.h. der Prozentrelativierung der IGF-1-RNA-Menge eines jeden Versuchstieres, zu. Diese Graphik wurde durch Microsoft Office Excel 2007 erstellt. 


\section{Ergebnisse}

\section{1. Knochen (Femur)}

Zunächst sollen die knochenbezogenen Ergebnisse dargestellt werden. Dabei werden die Daten der Genexpression und der Proteinkonzentration von IGF-1 beschrieben. Die IGF-1-Konzentrationen beziehen sich sowohl auf das Volumen der pufferhaltigen Probelösung $(\mathrm{ng} / \mathrm{ml})$ und als auch auf die Masse des Gesamtproteins einer jeden Probe $(\mathrm{ng} / \mathrm{mg})$. Anschließend werden 2 Korrelationsgraphen dargestellt, in denen einzelne Proteinkonzentrationen eines jeden Versuchstieres dessen Genexpression zugeordnet werden. Dabei gehen einer der beiden Korrelationsgraphen aus den Daten der Proteinkonzentration in der Einheit $\mathrm{ng} / \mathrm{ml}$ und der andere aus den Proteinkonzentrationen in der Einheit ng/mg hervor.

Zur Veranschaulichung der Ergebnisse in 4.1.1, 4.1.2., 4.1.3., 4.1.4. und 4.1.5. dienen die Abbildungen 4.1., 4.2. ,4.3., 4.4. und 4.5..

\section{1. 1. Genexpression von IGF-1 im Knochen}

E2 $3.5 \mu \mathrm{g} / \mathrm{ml}$ führte zu einem leichten Anstieg der Genexpression $(110.06 \%$ +/53.15) gegenüber der Kontrollgruppe (Cremophor) (100\% +/- 12.26). Diese Veränderung war nicht signifikant. Die Genexpression (Prozentrelativierung der IGF1-RNA) der mit E2 $0.5 \mu \mathrm{g} / \mathrm{ml}(99.91 \%+/-57.62)$ und T $3.5 \mathrm{mg} / \mathrm{ml}(100.87 \%+/-$ 60.26) behandelten Gruppen veränderte sich kaum gegenüber der Cremophorgruppe.

BC $62.5 \mathrm{mg} / \mathrm{ml}$ bewirkte einen geringfügigen Anstieg der Genexpression (107.56\% $+/$ - 60.06). CR $62.5 \mathrm{mg} / \mathrm{ml}$ dagegen zeigte einen deutlichen jedoch nicht signifikanten $(p>0.05)$ Abfall dieser (54.18\% +/- 17.41) (Abb. 4.1.). 




Abb. 4.1.: Einflüsse von E2 3.5, E2 0.5, T, BC und CR auf die Genexpression von IGF-1 in Femur von orx Ratten

\section{1. 2. IGF-1- Konzentration bezogen auf das Volumen der pufferhaltigen Probelösung im Knochen}

Die pulverisierte Gewebeproben - hier aus dem Femur - aller Versuchsratten wurden im Rahmen der Präparation entsprechend ihrer Masse im gleichen Verhältnis mit der Pufferlösung gemischt (1 mg Gewebe zu $10 \mu \mathrm{l}$ Puffer). Somit stellt die proteinhaltige Pufferlösung der Proben ein einheitliches Medium zur Messung der IGF-1-Konzentration dar.

Die mittlere IGF-1-Konzentration in der mit E2 $3.5 \mu \mathrm{g} / \mathrm{ml}$ behandelten Gruppe (187.05 $\mathrm{ng} / \mathrm{ml}$ ) stieg im Vergleich zur Cremophorgruppe (155.12 ng/ml) an. Der Anstieg war nicht signifikant. E2 0.5 führte zu einer geringeren Zunahme der IGF-1 Konzentration (183.22 $\mathrm{ng} / \mathrm{ml}$ ) als E2 $3.5 \mu \mathrm{g} / \mathrm{ml}$. Die Konzentration der mit T behandelten Gruppe nahm geringfügig ab (142.96 ng/ml).

Der Anstieg der IGF-1 Konzentration unter BC fiel niedriger als in den E2-Gruppen aus (168.91 ng/ml). Am deutlichsten stieg die IGF-1-Konzentration in der mit CR behandelten Gruppe an (200.7 ng/ml). Dieser Anstieg war jedoch wie die restlichen Veränderungen nicht signifikant (Abb. 4.2.). 


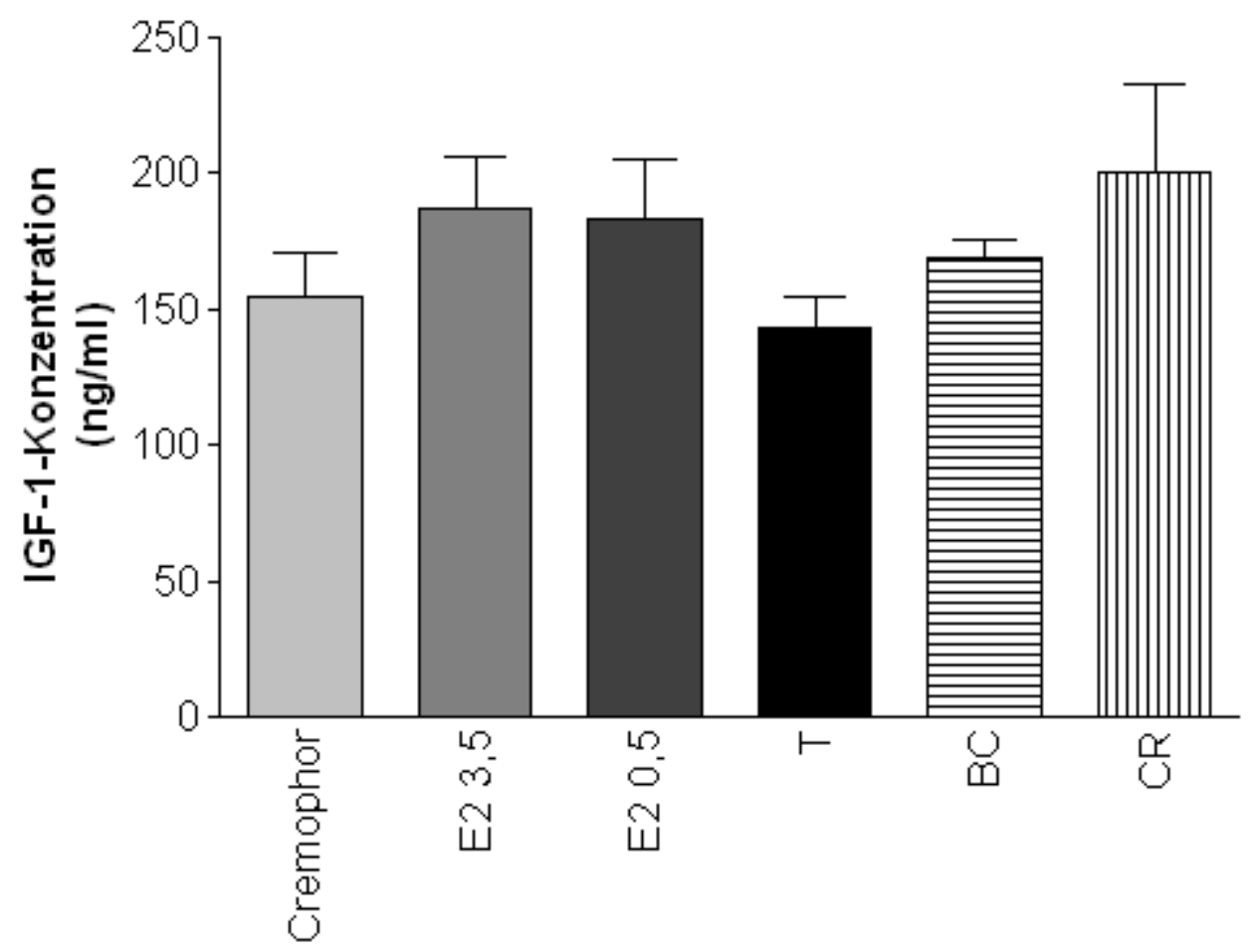

Abb. 4.2. : Einflüsse von E2 3.5, E2 0.5, T, BC und CR auf die Konzentration von IGF-1 (ng/ml) in Femur von orx Ratten

\section{1. 3. IGF-1-Konzentration bezogen auf das Gesamtprotein im Knochen}

In diesem Abschnitt wurden die radioimmunologisch gemessenen IGF-1Konzentrationen (in $\mathrm{ng} / \mathrm{ml}$ Pufferlösung) auf die Gesamtproteinkonzentrationen der jeweiligen Proben bezogen, so daß die Werte in der Einheit ng/mg Protein dargelegt werden.

In der mit E2 3.5 behandelten Gruppe kam es zu einer deutlichen Abnahme der mittleren IGF-1-Konzentration (399.44 ng/mg) gegenüber der Kontrollgruppe (528.95 $\mathrm{ng} / \mathrm{mg})$. Unter E2 0.5 fiel die Konzentration weiter ab $(297.52 \mathrm{ng} / \mathrm{mg})$, auch wenn die Veränderungen in beiden Gruppen noch nicht signifikant waren. In der T-Gruppe war die Abnahme der IGF-1-Konzentration ausgeprägter $(221.51 \mathrm{ng} / \mathrm{mg})$ und signifikant $(p<0.01)$. Unter BC fiel die Konzentration von IGF-1 $(174.57 \mathrm{ng} / \mathrm{mg})$ noch weiter signifikant $(p<0.01) a b$. In der CR-Gruppe war die IGF-1-Konzentration ( 217.31 $\mathrm{ng} / \mathrm{mg}$ ) weiterhin signifikant niedriger $(\mathrm{p}<0.05)$ als in der Cremophor-Gruppe, fiel jedoch höher als unter BC aus (Abb. 4.3.). 




Abb. 4.3. : Einflüsse von E2 3.5, E2 0.5, T, BC und CR auf die IGF-1-Konzentration (ng/mg) bezogen auf das Gesamtprotein, in Femur von orx Ratten ( * $: p<0.05$ )

\section{1. 4. Einschätzung der Korrelation zwischen der Genexpression und der} Proteinkonzentration (ng/ml) im Knochen

Die Proteinkonzentrationen der einzelnen Versuchstiere in $\mathrm{ng} / \mathrm{ml}$ wurden ihren zugehörigen prozentualen Genexpressionen (des gleichen Versuchstiers) zugeordnet und graphisch dargestellt. Die Gerade im Diagramm war annährend horizontal. Im so erstellten Korrelationsgraphen ließ sich keine Korrelation zwischen den Proteinkonzentrationen $(\mathrm{ng} / \mathrm{ml})$ der einzelnen Versuchstiere und den prozentualen Daten ihrer Genexpression im Knochen erkennen. 


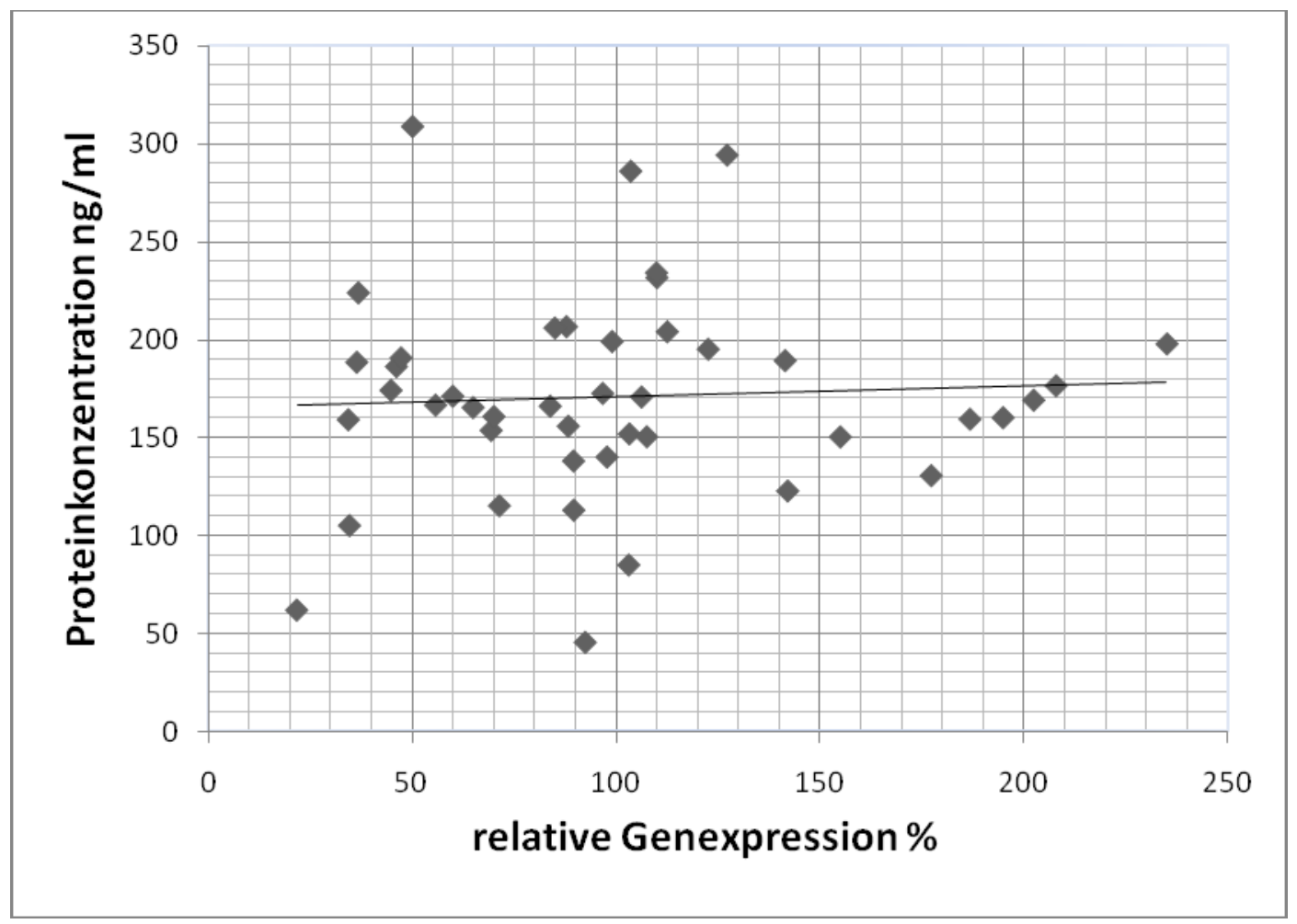

Abb. 4.4: Korrelationsgraph: Darstellung der Zusammenhänge zwischen den einzelnen Proteinkonzentrationen $(\mathrm{ng} / \mathrm{ml})$ und den zugehörigen Daten der Genexpression (\%) im Knochen

\section{1. 5. Einschätzung der Korrelation zwischen der Genexpression und der Proteinkonzentration (ng/mg) im Knochen}

Es wurden die auf das Gesamtprotein bezogenen Proteinkonzentrationen der einzelnen Versuchstiere in ng/mg ihren zugehörigen prozentualen Genexpressionen (des gleichen Versuchstiers) zugeordnet und graphisch dargestellt. Auch hier zeigte sich die Gerade annährend waagerecht. Eine Korrelation zwischen den Proteinkonzentrationen (ng/mg) der einzelnen Versuchstiere und den prozentualen Daten ihrer Genexpression ließ sich ebenfalls nicht erkennen. 


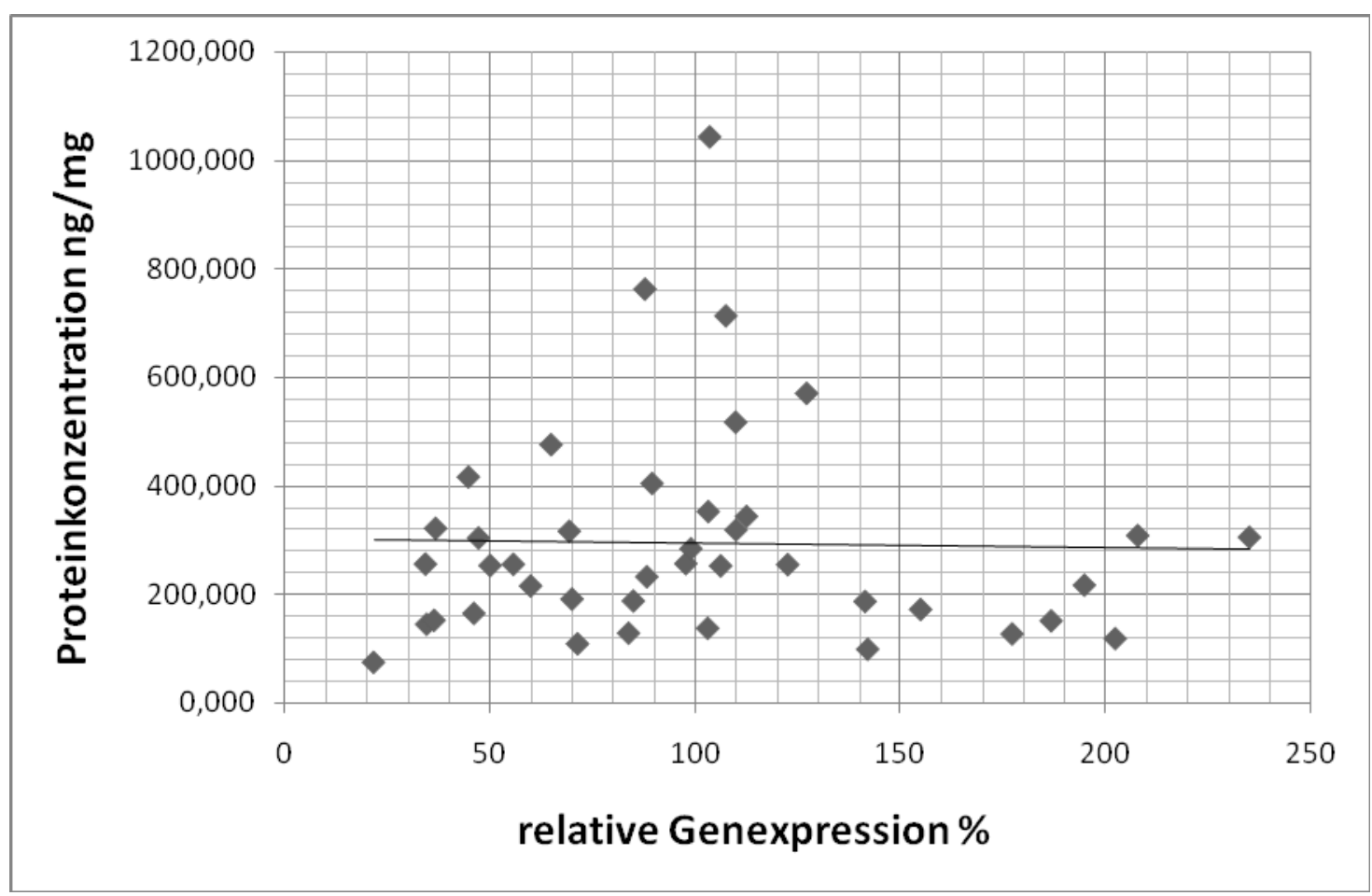

Abb. 4.5.: Korrelationsgraph: Darstellung der Zusammenhänge zwischen den einzelnen Proteinkonzentrationen ( $\mathrm{ng} / \mathrm{mg}$ ) und den zugehörigen Daten der Genexpression (\%) im Knochen

\section{2. Leber}

In diesem Abschnitt werden die leberbezogenen Ergebnisse dargestellt. Dabei werden die Daten der Genexpression und der Proteinkonzentration von IGF-1 beschrieben. Die IGF-1-Konzentrationen beziehen sich einmal auf das Volumen der pufferhaltigen Probelösung $(\mathrm{ng} / \mathrm{ml})$ der jeweiligen Probe und einmal auf die Masse des Gesamtproteins einer jeden Probe (ng/mg). Anschließend werden 2 Korrelationsgraphen dargestellt, in denen einzelne Proteinkonzentrationen eines jeden Versuchstiers dessen Genexpression zugeordnet werden. Dabei gehen einer der beiden Korrelationsgraphen aus den Daten der Proteinkonzentration in $\mathrm{ng} / \mathrm{ml}$ und der andere aus den Proteinkonzentrationen in ng/mg hervor.

Zur Illustration der Ergebnisse in 4.2.1, 4.2.2., 4.2.3., 4.2.4. und 4.2.5. dienen die Abbildungen 4.6., 4.7., 4.8., 4.9. und 4.10.. 


\section{2. 1. Genexpression von IGF-1 in der Leber}

Die Genexpression (Prozentrelativierung der RNA) von IGF-1 in der mit E2 $3.5 \mu \mathrm{g} / \mathrm{ml}$ behandelten Gruppe (143.83\% +/- 95.37) stieg gegenüber Cremophor $(100 \%+/-$ 39.37) am deutlichten an gefolgt von der mit E2 $0.5 \mu \mathrm{g} / \mathrm{ml}$ behandelten Gruppe (141.3\% +/- 112.35). Beide Veränderungen zeigten jedoch keine Signifikanz. T führte ebenfalls zu einem Anstieg der Genexpression von IGF-1 (128.18\%+/- 46.11), der aber niedriger als in den E2-Gruppen ausfiel. Unter BC nahm die Genexpression (126.46\% +/- 42.06 ) zu und war mit dem Anstieg in der T-Gruppe vergleichbar. In der mit CR behandelten Gruppe nahm die Genexpression ab (82.58\% +/- 47.31). Diese Abnahme war jedoch nicht signifikant (Abb. 4.4.).

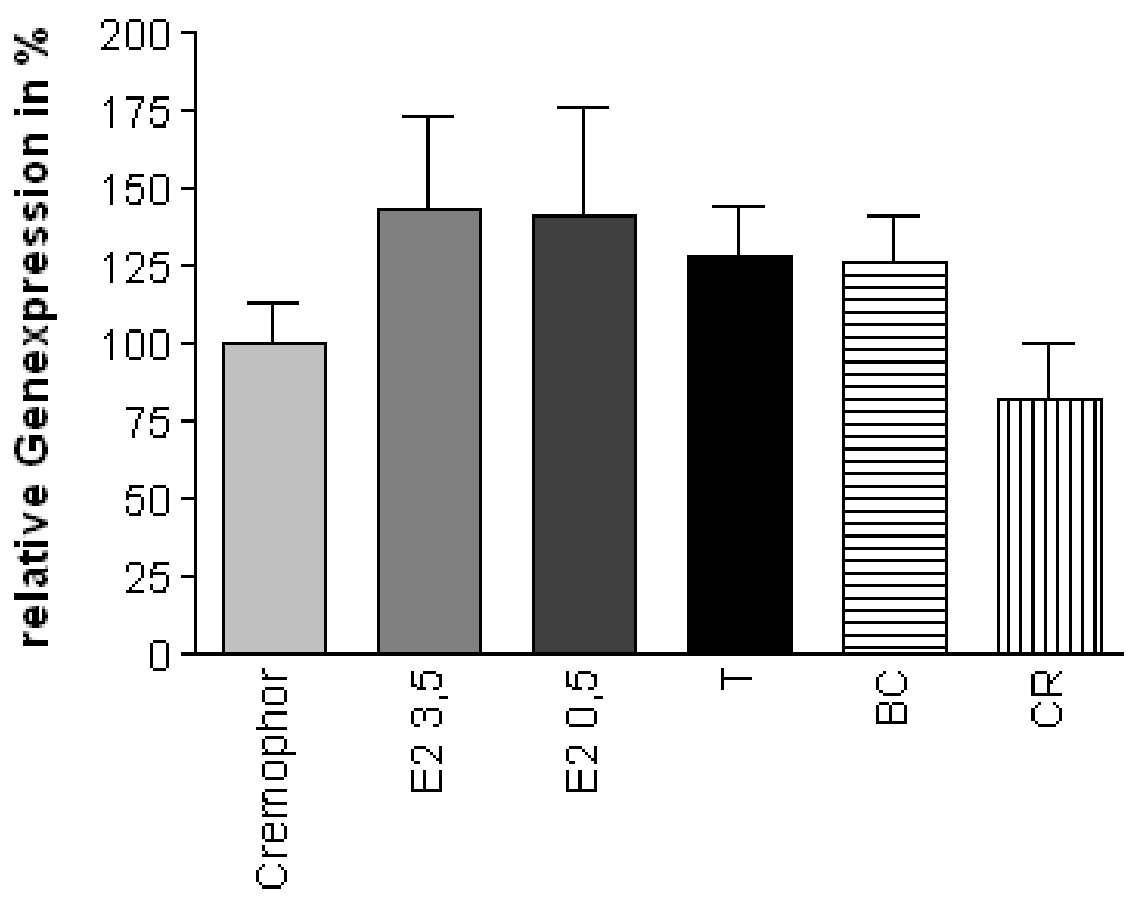

Abb. 4.6. : Einflüsse von E2 3.5, E2 0.5, T, BC und CR auf die Genexpression von IGF-1 in der Leber von orx Ratten 


\section{2. 2. IGF-1- Konzentration bezogen auf das Volumen der}

\section{pufferhaltigen Probelösung in der Leber}

Die pulverisierte Gewebeproben - hier aus der Leber - aller Versuchsratten wurden im Rahmen der Präparation entsprechend ihrer Masse im gleichen Verhältnis mit der Pufferlösung gemischt (1 mg Gewebe zu $10 \mu$ l Puffer). Somit stellt die proteinhaltige Pufferlösung der Proben ein einheitliches Medium zur Messung der IGF-1Konzentration dar.

E2 $3.5 \mu \mathrm{g} / \mathrm{ml}$ führte zum Anstieg der mittleren IGF-1 Konzentration (1125.83 ng/ml) gegenüber der Kontrolle (1015.99 ng/ml). Dieser Anstieg war nicht signifikant.

Eine Signifikanz $(p<0.01)$ zeigte jedoch die Zunahme der IGF-1-Konzentration unter E2 $0.5 \mu \mathrm{g} / \mathrm{ml}(1328.58 \mathrm{ng} / \mathrm{ml})$.

In der mit T behandelten Gruppe nahm die IGF-1-Konzentration im Vergleich zur Cremophorgruppe geringfügig und nicht signifikant ab $(983.10 \mathrm{ng} / \mathrm{ml})$.

BC bewirkte den zweithöchsten Anstieg der IGF-1 Konzentration (1165.38 ng/ml), der jedoch nicht signifikant war.

In der mit CR behandelten Gruppe kam es zu einem geringen Anstieg der IGF-1Konzentration (1096.67 ng /ml) (Abb. 4.5.).

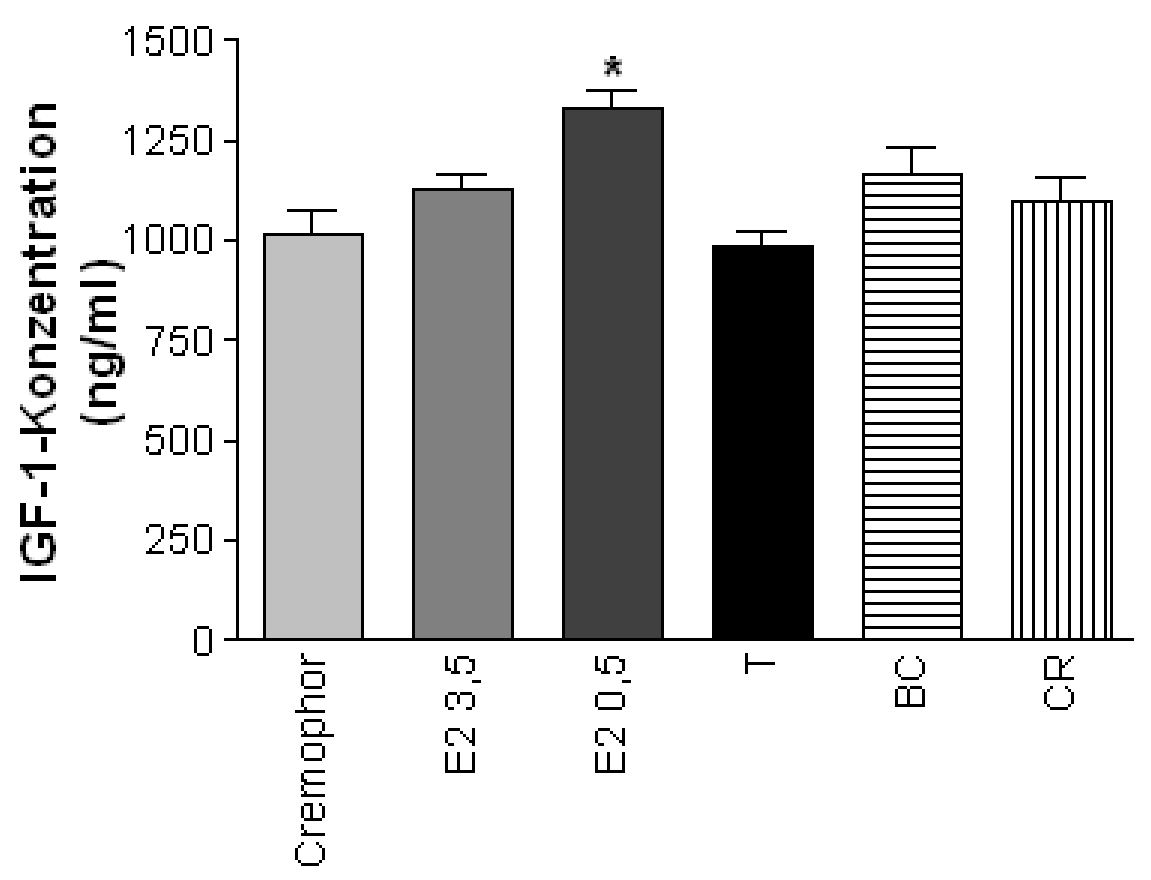

Abb. 4.7. : Einflüsse von E2 3.5, E2 0.5, T, BC und CR auf die IGF-1-Konzentration (ng/ml) in der Leber von orx Ratten ( ${ }^{*}: p<0.01$ ) 


\section{2. 3. IGF-1-Konzentration bezogen auf das Gesamtprotein in der Leber}

In diesem Abschnitt wurden die radioimmunologisch gemessenen IGF-1Konzentrationen (in ng/ml Pufferlösung) auf die Gesamtproteinkonzentrationen der jeweiligen Proben bezogen, so daß die Werte in der Einheit ng/mg Protein dargelegt werden.

In der mit E2 3.5 behandelten Gruppe kam es zu einem geringfügigen Anstieg der mittleren IGF-1-Konzentration (745.24 ng/mg) im Vergleich zur Cremophor-Gruppe (706.51 ng/mg). Unter E2 0.5 stieg die IGF-1-Konzentration mehr an (789.45 ng/mg). In der T-Gruppe fiel die IGF-1-Konzentration (564.39 ng/mg) gegenüber der Cremophorgruppe ab. Unter BC erfuhr die IGF-1-Konzentration den stärksten Anstieg (938.17 ng/mg). In der CR-Gruppe nahm die IGF-1-Konzentration (767.24 $\mathrm{ng} / \mathrm{mg}$ ) stärker als in der E2 3.5-Gruppe zu. Keine der o.g. Veränderungen waren signifikant $(p>0.05)$ (Abb. 4.6.).

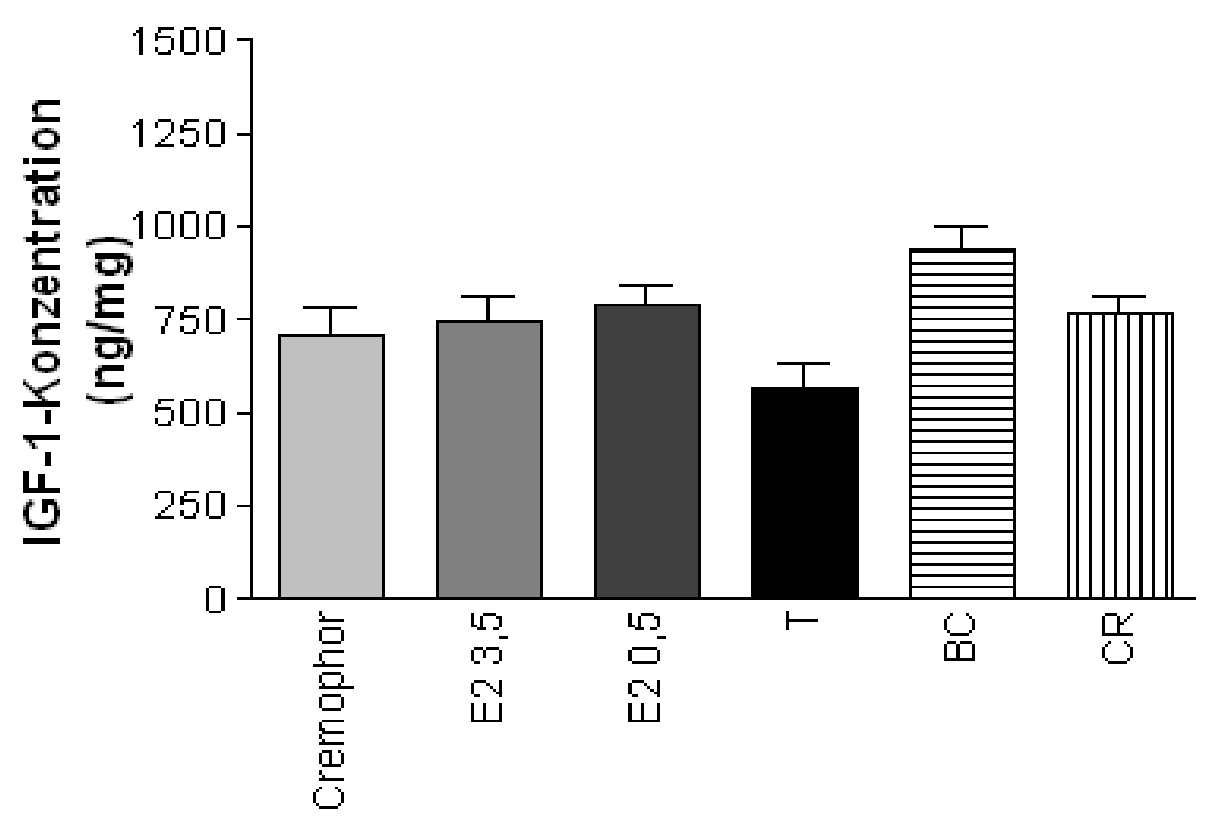

Abb. 4.8. : Einflüsse von E2 3.5, E2 0.5, T, BC und CR auf die IGF-1-Konzentration (ng/mg) bezogen auf das Gesamtprotein, in der Leber von orx Ratten 


\section{2. 4. Einschätzung der Korrelation zwischen der Genexpression und der}

Proteinkonzentration (ng/ml) in der Leber

Die Proteinkonzentrationen der einzelnen Versuchstiere in $\mathrm{ng} / \mathrm{ml}$ wurden ihren zugehörigen prozentualen Genexpressionen (des gleichen Versuchstiers) zugeordnet und graphisch dargestellt. Die Gerade im Diagramm war annährend horizontal. Im so erstellten Korrelationsgraphen ließ sich keine Korrelation zwischen der Proteinkonzentration $(\mathrm{ng} / \mathrm{ml})$ der einzelnen Versuchstiere und den prozentualen Daten ihrer Genexpression in der Leber erkennen.

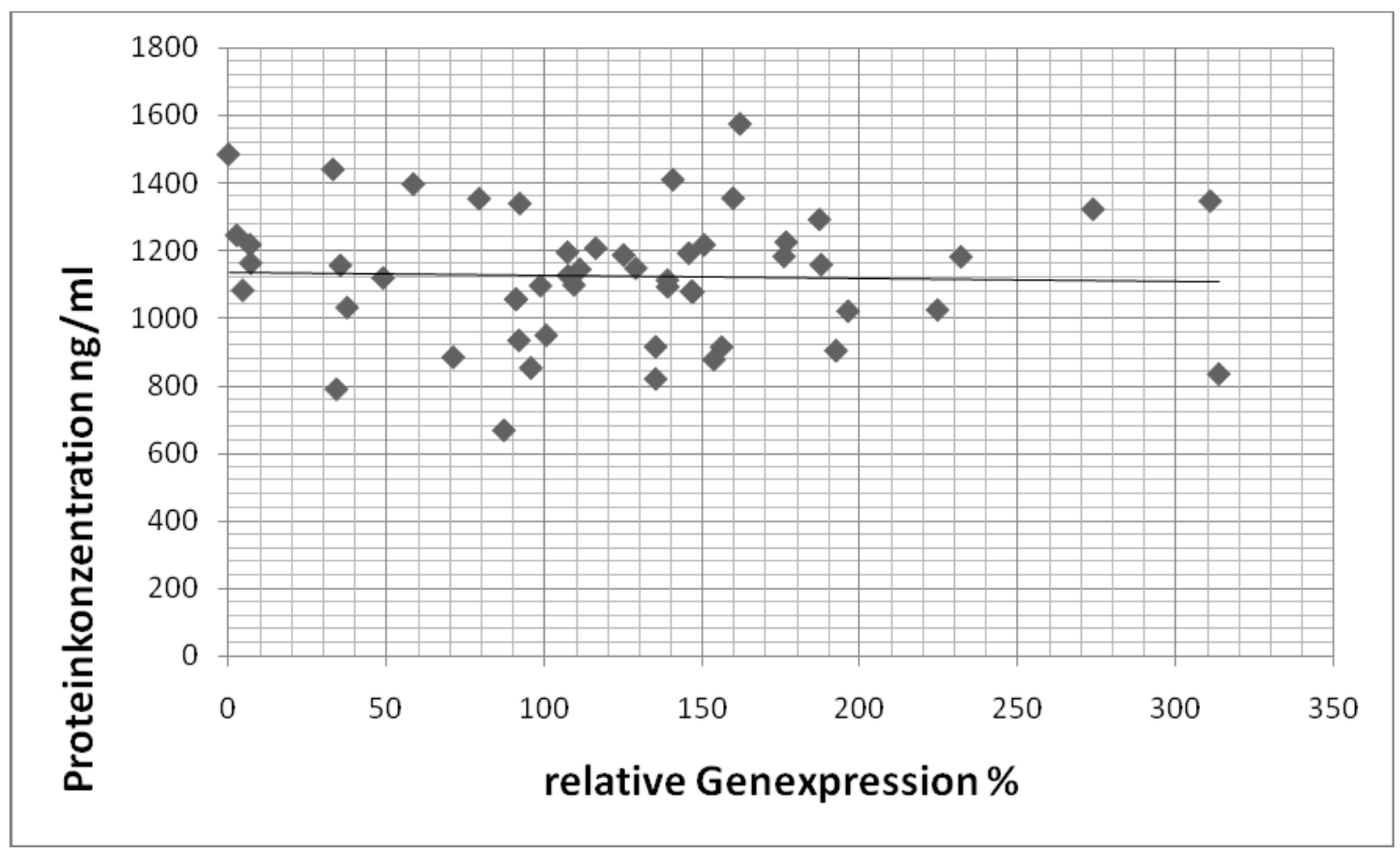

Abb. 4.9.: Korrelationsgraph: Darstellung der Zusammenhänge zwischen den einzelnen Proteinkonzentrationen $(\mathrm{ng} / \mathrm{ml})$ und den zugehörigen Daten der Genexpression (\%) in der Leber 


\section{2. 5. Einschätzung der Korrelation zwischen der Genexpression und der}

\section{Proteinkonzentration $(\mathrm{ng} / \mathrm{mg})$ in der Leber}

Hier wurden die auf das Gesamtprotein bezogenen Proteinkonzentrationen der einzelnen Versuchstiere in $\mathrm{ng} / \mathrm{mg}$ ihren zugehörigen prozentualen Genexpressionen (des gleichen Versuchstiers) zugeordnet und graphisch dargestellt. Die Gerade zeigte sich annährend waagerecht. Eine Korrelation zwischen der Proteinkonzentration $(\mathrm{ng} / \mathrm{mg})$ der einzelnen Versuchstiere und den prozentualen Daten ihrer Genexpression ließ sich nicht erkennen.

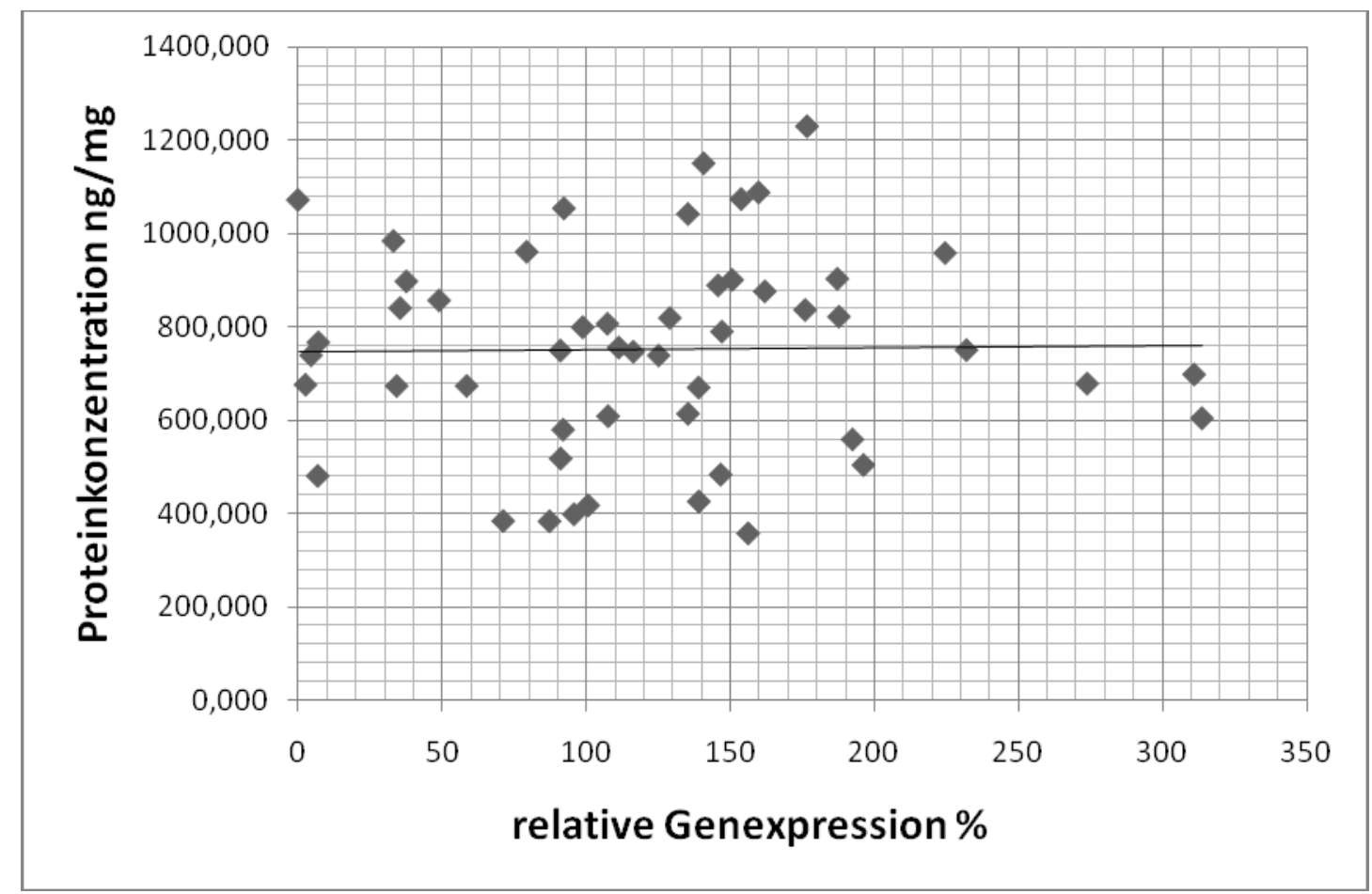

Abb. 4.10.: Korrelationsgraph: Darstellung der Zusammenhänge zwischen den einzelnen Proteinkonzentrationen (ng/mg) und den zugehörigen Daten der Genexpression (\%) in der Leber 


\section{Diskussion}

In dieser experimentellen Arbeit wurden die Einflüsse von E2 in zwei unterschiedlichen Konzentrationen, von $\mathrm{T}$ und den Extrakten der beiden Arzneipflanzen BC und CR auf die mRNA- und Proteinkonzentration von IGF-1 untersucht. Dabei wurde IGF-1 in Knochen (Femur) und Leber von männlichen orchiektomierten (orx) Ratten gemessen.

Die männliche orx Ratte stellt ein Modell für die endokrinologischen Verhältnisse im hypogonadalen Mann dar. Ein bereits anerkanntes Modell für die Forschung der Osteoporose im weiblichen Geschlecht ist die ovarektomierte (ovx) Ratte. Wegen der aktuellen sozioökonomischen Entwicklungen nimmt die Lebenserwartung der Menschen und damit der Anteil älterer Männer an der Bevölkerung zu. Der männliche Hypogonadismus im Alter, der zutreffender als Partielles Androgendefizit des alternden Mannes (PADAM) bezeichnet wird, bringt hormonelle Veränderungen mit sich, die sich klinisch manifestieren und Beschwerden sowie Krankheiten verursachen können. Somit nimmt das Modell der orx Ratte zusehends an Bedeutung zu.

In Männern wird nach Beginn der siebten Lebensdekade eine alters-assoziierte Abnahme von T statistisch relevant (Vermeulen, 1988).

Ein Androgenmangel im Mann kann neben sexuellen Dysfunktionen und psychovegetativen Beschwerden, Abnahme der Muskelmasse sowie Anämie insbesondere zur Osteoporose führen. Es wurde früh über die Entwicklung der Osteoporose in Eunuchen berichtet (Albright und Reifenstein, 1948). Niedrige Serumkonzentrationen von Gesamttestosteron in über 60-jährigen Männern können von klinischen Symptomen einer Osteoporose, die mit diffusen Knochenschmerzen und erhöhter Frakturgefährdung einhergehen können, begleitet werden (Schill, 2001). Typische osteoporotische Brüche betreffen den Unterarm, die Wirbelsäule und die Hüfte. Wirbelbrüche verursachen häufig chronische Schmerzzustände, eine Destabilisierung des Systems Wirbelsäule und damit einhergehend eine massive Verschlechterung der Lebensqualität. Statistisch tritt jede dritte Hüftfraktur bei Männern auf, und mehr als $11 \%$ der männlichen Bevölkerung im Alter von über 50 Jahren erleiden diese Fraktur (Kastelan, 2007).

Es sollte jedoch erwähnt werden, daß eine Metabolisierung von T zu E2 für die Androgenwirkung im Knochen unerläßlich ist. Smith et al. berichteten über einen Mann mit homozygoter Mutation im Östrogenrezeptor (ER)-Gen, der trotz normaler 
T-Spiegel eine Osteopenie, nicht geschlossene Epiphysenfugen und einen stark erhöhten Knochenumbau aufwies (Smith et al., 1994). Ähnliche Fälle wurden über Männer mit homozygoter Mutation im Aromatase-Gen berichtet (Morishima et al., 1995; Carani et al., 1997).

Parallel zum Menschen führt der Orchiektomie-induzierte Hypogonadismus in männlichen Säugetieren wie Ratten ebenfalls zur Entwicklung einer Osteoporose, die im Rahmen der Messung der BMD in einigen experimentellen Studien nachweisbar gewesen ist (Stürmer et al., 2006; Seidlova-Wuttke et al., 2005; Franklin M et al., 2006).

Im Femurknochen der in dieser Studie untersuchten männlichen und orx Ratten wurde der Wachstumsfaktor IGF-1 bestimmt.

IGF-1 vermittelt als Somatomedin (Salmon und Daughaday, 1957) die wachstumsstimulierende Wirkung des $\mathrm{GH}$, besonders auf das Skelett von Säugetieren. Dieser Wachstumsfaktor wirkt - von Typ-1-IGF-Rezeptor ausgehend hauptsächlich mitogen und ist für das proliferative Zellwachstum sehr wichtig (Baserga et al. 1997). Bei hypophysektomierten Versuchstieren führte die Gabe von IGF-1 ohne die Anwesenheit von GH zu einer Zunahme der Muskelmasse und einem deutlichen Längenwachstum (Kiess und Höflich, 1995). Im Knochengewebe wird IGF-1 von Osteoblasten gebildet. Es stimuliert die Proliferation und Differenzierung von Osteoblasten.

In zahlreichen klinischen und tierexperimentellen Studien wurde die Rolle von IGF-1 im Knochenmetabolismus und im Pathomechanismus von Osteoporose bereits untersucht.

In einer klinischen Studie an postmenopausalen Frauen mit Osteoporose fielen die Serumwerte von IGF-1 und IGFBP- 3 im Vergleich zu prämenopausalen Frauen oder postmenopausalen Frauen ohne Osteoporose signifikant niedriger aus. Im Gegensatz zu den Markern des Knochenumsatz wie Osteocalcin, knochenspezifische AP oder N-Telopeptid Kollagen Typ 1 im Urin, korrelierten IGF-1 und IGFBP-3 im Serum positiv mit der BMD der Lendenwirbelsäule. Somit weisen erniedrigte zirkulierende IGF-1 und IGFBP-3 einen möglichen Pathomechanismus der postmenopausalen Osteoporose auf und stellen sich als relativ zuverlässige Marker des Knochenumsatzes dar (Kim et al., 1999). 
Eine Langzeittherapie mit $\mathrm{GH}$ führte bei postmenopausalen Frauen mit manifester Osteoporose $\mathrm{zu}$ einem Anstieg der BMD und zu einer Verbesserung der Zielorganansprechbarkeit des Parathormons und $z u$ dessen verändertem Sekretionsmuster, das sich positiv auf den Knochenaufbau auswirkte (Franklin $\mathrm{J}$ et al., 2008). So wird sichtbar, daß Veränderungen in der Wachstumshormon/IGF-1Achse mit der postmenopausalen Entwicklung der Osteoporose im Alter verknüpft sind.

Weiterhin zeigten Fowlkes et al., daß in älteren männlichen Mäusen, in denen die Bildung neuen Knochens in der Regel deutlich beeinträchtigt ist, das sowohl lokal als auch systemisch verabreichte rekombinante humane IGF-1 zu einem signifikanten Anstieg der Synthese neuen Knochens an der Osteotomiestelle führte (Fowlkes et al., 2006).

Mit zunehmendem Alter nehmen die IGF-1-Konzentrationen sowohl im Serum als auch im Knochen ab, was teilweise von einer verminderten $\mathrm{GH}$-Sekretion abhängt. Ferner überwiegen im Alter die Spiegel von den inhibitorischen IGFBindungsproteinen (IGFBP) 4 und 6 gegenüber den stimulatorischen IGFBP 3 und 5 , was der verminderten Wirkung von IGF-1 beitragen kann (Rosen und Donahue, 1998). Außerdem zeigen die Osteoblasten älterer Individuen eine zunehmende Resistenz gegenüber IGF-1 (Davis und Simmen, 1997). Diese Ergebnisse können zum Teil die altersabhängige Osteopenie bzw. Osteoporose erklären.

Sicherlich sind an der Regulation der Knochenhomöstase verschiedene Hormone wie Sexualhormone, Calcitonin, Parathormon und Vitamin D3 u.a. sowie unterschiedliche Wachstumsfaktoren und Zytokine, insbesondere das RANKL / RANK / OPG-Zytokin-System, beteiligt, die alle wie in einem Netzwerk miteinander verknüpft sind. Andere Faktoren wie Ernährung, Bewegung und die genetische Veranlagung sind für den Pathomechanismus der Osteoporose von Bedeutung. Jedoch sind nach den obigen Ausführungen die herausragende Rolle von IGF-1 im Knochenmetabolismus und Pathomechanismus der Osteoporose nicht zu übersehen.

Es stellt sich grundsätzlich die Frage, ob die osteoporotische Entwicklung im Rahmen des männlichen Hypogonadismus durch eine Hormontherapie aufgehalten bzw. verzögert werden kann. 
Tenover et al. (1990) untersuchten in einer doppelblinden und Placebo-kontrollierten Studie die Wirkungen des Testosteronenanthats in einer kleinen Gruppe gesunder Männer zwischen 57 und 76 Jahren für die Dauer von 3 Monaten. Dabei ging die Urinausscheidung von Hydroxyprolin, einem Marker der Knochenabsorption, zurück. Auch tierexperimentelle Studien an männlichen orchieektomierten Ratten konnten zeigen, daß $T$ die Orchiektomie-induzierte Osteoporose teilweise aufhalten kann (Stürmer et al., 2006; Seidlova-Wuttke et al., 2005). Gegenwärtig wird eine Testosteronsubstitution bei Männern mit manifestem Hypogonadismus angestrebt.

Eine Substitutionstherapie mit T kann aber auch unerwünschte Wirkungen entfalten. Mögliche unerwünschte Wirkungen umfassen die Entwicklung einer Polyzythämie, da Androgene sowohl die Erytropoetinsynthese in den Nieren stimulieren als auch direkt die hämatopoetischen Stammzellen zur Blutzellbildung anregen. Hajjar et al. (1997) analysierten retrospektiv eine Langzeittherapie mit $T$ bei 45 älteren hypogonadalen Männern, die alle 2 Wochen $200 \mathrm{mg}$ Testosteronenanthat bzw. -cypionat für mindestens 2 Jahre erhielten. Nach 2 Jahren zeigte sich ein signifikanter Anstieg des Hämatokrits in der Testosterongruppe. 24\% der mit $T$ behandelten Probanden entwickelten eine Polyzythämie, die eine passagere Therapieunterbrechung oder eine Phlebotomie erforderte.

Außerdem kann die Substitutionstherapie mit Androgenen die Entwicklung einer benignen Prostatahyperplasie beschleunigen (Schill, 2001).

Eine gefürchtete Nebenwirkung der Testosteronbehandlung ist die Entwicklung eines manifesten Prostatakarzinoms, dessen Präkanzerosen oder die Progression eines subklinischen und maskierten Prostatakarzinoms. In der bereits erwähnten klinischen Studie von Tenover et al. (1990) über die dreimonatige Therapie mit T wurde ein Anstieg des Prostata-spezifischen Antigens (PSA) in 30\% der Männer sogar 3 Monate nach Therapieende beobachtet. Eine Applikation von T führte im Gegensatz zu E2 zu einer Beeinflussung der Genexpression in der Prostata von orx Ratten (Seidlova-Wuttke et al., 2005). Aufgrund der unsicheren Datenlage bezüglich der Entstehung eines Prostatakarzinoms im Rahmen einer T-Substitution wird diese nur für hypogonadale Männer in fortgeschrittenem Lebensalter mit einem PSA-Wert unter den altersspezifischen Grenzen empfohlen. Unter der Therapie mit $\mathrm{T}$ wird aufgrund der heutigen Datenlage empfohlen, in dreimonatlichen Abständen eine PSA-Bestimmung und eine rektale Palpation bzw. sonographische Kontrollen der Prostata durchführen zu lassen (Djavan und Marberger, 2002). 
Die gefürchtete Einflußnahme von Androgenen auf die Prostata stellt für die medizinische Forschung eine große Motivation dar, in der hormonellen Therapie der Osteoporose im hypogonadalen Mann nach Alternativen zu suchen. Eine Östrogensubstitution des hypogonadalen Mannes scheidet wegen der Feminisierung aus verständlichen Gründen aus.

Die Arzneipflanze Cimicifuga racemosa (CR) rückte in den Blickpunkt der Forschung. Der Extrakt aus dem Rhizom dieser Pflanze wird bereits in der Prophylaxe und Therapie postmenopausaler Beschwerden der Frau verwendet und ist unter den Präparatnamen wie Klimadynon oder Menofem auf dem Markt erhältlich. In zahlreichen Studien wurde der antiosteoporotische Effekt von CR sichtbar. In einer Studie an ovx Ratten konnte unter einer oralen Behandlung eines CR-Extrakts die Ovarektomie-induzierte Osteoporose reduziert werden, was in der Bestimmung der BMD und in der biomechanischen Untersuchung des Knochens im Vergleich mit ovx Kontrolltieren nachweisbar war (Nisslein und Freudenstein, 2003). In einer humanen osteoblastären Zellkultur stiegen unter Zusatz von einem CR-Extrakt die Genexpression sowie die Proteinsekretion von Osteoprotegerin (OPG), das auch "osteoclastogenesis inhibiting factor" genannt wird und die Entwicklung von Osteoklasten aus Vorläuferzellen im Knochenmark verhindert, signifikant an. Die Expression seines Gegenspielers receptor activator of nuclear factor-kappa-B ligand (RANKL) wurde jedoch nicht beeinflußt. Unter CR nahmen ferner in dieser Zellkultur die Aktivität der knochenspezifischen AP und die Expression von Osteocalcin, beides Marker für die Osteoblastendifferenzierung, deutlich zu (Viereck et al., 2005). Andere klinische und tierexperimentelle Studien konnten zeigen, daß der Extrakt aus CR im weiblichen Geschlecht organselektiv wirkt und insbesondere auf den Uterus keine unerwünschte Wirkungen entfaltet (Wuttke et al., 2002 b; Seidlova-Wuttke et al., 2003; Freudenstein und Bodinet, 1999). CR wurde auch in einem männlichen orx Rattenmodell untersucht. Hier wies der CR-Extrakt wie das ebenfalls eingesetzte T und das E2 eine signifikante antiosteoporotische Wirkung, die in der quantitativen Computertomographie der tibialen Metaphyse sichtbar wurde, auf. Interessanterweise zeigte der CR-Extrakt ähnlich wie das E2 aber im Gegensatz zu T keine Einflußnahme auf die Genexpression in der Prostata (Seidlova-Wuttke et al., 2005). In Bezug auf das Prostatakarzinom und CR konnten weitere experimentelle Studien sehr interessante Ergebnisse liefern. Sowohl der CR Extrakt BNO 1055 als auch das Petasiphenon, ein Phenol, das aus dem CR-Extrakt isoliert worden war, 
konnten die Proliferation von LNCaP-Zellen, die dem humanen Prostatakarzinom entstammen und androgensensitiv sind, in immungeschwächten Mäusen wie auch in vitro signifikant hemmen (Seidlova-Wuttke et al., 2006; Jarry et al., 2007). Ferner konnte gezeigt werden, daß ein isopropanolischer Extrakt von $C R$ in vitro sowohl das Wachstum von LNCaP-Zellen als auch die Vermehrung von nicht androgensensitiven Prostatakarzinomzellen über die Induktion von Apoptose signifikant inhibiert (Hostanska et al., 2005).

In der antiosteoporotischen Therapie des hypogonadalen Mannes weckte die isoflavonhaltige Pflanze Belamcanda chinensis (BC), die in der traditionellen chinesischen Medizin Anwendung findet, Aufmerksamkeit. Für BC und für die aus dem Rhizom dieser Pflanze isolierten Isoflavone Tectoridin und Tectorigenin konnten ein antiosteoporotischer Effekt und eine SERM-Aktivität in ovx Ratten nachgewiesen werden. (Seidlova-Wuttke et al., 2000; Seidlova-Wuttke et al., 2004; Becker, 2002). In einer experimentellen Studie wurden LNCaP-Zellen den männlichen Nacktmäusen subkutan injiziert. Unter einer Fütterung mit einem Extrakt aus BC wurde das Wachstum der subkutanen Tumore deutlich reduziert. In der gleichen Studie wurden LNCaP-Zellen in vitro mit dem BC-Extrakt, Tectorigenin oder anderen Isoflavonen aus BC behandelt. Dabei ließ sich eine Hemmung der IGF-1-Rezeptor-vermittelten Proliferation von Prostatakarzinomzellen zeigen (Thelen et al., 2005). Somit stellen sich sowohl $C R$ als auch BC als interessante Forschungsobjekte in der alternativen antiosteoporotischen Therapie des hypogonadalen Mannes dar.

Der bedeutende Einfluß von Sexualhormonen auf das Knochenwachstum und die Regulation der Knochenhomöstase ist allgemein bekannt. Besonders bei Östrogenen ist der Mechanismus der antiosteoporotischen Wirkung gut untersucht. Die androgene Hemmung der Knochenresorption erfolgt größtenteils indirekt durch die Aromatisierung von T zu E2 (Falahati-Nini et al., 2000).

In der gegenwärtigen experimentellen Arbeit wurden die männlichen orx Ratten gruppenweise mit E2 in einer hohen (E2 $3.5 \mu \mathrm{g} / \mathrm{ml}$ ) und einer niedrigen (E2 0.5 $\mu \mathrm{g} / \mathrm{ml})$ Konzentration, $\mathrm{T}(3.5 \mathrm{mg} / \mathrm{ml})$, dem Extrakt der BC $(62.5 \mathrm{mg} / \mathrm{ml})$ und dem Extrakt der CR $(62.5 \mathrm{mg} / \mathrm{ml})$ behandelt. Wegen der subkutanen Applikation und der 10-tägigen Dauer entsprach diese Arbeit einem subakuten Versuchsansatz.

Dabei wurde die Genexpression und die Proteinkonzentration von IGF-1 im Femur der Ratten bestimmt. Die IGF-1-Konzentration wurde sowohl auf das Volumen der pufferhaltigen Probelösung (mit der Einheit $\mathrm{ng} / \mathrm{ml}$ ) als auch auf die Masse des 
Gesamtproteins der Probe (mit der Einheit ng/mg) bezogen. Dabei stellt die pufferhaltige Probelösung aufgrund des gleichen Mischungsverhältnisses zwischen Probengewicht und Puffervolumen (1 $\mathrm{mg}$ Probe in $10 \mu \mathrm{l}$ Puffer) ein einheitliches Medium zur Messung der Proteinkonzentration dar. Der Bezug von IGF-1 auf das Gesamtprotein spiegelt den Anteil von IGF-1 an dem Gesamtprotein einer jeden Probe wider.

Im Knochen dieser Ratten stiegen die Proteinkonzentrationen von IGF-1 (in ng/ml) in beiden E2-Gruppen nicht signifikant an, wobei die höherdosierte E2-Gruppe (E2 3.5) zu einem stärkeren Anstieg führte. Nur unter E2 3.5 konnte sich der Anstieg der Proteinkonzentration (in $\mathrm{ng} / \mathrm{ml}$ ) in einer Zunahme der IGF-1-mRNA widerspiegeln. Obwohl diese Ergebnisse nicht signifikant sind, lassen sie die Schlußfolgerung zu, daß E2 dosisabhängig die lokale IGF-1-Synthese im Knochen steigert. Somit könnte die Stimulation der lokalen IGF-1-Synthese im Knochen einem der Mechanismen entsprechen, die zu der wachstumsstimulierenden und antiosteoporotischen Wirkung der Östrogene führen. Der Anteil von IGF-1 am Gesamtprotein nimmt aber in beiden Estradiolgruppen ab, wobei das niedrig dosierte E2 einen geringeren Anteil aufweist. Diese Veränderungen können insbesondere ein Ausdruck für die allgemeinstimulierende Wirkung auf die Proteinsynthese und für die anabole Stoffwechselage im Knochen durch die Östrogene sein. Folglich nimmt IGF-1 im Knochen unter E2 einen geringeren Anteil am Gesamtprotein als in den Kontrollratten ein, obwohl die IGF-1-Konzentrationen in der Probelösung in der Estradiolgruppe selbst steigen.

In einer anderen Studie an weiblichen ovx Ratten konnte in einem subakuten Versuchsansatz über 7 Tage mit E2 ein Anstieg der IGF-1 Genexpression im Knochen beobachtet werden (Becker, 2002). Auch die akute intravenöse Gabe von E2 führte in ovx Ratten zu einem deutlicheren Anstieg der IGF-1-mRNA im Knochen (Becker, 2002; Seidlova-Wuttke et al., 2003). In der Literatur wurde erwähnt, daß Östrogene die hypophysäre Sekretion des GH stimulieren, wodurch ein Teil ihrer wachstumsstimulierenden Wirkung auf das Skelett erklärt werden kann (Lampit und Hochberg, 2003; Venken et al., 2005).

In einer Studie an männlichen orx Mäusen während der Pubertät, deren $\mathrm{GH}$ Rezeptorgen zerstört worden war (GHR-KO-Mäuse), führte die subkutane E2Applikation zu einem signifikanten Anstieg des Knochenwachstums. Dabei stiegen die IGF-1-Werte im Serum und die hepatische IGF-1 Synthese deutlich an, während die lokale IGF-1-Synthese im Femurknochen und Muskel dieser Mäuse nicht 
verändert wurde. Die Autoren dieser Studie gingen von einem neuen Wirkmechanismus von E2 in der Stimulation des pubertären Skelettwachstums aus, bei dem unabhängig vom GH-Rezeptor die IGF-1-Synthese in der Leber angeregt wird (Venken et al., 2005). Hierbei wird auch die große Bedeutung des Organs Leber deutlich, die als Hauptbildungsort der IGFs IGF-1 in die Blutbahn abgibt, damit es seine endokrine Wirkung entfalten kann.

In dieser Arbeit beeinflußte T kaum die lokale Synthese von IGF-1 im Knochen. Der Anteil von IGF-1 am Gesamtprotein nahm signifikant ab. Androgene haben bekanntermaßen eine starke anabole und die Proteinsynthese stimulierende Potenz. Damit kann der signifkant geringe Anteil von IGF-1 am Gesamtprotein darin begründet werden, daß unter dem Einfluß von $T$ das Gesamtprotein im Knochen unserer Versuchstiere deutlich angestiegen ist. Nach diesen Ergebnissen können Androgene per se ihren bekannten Einfluß auf das Wachstum und den Erhalt des Skeletts nicht über das lokale IGF-System ausüben. Allerdings erfolgt ein nicht zu unterschätzende Teil ihrer Wirksamkeit am Knochen durch deren Umwandlung in Östrogene. Die hier vorliegenden Ergebnisse werden in einer experimentellen Studie bestätigt, in der männliche orx Mäuse, die keinen Wachtumshormonrezeptor exprimieren (GHR-KO-Mäuse), mit Adrogenen behandelt wurden. Die Androgensubstitution führte in den pubertären GHR-KO-Mäusen zu einem Wachtumsanstieg des trabekulären und kortikalen Knochens sowie der Muskelmasse, ohne die systemische oder lokalen IGF-1- Produktion im Knochen und Muskulatur zu beeinflussen (Venken et al., 2007).

BC führte im Knochen unserer Versuchstiere zu einem nicht signifikanten und diskreten Anstieg der IGF-1-Konzentration (in $\mathrm{ng} / \mathrm{ml}$ ), während die Genexpression ebenfalls leicht zunahm. Somit verhält sich BC so ähnlich wie E2 in seinen beiden Konzentrationen. Die osteoprotektive Wirksamkeit und die SERM-Aktivität dieser Arzneipflanze und deren Isoflavone Tectoridin und Tectorigenin konnten in tierexperimentellen Studien belegt werden (Seidlova-Wuttke et al., 2000; SeidlovaWuttke et al., 2004). Der Anteil von IGF-1 am Gesamtprotein nahm unter dem Einfluß von $\mathrm{BC}$ signifikant und am stärksten ab, was ebenfalls für die hohe eiweißanabole Wirkung der Isoflavone von BC im Knochen, die mit einer verstärkten Proteinbiosynthese einhergeht, sprechen kann.

An ovarektomierten Ratten konnte außerdem gezeigt werden, daß sowohl die einmalige intravenöse (i.v.) Applikation von Tectoridin als auch die subkutane 
Verabreichung von einem Extrakt der BC und seiner Isoflavone über 7 Tage die IGF1-Genexpression im Knochen dieser Ratten steigerte, wobei nur der Anstieg unter der intravenösen Gabe überdeutlich und signifikant ausfiel. Dabei waren die Wirkungen von BC auf die IGF-1-Genexpression im Knochen ähnlich wie die des E2. Die chronische orale Applikation von BC und E2 führte in dieser Studie zu einer Abnahme der Genexpression von IGF-1 wie auch zum Rückgang der Genexpression von TGF- $\beta$, Osteocalcin, Osteoprotegerin und Tartrat-resistente sauere Phosphatase im Knochen der ovx Ratten, womit eine allgemeine Abnahme des Knochenumsatz durch die dreimonatige Verabreichung der beiden Substanzen und ihre ähnliche Wirkung auf das Knochengewebe gezeigt werden konnten (Becker, 2002). Die bis heute identifizierten Wirkstoffe der BC werden auch Phytöstrogene genannt.

Die Behandlung unserer Ratten mit einem Extrakt aus $C R$ führte zu interessanten Ergebnissen. Während die Genexpression von IGF-1 im Knochen deutlich aber nicht signifikant abnahm, kam es im Vergleich mit den anderen Gruppen zu dem stärksten Anstieg der IGF-1-Proteinkonzentration (in ng/ml) im Femur der Ratten, die die IGF1-Konzentrationen der E2-Gruppen in der Dynamik übertraf. Obwohl dieser Anstieg keine Signifikanz aufwies, war das divergente Verhalten der Genexpression und der IGF-1-Proteinsynthese unter CR mehr als deutlich. In zahlreichen klinischen und tierexperimentellen Studien wurde die antiosteoporotische Wirksamkeit dieser Arzneipflanze belegt (Seidlova-Wuttke et al., 2003; Nisslein und Freudenstein, 2003; Viereck et al, 2005; Wuttke et al., 2002 b). CR stimulierte mehr als die Östrogene die lokale IGF-1-Synthese im Knochengewebe unserer Versuchstiere. Somit werden die Wirksubstanzen, die in dem Extrakt dieser Pflanze enthalten und bis heute nur vereinzelt identifiziert worden sind, ihre antiosteoporotische Wirkung möglicherweise auch über die Anregung der lokalen IGF-1-Synthese ausüben. Der signifikant niedrige Anteil von IGF-1 am Gesamtprotein spricht ähnlich wie bei BC für eine hohe eiweißanabole Potenz von CR im Knochen.

Die Divergenz bezüglich der erniedrigten relativen mRNA-Menge und der erhöhten Proteinkonzentrationen von IGF-1 (in $\mathrm{ng} / \mathrm{ml}$ ) ist nicht einfach zu erklären. Eine Erklärung für diesen besonderen Fall könnte sein, daß die Transkription und die Proteinbiosynthese von IGF-1 unter CR relativ schnell erfolgte und die mRNA teilweise durch RNAsen abgebaut wurde, so daß im Gegensatz zu den anderen Gruppen nur ein Teil der mRNA gemessen werden konnte. Es ist sogar beschrieben worden, daß die intravenöse Zufuhr von einem CR-Extrakt akut zu einem leichten 
Anstieg der IGF-1-Genexpression im Knochen von ovx Ratten geführt hatte (Seidlova-Wuttke et al., 2003).

Aufgrund der hier vorliegenden Ergebnisse führen beide in dieser Studie eingesetzten Arzneipflanzen zu einer verstärkten lokalen IGF-1-Synthese im Knochengewebe, wenn auch diese nicht signifikant ist. Dabei ist die lokale IGF-1Synthese im Knochen unter CR deutlicher ausgefallen. Da IGF-1 von Osteoblasten sezerniert wird und lokal durch einen autokrinen bzw. parakrinen Mechanismus die Differenzierung und die Proliferation der Osteoblasten stimuliert sowie den Aufbau der Knochenmatrix anregt, legt die verstärkte lokale IGF-1-Synthese eine osteoprotektive Wirkung nahe. Gerade der osteoprotektive Charakter von insbesondere $\mathrm{CR}$, die in einem höheren Maß als BC die Proteinexpression von IGF-1 im Knochen anregt, wird in den zahlreichen oben aufgeführten Studien bestätigt. Interessanterweise stieg das Gesamtprotein in Femur unserer Versuchstiere unter den Einflüssen von $B C$ und $C R$ am stärksten an, wenn man es mit den anderen Gruppen vergleicht. Dabei erscheint die eiweißanabole Potenz der beiden Arzneipflanzen im Knochengewebe unserer Ratten als beachtlich und übertrifft die der Androgene.

Damit wir überprüfen konnten, ob die Proteinexpression mit der Genexpression von IGF-1 im Knochen quantitativ korreliert, haben wir die Proteinkonzentrationen der einzelnen Versuchstiere (in $\mathrm{ng} / \mathrm{ml}$ und $\mathrm{ng} / \mathrm{mg}$ ) ihren zugehörigen prozentualen Genexpressionen (des gleichen Versuchstiers) zugeordnet und graphisch dargestellt. Dabei stellten die X-Achse unseres Diagramms die IGF-1-Genexpression der Versuchsratten in Prozent und die Y-Achse die IGF-1-Proteinkonzentrationen in der jeweiligen Einheit ng/ml oder ng/mg dar. Die beiden Geraden verliefen annährend horizontal, so daß die relative Genexpression und die Proteinkonzentrationen der einzelnen Tiere miteinander nicht korrelierten. Es ist folglich nicht automatisch davon auszugehen, daß die Expression eines Gens gleichbedeutend mit der Expression des durch dieses Gen kodierten Proteins ist. Die Transkription, die posttranskriptionelle Phase der Proteinbiosynthese und die Translation sind bekanntlich starken regulatorischen Mechanismen unterworfen.

Da sowohl CR als auch BC oder deren isolierte Komponenten bezüglich des Prostatakarzinoms eine antiproliferative und inhibitorische Wirksamkeit aufweisen (Seidlova-Wuttke et al., 2005; Seidlova-Wuttke et al., 2006; Jarry et al., 2007; Hostanska et al., 2005; Thelen et al., 2005), können sie nützliche Alternativen in der 
antiosteoporotischen Therapie des hypogonadalen Mannes darstellen. Allerdings sind weitere experimentelle Studien erforderlich, um einen tieferen Einblick in die osteoprotektive und antikarzinomatöse Wirksamkeit der beiden Arzneipflanzen im hypogonadalen Mann zu erhalten.

In der vorliegenden Arbeit wurde die Leber der männlichen und orx Ratten ebenfalls auf die Gen- und Proteinexpression von IGF-1 untersucht. Die Leber stellt den Hauptbildungsort der IGFs dar. Von hier wird IGF-1 in die Blutbahn abgegeben und kann in peripheren Oganen seine endokrine Wirkungen ausüben. IGF-1 kann aber auch über den IGF-Typ 1-Rezeptor wie auch über den Insulinrezeptor insulinartige metabolische Wirkungen, die insbesondere die Leber als das Stoffwechselorgan betreffen, entfalten. Allerdings sind die metabolischen Effekte von IGF-1 schwächer ausgeprägt als die des Insulins (Baserga und Rubin 1995). IGF-1 stimuliert die Glukoseaufnahme durch die Zelle und die Glykogensynthese in der Leber (Lodish et al., 1996). Ferner konnte an transgenen Mäusen, die kein Wachstumshormon (GH) exprimierten und eine eingeschränkte Kalorienzufuhr erhielten, gezeigt werden, daß die meisten Gene, die in der Leber dieser Mäuse exprimiert wurden und an der Stressreaktion und dem xenobiotischen Stoffwechsel beteiligt waren, von GH und IGF-1 reguliert wurden (Higami et al., 2006).

Es gibt Publikationen, in denen erhöhte zirkulierende IGF-1-Spiegel mit erhöhter Tumorinzidenz und einer Verkürzung der Lebensdauer in Verbindung gebracht werden. Das Biguanid Phenformin, das durch die Abnahme des Blutzuckerspiegels zu einer Verminderung der Insulinämie und durch die Insulinabnahme und die vermehrte IGFBP-1-Produktion zur Verminderung zirkulierender IGF-1-Spiegel führte, wirkte sich auf die Lebendauer von Mäusen, die zur Tumorbildung neigten, verlängernd aus (McCarty, 2004).

Aufgrund von kanzerogenen Wirkungen von Wachstumsfaktoren wie IGF-1 besteht der Verdacht, daß es einen Zusammenhang zwischen erhöhten Serumkonzentrationen von IGF-1 und der Entstehung von Malignomen wie dem Mammakarzinom oder Kolonkarzinom gibt (McCarty, 2001; Campagnoli et al., 1994). Dabei stellt sich die Leber als Quelle des zirkulierenden IGF-1 dar. Jedoch sollten die mitogenen und kanzerogenen Eigenschaften von IGF-1 differenzierter beurteilt werden. In einer experimentellen Studie konnte nämlich gezeigt werden, daß IGF-1 auf zwei morphologisch und funktionell ähnliche Zellen der Rattenleber, die 
hepatischen Sternzellen und die Myofibroblasten, bezüglich der Proliferation und der zugrunde liegenden Mechanismen völlig unterschiedlich wirkte. In den Sternzellen wurde über die Aktivierung proapoptotischer Gene die Apoptose induziert, während die Myofibroblasten sich durch die IGF-1-induzierte Aktivierung antiapoptotischer Gene vermehren konnten (Saile et al., 2004).

Die Ergebnisse unserer Messungen zeigten, daß die relative Genexpression von IGF-1 in beiden E2-Gruppen deutlich aber nicht signifikant anstiegen. Die IGF-1Konzentrationen (in $\mathrm{ng} / \mathrm{ml}$ ) nahmen ebenfalls in beiden Gruppen zu, wobei der Anstieg unter dem niedrig dosierten E2 $(0.5 \mu \mathrm{g} / \mathrm{ml})$ deutlich stärker und signifikant ausfiel. Interssanterweise verhielt sich die IGF-1-Konzentration nicht proportional zu der gewählten E2-Dosis. Auch der Anteil von IGF-1 am Gesamtprotein nahm in beiden Gruppen nicht signifikant zu. Parallel zu den Ergebnissen aus dem Knochen unserer Ratten führte die Estradiolbehandlung in der Leber zu einem Anstieg der IGF-1-Konzentrationen. Diese Ergebnisse werden in einer Studie bestätigt, in der männliche orx Mäuse, die sich in der Pubertät befanden und keinen Wachstumshormonrezeptor exprimierten, eingesetzt und mit E2 subkutan substituiert wurden. Unter E2 kam es unabhängig von $\mathrm{GH}$ zu einem deutlichen Wachstum und zu einer signifikanten Zunahme der hepatischen IGF-1-Synthese und der zirkulierenden IGF-1-Spiegel (Venken et al., 2005). Außerdem nimmt man an, daß Östrogene besonders in der postnatalen und peripubertären Phase die Synthese des GH und somit die Bildung von IGF-1 stimulieren (Mauras et al, 1996). Es gibt aber auch Publikationen, die bezüglich des Einflusses der Östrogene auf die hepatische IGF-1-Synthese gegensätzliche Ergebnisse beschreiben. In einer klinischen Studie führte die orale Östrogenbehandlung von postmenopausalen Frauen zu einem Rückgang der IGF-1-Serumspiegel, was wahrscheinlich auf den hepatozellulären Effekt der Östrogene zurückgeführt werden kann (Campagnoli et al., 1994). Allerdings wurde in dieser klinischen Studie aus verständlichen Gründen die hepatische IGF-1-Synthese nicht gemessen. Die IGF-1-Werte im Blut waren hier indirekte Parameter für die vermehrte IGF-1-Synthese in der Leber durch die Östrogene.

Die Untersuchung an dem transgenen, das GH überexprimierenden Knochenfisch Tilapia zeigte, daß trotz einer deutlich erhöhten hepatischen IGF-1-Synthese die Serumkonzentrationen von IGF-1 niedriger als in Kontrollfischen ausfielen. In der Leber und im Serum der transgenen Fische zeigten sich jedoch erhöhte Spiegel von 
IGF-1-bindenden Proteinen (IGFBP). Der erhöhte Gehalt von IGFBP in der Leber führte zu einer Retention von IGF-1 und / oder zu einer verlangsamten Freisetzung von IGF-1 in den Kreislauf. Somit kam es zu einer Anhäufung von IGF-1 in den Hepatozyten (Eppler et al., 2007). Diese Studie läßt die Schlußfolgerung zu, daß das zirkulierende IGF-1 nicht automatisch die hepatische IGF-1-Synthese widerspiegelt. Außerdem läßt sich das verstärkte Wachstum der transgenen Fische, in deren Skelettmuskulatur eine doppelt so hohe IGF-1-Genexpression gemessen werden konnte, wahrscheinlich auf die verstärkte autokrine / parakrine Wirkung von IGF-1 in Organen wie Skelettmuskel und Knochen und nicht auf die endokrine Wirkung von IGF-1 zurückführen. Somit kann die lokale IGF-1-Synthese im Knochen für Wachstum und Knochenerhalt eine übergeordnete Rolle spielen, wenn man diese mit der endokrinen Wirkung des hepatischen IGF-1 vergleicht.

Unter T nahm zwar die Genexpression von IGF-1 in der Leber leicht zu. Die IGF-1Konzentrationen (sowohl in $\mathrm{ng} / \mathrm{ml}$ als auch in $\mathrm{ng} / \mathrm{mg}$ ) jedoch sanken im Vergleich zu den Kontrollratten nicht signifikant ab. Auch hier erhielt man ähnliche Ergebnisse wie aus dem Knochen der Versuchstiere. T beeinflußt sowohl in der Leber als auch im Knochen kaum die IGF-1-Synthese.

Unter BC stieg die Genexpression von IGF-1 in der Leber unserer Versuchstiere leicht an. Die Konzentration (in ng/ml) des hepatischen IGF-1 dagegen nahm deutlich zu, obwohl diese Veränderung nicht signifikant war. Sie übertraf sogar den Anstieg der IGF-1-Konzentration unter dem hoch dosierten E2 $(3.5 \mu \mathrm{g} / \mathrm{ml})$. In den mit BC behandelten Ratten stieg der Anteil von IGF-1 am Gesamtprotein am stärksten an. Dabei fiel das mittlere Gesamtprotein (12.65 $\mu \mathrm{g} / \mathrm{tube}) \mathrm{im}$ Vergleich zu den anderen Gruppen am niedrigsten aus. Auffällig ist die starke Divergenz der Gesamtproteinkonzentrationen in den beiden Organen Femur und Leber unserer Versuchsratten unter dem Einfluß von BC, da in Femur unter BC die höchste mittlere Gesamtproteinkonzentration (10.19 $\mu \mathrm{g} /$ tube) gemessen wurde. Dieses Phänomen kann für die organselektive Wirkung von BC auf die Proteinbiosynthese sprechen. Die hepatische IGF-1-Expression wird nach diesen Ergebnissen durch die Phytoöstrogene der BC deutlich stimuliert. In einer tierexperimentellen Studie führte jedoch die intravenöse Applikation von Tectoridin, ein Isoflavon aus dem Rhizom der $\mathrm{BC}$, in weiblichen ovx Ratten zu einer raschen, aber relativ schwachen Hemmung der hepatischen Genexpression von IGF-1 (Seidlova-Wuttke et al., 2000). Trotz der widersprüchlichen Datenlage verhalten sich in der vorliegenden Arbeit die 
Phytoöstrogene der BC bezüglich der IGF-1-Synthese in Leber und Knochen ähnlich wie das E2.

Unter der Behandlung mit CR zeigte sich in der Leber unserer Ratten ein ähnliches divergentes Verhalten zwichen der Gen- und Proteinexpression von IGF-1 wie im Knochen auch. Während die hepatische Genexpression von IGF-1 deutlich aber nicht signifikant abfiel, nahm dessen Proteinkonzentration leicht zu. Die hepatische IGF-1-Konzentration (in ng/ml) in der CR-Gruppe blieb unter der IGF-1-Konzentration der beiden Estradiolgruppen und der BC-Gruppe. Anders als in der Leber führte CR aber im Knochen zum stärksten Anstieg der IGF-1-Konzentration (in ng/ml). Somit stimuliert der Extrakt der CR die lokale IGF-1-Synthese im Knochen deutlich stärker als die hepatische IGF-1-Synthese und weist so eine Organselektivität auf. Diese wird deutlicher, wenn man die mittlere Gesamtproteinkonzentrationen in Knochen und Leber unserer Versuchstiere unter dem Einfluß von CR vergleicht. Die mittlere Gesamtproteinkonzentration im Knochen (9.62 $\mu \mathrm{g} / \mathrm{tube})$ ist die zweit höchste im Vergleich mit den anderen Gruppen, während diese in der Leber (14.3 $\mu \mathrm{g} / \mathrm{tube})$ die zweit niedrigste darstellt. Die lediglich schwache Zunahme der hepatischen IGF-1Synthese kann vorteilhaft sein, wenn man bedenkt, daß die Leber als Quelle der zirkulierenden IGFs gilt, und erhöhte IGF-1-Spiegel im Serum mit der Entstehung von Malignomen assoziiert werden. Somit kommt auch unter diesem Aspekt CR ihrer Rolle in der zukünftigen antiosteoporotischen Therapie des hypogonadalen Mannes näher.

Die graphische Zuordnung der Proteinkonzentrationen der einzelnen Ratten (sowohl in $\mathrm{ng} / \mathrm{ml}$ als auch in $\mathrm{ng} / \mathrm{mg}$ ) zu der jeweiligen Genexpression ließ in der Leber keine Korrelation erkennen. Wie im Knochen korrelieren in der Leber die Protein- und Genexpression auch nicht miteinander.

Mit Sicherheit sind weitere zunächst tierexperimentelle Studien erforderlich, um das Ausmaß der osteoprotektiven Wirksamkeit der beiden Arzneipflanzen Cimicifuga racemosa und Belamcanda chinensis besonders im männlichen Geschlecht weiter zu objektivieren und die zugrundeliegenden Wirkmechanismen näher zu erforschen. Ferner scheint es sinnvoll zu sein, weitere noch unbekannte Wirksubstanzen der CR zu identifizieren.

Es gibt keine Selbstverständlichkeit für die Nebenwirkungslosigkeit von Präparaten pflanzlicher Herkunft. Setchell et al. beschrieben bereits 1987 die gesundheitlichen 
Probleme in einem Bestand von Geparden in der Gefangenschaft. Durch ihre Diät auf der Basis von Soja war es zu Beeinträchtigungen der Leberfunktion und zu Fruchtbarkeitsstörungen gekommen. Gerade diese Beobachtungen weisen auf die Wichtigkeit von Untersuchungen im Hinblick auf eine eventuelle klinische Verwendung von Phytoöstrogenen in der Humanmedizin hin.

In Langzeitstudien können unerwünschte Wirkungen der beiden Pflanzen auf weitere Organe wie die Leber, ihre Kanzerogenität und das Feminisierungspotential insbesondere von den Phytoöstrogenen der BC überprüft werden. 


\section{Zusammenfassung}

In Männern wird die altersassoziierte Abnahme des Testosterons nach dem 60. Lebensjahr statistisch relevant. Der Androgenmangel führt insbesondere zur Osteoporose, die von diffusen Knochenschmerzen und erhöhter Frakturgefährdung begleitet wird. Angesichts der zunehmenden Lebenserwartung der Weltbevölkerung werden das Partielle Androgendefizit des alternden Mannes (PADAM) und die senile Osteoporose in Männern zunehmend bedeutender. Eine Testosteronsubstitution, die bei manifestem Hypogonadismus im Mann heute Anwendung findet, kann aber im Rahmen ihrer unerwünschten Wirkungen u.a. zu einem Prostatakarzinom führen. Deswegen sucht man nach alternativen Therapien der Osteoporose im hypogonadalen Mann. Dabei rückten die Arzneipflanzen Belamcanda chinensis (BC) und Cimicifuga racemosa $(C R)$ in den Blickpunkt der Forschung. Für die isoflavonhaltige $B C$ wurde in experimentellen Studien eine antiosteoporotische Wirksamkeit und eine SERM-Aktivität nachgewiesen. Der Extrakt aus dem Rhizom der CR wird bereits in der Prophylaxe und Therapie postmenopausaler Beschwerden der Frau angewandt und zeigt osteoprotektive Effekte. Sowohl für BC oder deren Inhaltsstoffe als auch für $\mathrm{CR}$ sind in jüngster Zeit antiproliferative Effekte auf das Prostatakarzinom beschrieben worden.

In dieser experimentellen Arbeit wurden die Einflüsse von Estradiol 17-beta (E2) in zwei unterschiedlichen Konzentrationen, Testosteron und Extrakten von BC und CR auf die IGF-1-Synthese untersucht. Dabei scheint IGF-1, das als Somatomedin die wachstumsstimulierenden Wirkungen des Wachstumshormons vermittelt, eine herausragende Rolle im Knochenmetabolismus und Pathomechanismus der Osteoporose zu spielen. IGF-1 wurde in Knochen (Femur) und Leber von männlichen orchiektomierten Ratten, die ein Modell für die endokrinologische Verhältnisse im hypogonadalen Mann darstellen, gemessen. Dabei stellt die Leber als Hauptbildungsort der IGFs, von wo diese ihre endokrinen Wirkungen entfalten, ein interessantes Untersuchungsobjekt dar. Die Versuchstiere wurden für die Dauer von 10 Tagen mit einer definierten Menge der o.g. Substanzen subkutan behandelt und anschließend getötet, damit die Organe zur Messung der Genexpression von IGF-1 und der IGF-1-Konzentration entnommen werden konnten.

Sowohl im Knochen als auch in der Leber steigerten beide Konzentrationen von E2 die IGF-1-Synthese. Somit scheint die IGF-1-Synthese einer der Mechanismen zu 
sein, die zu der wachstumsstimulierenden und antiosteoporotischen Wirkung der Östrogene führen. Dagegen beeinflußte das Testosteron in beiden Organen kaum die Synthese von IGF-1. BC, deren Wirkstoffe auch Phytöstrogene genannt werden, verhielt sich bezüglich der Genexpression und Synthese von IGF-1 ähnlich wie E2. Die mittlere Gesamtproteinkonzentration unter dem Einfluß von BC zeigte in Knochen und Leber eine starke Divergenz. Dieses Ergebnis spricht für die organselektive Wirkung von BC. CR lieferte in beiden Organen interessante Ergebnisse. Während die Genexpression von IGF-1 deutlich abnahm, stieg die IGF1-Konzentration $(\mathrm{ng} / \mathrm{ml})$ an. Dabei nahmen unter CR die lokale IGF-1-Synthese und die mittlere Gesamtproteinkonzentration im Knochen deutlich stärker als in der Leber zu. Der schwache Anstieg der hepatischen IGF-1-Synthese scheint vorteilhaft zu sein, da zirkulierende IGF-1-Spiegel mit einer erhöhten Inzidenz von Neoplasien assoziiert werden. Somit üben die Wirksubstanzen beider Arzneipflanzen ihre antiosteoporotische Wirkung unter anderem über die Anregung der lokalen IGF-1Synthese aus. Interessanterweise korrelierte die Höhe der IGF-1-Konzentrationen der einzelnen Versuchstiere in den Organen Knochen und Leber nicht mit der Höhe inrer Genexpression.

Weitere Studien sollten die Rolle von CR und BC als nützliche Alternativen in der antiosteoporotischen Therapie des hypogonadalen Mannes klären. 


\section{Anhang}

\section{1. Abkürzungsverzeichnis}

\begin{tabular}{|c|c|}
\hline AP & alkalische Phosphatase \\
\hline AR & Androgenrezeptor \\
\hline $\mathrm{BC}$ & Belamcanda chinensis \\
\hline BMD & Knochenmineraldichte \\
\hline BMP & Knochen-morphogenetisches Protein \\
\hline C & Kohlenstoff \\
\hline CpM & radioaktiver Zerfall pro Minute \\
\hline CR & Cimicifuga racemosa \\
\hline DHEA & Dehydroepiandrosteron \\
\hline $\mathrm{DHT}$ & Dihydrotestosteron \\
\hline dNTP & Desoxyribonukleosid-Triphosphat \\
\hline E2 & Estradiol 17-beta \\
\hline ER & Östrogenrezeptor \\
\hline ERE & estrogen responsive elements \\
\hline ERK & Extracellular-Regulated Kinase \\
\hline FAM & 6-Carboxy-Fluorescein \\
\hline FET & Fluoreszenz-Energietransfer \\
\hline $\mathrm{GH}$ & Wachstumshormon \\
\hline GHBP & GH-bindendes Protein \\
\hline GnRH & Gonadotropin-Releasinghormon \\
\hline HRT & Hormonersatztherapie \\
\hline HVL & Hypophysenvorderlappen \\
\hline IDDM & Insulinpflichtiger Diabetes mellitus \\
\hline IGF -1 & Insulin-like Growth Factor 1 \\
\hline IGFBP & IGF-Bindungsprotein \\
\hline IL & Interleukin \\
\hline $\mathrm{LH}$ & Luteinisierendes Hormon \\
\hline MAP - Kinase & Mitogen-activated Protein-Kinase \\
\hline NSB & Nicht-spezifische Bindung \\
\hline OPG & Osteoprotegerin \\
\hline orx & orchiektomiert \\
\hline ovx & ovarektomiert \\
\hline PADAM & Partielles Androgendefizit des alternden Mannes \\
\hline PBS & Phosphat Buffer Solution \\
\hline
\end{tabular}


PDEF

$P G$

$P I 3$ - Kinase

PSA

RANKL

RIA

SERM

SHBG

sv40T Ag

$T$

TA

TAMRA

TGF

TNF

UpM
Prostate-derived Ets transcription factor

Prostaglandin

Phosphatidyl-Inositol-3-Kinase

Prostata-spezifisches Antigen

Receptor activator of nuclear factor-kappa-B ligand Radio-Immunoassay

Selective Estrogen Receptor Modulator

Sexualhormonbindendes Globulin

Simian virus 40 large tumor antigen

Testosteron

Totalaktivität

6-Carboxy-tetramethyl-rhodamin

Transforming Growth Factor

Tumor Necrosis Factor

Umdrehung pro Minute 
Abb. 1.

Abb. 2.

Abb. 4.1.

Abb. 4.2.

Abb. 4.3.

Abb. 4.4.

Abb. 4.5.

Abb. 4.6.

52

Abb. 4.7.

Abb. 4.8.

Abb. 4.9.

Abb. 4.10. 


\section{Literaturverzeichnis}

Abu E (1997): The localisation of androgen receptors in human bone. J Clin Endocrinol Metab 82, 3493-3497.

Akhmedkhanov A, Zeleniuch-Jacquotte A, Toniolo P (2001):

Role of exogenous and endogenous hormones in endometrial cancer: review of the evidence and research perspectives. Ann N Y Acad Sci 943, 296 - 315.

Albright F, Reifenstein EC: Metabolic bone disease and osteoporosis. In: The parathyroid glands and metabolic bone disease; Albright F, Reifenstein EC editors, Williams \& Wilkins, Baltimore 1948, 145-204.

Alekel DL, St Germain A, Peterson CT, Hanson KB, Stewart JW, Toda T (2000): Isoflavone-rich soy protein isolate attenuates bone loss in the lumbar spine of perimenopausal women. Am J Clin Nutr 72, 844-852.

Alen M, Hakkinen K, Komi PV (1984): Changes in neuromuscular performance and muscle fiber characteristics of elite power athelets self-administering androgenic and anabolic steroids. Acta Physiol Scand 122, 535.

Anthony MS, Clarkson TB, Wiliams JK (1998):

Effects of soy isoflavones on atherosclerosis: potential mechanisms. Am J Clin Nutr 68, $1390-1393$.

Aronica SM, Kraus WL, Katzenellenbogen WS (1994): Estrogen actions via the cAMP signaling pathway: stimulation of adenylat cyclase and cAMP-regulated gene transcription. Proc Natl Acad Sci U S A 91, 8517-8521.

Bagdade JD, Wolter J, Subbabiah PV, Ryan W (1990): Effects of tamoxifen treatment on plasma lipids and lipoprotein lipid composition. J Clin Endocrinol Metab 70, 11321135.

Baker HW, Hudson B: Changes in the pituitary-testicular axis with age. In: The pituitary and testis, Clinical and experimental studies, Monographs on Endocrinology 25; De Kretser BM, Burger HG, Hudson B editors, Springer, Berlin-Hamburg-New York 1983 71-82.

Barakat, RR (1996): Tamoxifen and endometrial neoplasia. Clin Obstet Gynecol 39, 629-640.

Barakat RR (1998): Tamoxifen and the endometrium. Cancer Treat Res 94, 195-207.

Baserga R, Hongo A, Rubini M, Prisco M, Valentinis B (1997):

The IGF-I receptor in cell growth, transformation and apoptosis.

B B A 1332, 105-126. 
Beamer WG, Donahue LR, Rosen CJ, Baylink DJ (1996): Genetic variability in adult bone density among inbred stains of mice. Bone 18, 397-403.

Beato M, Klug J (2000): Steroid hormone receptors: an update. Hum Reprod Update 6, 225-236.

Beato M, Herrlich P, Schutz G (1995): Steroid hormone receptors: many actors in search of a plot. Cell 83, 851-857.

Becker, T: Phytoestrogene Wirkung von Belamcanda chinensis an Uterus und Knochen der ovarektomierten Ratte. Biol. Diss. Hannover/ Göttingen 2002, 53-56.

Benz DJ, Haussler MR, Thomas MA, Speelman B, Komm BS (1991): Highaffinity androgen binding and androgenic regulation of alpha 1(I)procollagen and transforming growth factor-beta steady state messenger ribonucleic acid levels in human osteoblast-like osteosarcoma cells. Endocrinology 128, 2723-2730.

Birkhäuser MH: Ovar: Ovar und Follikel. In: Klinische Pathophysiologie, 8. Auflage; hrsg. v. Siegenthaler W, Thieme-Verlag, Stuttgart 2000 a, 379 - 383.

Birkhäuser MH: Ovar: Physiologische Grundlagen. In: Klinische Pathophysiologie, 8. Auflage; hrsg. v. Siegenthaler W, Thieme-Verlag, Stuttgart 2000 b, 384.

Birkhäuser $\mathrm{MH}$ : Ovar: Nicht steroidale endokrine, parakrine und autokrine ovarielle Faktoren. In: Klinische Pathophysiologie, 8. Auflage; hrsg. v. Siegenthaler W, Thieme-Verlag, Stuttgart 2000 c, 385.

Birkhäuser MH: Ovar: Allgemeine und spezielle Pathophysiologie. In: Klinische Pathophysiologie, 8. Auflage; hrsg. v. Siegenthaler W, Thieme-Verlag, Stuttgart 2000 d, 405-406.

Blaschek W : Drogen A-K. In: Hagers Handbuch der pharmazeutischen Praxis, 5. Auflage, Folgeband 2; Blashek editor, Springer-Verlag, Berlin 1998 374-381.

Boschitsch E (1998): Die Hormonersatztherapie aus osteologischer Perspektive. J Menopause 5 (2) (Ausgabe für Deutschland), 10-14.

Bremner WJ, Vitiello MV, Prinz PN (1983): Loss of circadian rhythmicity in blood testosterone levels with aging in normal men. J Clin Endocrinol Metab 56, 1278-81.

Bruck B, Brehme U, Gugel N, Hanke S, Finking G, Lutz C, Benda N, Schmahl FW, Haasis R, Hanke H (1997): Gender-specific differences in the effects of testosterone and estrogen on the development of atherosclerosis in rabbits. Arterioscler Thromb Vasc Biol 17, 2192-2199.

Bucay N, Sarosi I, Dunstan CR, Morony S, Tarpley J, Capparelli C, Scully S, Tan HL, Xu W, Lacey DL (1998):

Osteoprotegerin-deficient mice develop early onset osteoporosis and arterial calcification. Genes Dev 12, 1260-1268. 
Burdette E, Liu J, Lantvit D, Lim E, Booth N, Bhat KP, Hedayat S, Van Breemen RB, Constantinou AI, Pezzutu JM (2002): Trifolium pratense (red clover) exhibits estrogenic effects in vivo in ovarectomized Sprague-Dawley rats. J Nutr 132, 27-30.

Byers M, Kuiper GG, Gustafsson JA, Park-Sage OK (1997): Estrogen receptor -beta mRNA expression in rat ovary: down-regulation by gonadotropins. Mol Endocrinol 11, 172-182.

Campagnoli C, Biglia N, Lanza MG, Lesca L, Peris C, Sismondi P (1994): Androgenic progestogens oppose the decrease of insulin-like growth factor I serum level induced by conjugated oestrogens in postmenopausal women. Maturitas 19(1), 25-31.

Campos H, McNamara JR, Wilson PWF, Ordovas JM, Schaefer EJ (1988):

Differences in low density lipoprotein subfractions and apolipoproteins in premenopausal and postmenopausal women. J Clin Endocrinol 67, 30-35.

Carani C, Qin K, Simoni M, Faustini-Fustini M, Serpente S, Boyd J, Korach KS, Simpson ER (1997): Effect of testosterone and estradiol in a man with aromatase deficiency. N Engl J Med 337, 91-95.

Cato AC, Nestl A, Mink S (2002): Rapid actions of steroid receptors in cellular signalling pathways. Sci STKE 2002, 9.

Chae CU, Ridker PM, Manso JE (1997): Postmenopausal hormone replacement therapy and cardiovascular disease. Thromb Haemost 78, 770-780.

Couse JF, Korach KS (1999): Estrogen receptor null mice: what have we learned and where will they lead us? Endocr Rev 20, 358-417.

Couse JF, Lindzey J, Grandien K, Gustafsson JA, Korach KS (1997):

Tissue distribution and quantitative analysis of estrogen receptor-alpha (ERalpha) and estrogen receptor-beta (ERbeta) messenger ribonucleic acid in the wild-type and ERalpha- knockout mouse. Endocrinology 138, 4613-4621.

Couse JF, Curtis HS, Korach KS (2000): Receptor null mice reveal contrasting roles for estrogen receptor alpha and beta in reproductive tissues. J Steroid Biochem Mol Biol 74, 287-296.

Davis ME, Simmen RC (1997): Genetic parameter estimates for serum insuli-like growth factor I concentration and performance trails in Angus beef cattle. J Anim Sci 75 (2), 317-324.

Day R, Ganz PA, Costantino JP, Cronin WM, Wickerham DL, Fisher B (1999):

Health-related quality of life and tamoxifen in breast cancer prevention: a report from the National Surgical Adjuvant Breast and Bovel Project P-1 Study. J Clin Oncol 17, 2659-2669.

Diczfalusy E (1998): An aging humankind: is our future behind us? The Aging Male 1, 8-19. 
Diel P, Schulz T, Smolnikar K, Strunck E, Vollmer G, Michna H (2000):

Ability of xeno- and phytoestrogens to modulate expression of estrogen-sensitive genes in rat uterus: estrogenicity profiles and uterotropic activity.

J Steroid Biochem Mol Biol 73, 1 - 10.

Diel P, Smolnikar K, Schulz T, Laudenbach-Leschowski U, Michna H, Vollmer G (2001): Phytoestrogens and carcinogenesis-differental effets of genistein in experimental models of normal and malignant rat endometrium. Hum Reprod 16, 997-1006.

Djavan B, Marberger M (2002): Androgensubstitution des Mannes aus der Sicht des Urologen. A M A 29 (2), 43-47.

Döcke F: Hypothalamus-Hypophysen-System. In: Veterinärmedizinische Endokrinologie 3. Aufl.; hrsg. v. Döcke F, Gustav Fischer Verlag, Jena - Stuttgart 1994, 131-175.

Dodt C, Fehm HL: Endokrine Störungen: Störungen des Hypophysevorderlappens. In: Pathophysiologie, 1. Auflage; hrsg. v. Fölsch, UR, Kochsiek K, Schmidt RF, Springer-Verlag, Berlin 2000, 401.

EBCTC-Group (1996): ACOG committee opinion. Tamoxifen and endometrial cancer. Number 169, February 1996. Committee of Gynecologic practice. American College of Obstetricians and Gynecologists. Int J Gynaecol Obstet 53, 197-199.

Edmunds E, Lip GYH (2000): Cardiovascular risk in women: the cardiologist's perspective. Q J Med 93, 135-145.

Eich DM, Nestler JE, Johnson DE, Dworkin GH, Ko D, Wechsler AS, Hess ML (1993): Inhibition of accelerated coronary atherosclerosis with dehydroepiandrosterone in the heterotopic rabbit model of cardiac transplantation. Circulation 87, 261-269.

Eppler E, Caelers A, Shved N, Hwang G, Rahman AM, Maclean N, Zapf J, Reinecke M (2007): Insulin-like growth factor I (IGF-I) in a growth-enhanced transgenic (GHoverexpressing) bony fish, the tilapia (Oreochromis niloticus): indication for a higher impact of autocrine/paracrine than of endocrine IGF-I. Transgenic Res 16(4), 479-89.

Falahati-Nini A, Riggs BL, Atkinson EJ, O'Fallon WM, Eastell R, Khosla S (2000): Relative contributions of testosterone and estrogen in regulating bone resorption and formation in normal elderly men. J Clin Invest 106,1553-1560.

Fanti P, Monier-Faugere M C, Geng Z, Schmidt J, Morris PE, Cohen D, Malluche HH (1998): The phytoestrogen genistein reduces bone loss in short-term ovariectomized rats. Osteoporos Int 8, $274-281$.

Ferrara N (2000): Vascular endothelial growth factor and the regulation of angiogenesis. Recent Prog Horm Res 55, 15 - 35. 
Finkelstein JS, Klibanski A, Neer RM (1996): A longitudinal evaluation of bone mineral density in adult men with histories of delayed puberties; . J Clin Endocrinol Metab 81, 1152.

Fitzpatrick LA (1999): Selective estrogen receptor modulators and phytoestrogens: new therapies for the postmenopausak woman. Mayo Clin Proc 74, 601-607.

Fowlkes JL, Thrailkill KM, Liu L, Wahl EC, Bunn RC, Cockrell GE, Perrien DS, Aronson J, Lumpkin CK Jr (2006): Effects of systemic and local administration of recombinant human IGF-I (rhIGF-I) on de novo bone formation in an aged mouse model. J B M R 21(9), 1359-66.

Franklin J, Ahmad AM, Ul-Haq M, Durham BH, Whittingham P, Fraser WD, Vora JP (2008): Effects of Growth Hormone Administration on Bone Mineral Metabolism, Parathyroid Hormone Sensitivity and Parathyroid Hormone Secretory Rhythm in Postmenopausal Women with Established Osteoporosis. J B M R 23, 721-729.

Franklin M, Bu S, Lerner MR, Lancaster EA, Bellmer D, Marlow D, Lightfoot SA, Arjmandi BH, Brackett DJ, Lucas EA (2006): Dried plum prevents bone loss in a male osteoporosis model via IGF-I and the RANK pathway. Bone 39(6), 1331-42.

Freudenstein J, Bodinet C : Influence of an isopropanolic acqueous extract of Cimicifugae racemosae rhizoma on the proliferation of MCF-7 cells. Poster, 23. Int. LOF-Symposium der Gesellschaft für Phytotherapie, Gent 1999.

Froesch RE, Gulper HP, Schmid C, Binz K, Zapf J (1990): Therapeutic potential of IGF-I. TEM, 254-260.

Froesch RE, Hussain MA, Schmid C, Zapf J (1996):

Insulin-like growth factor I: physiology, metabolic effects and clinical uses.

Diabetes/Metab Rev 12(3), 195-215.

Fröhlich M, Schunkert H, Hense H-W, Tropitzsch A, Hendricks P, Döring A, Riegger GAJ, Koenig W (1997): Effects of hormone replacement therapies on fibrinogen and plasma viscosity in postmenopausal women. $\mathrm{Br} \mathrm{J}$ Haematol 100, 577-581.

Gehm BD, McAndrews JM, Chien PY, Jameson JL (1997):

Resveratrol, a polyphenolic compound found in grapes and wine, is an agonist for the estrogen receptor. Proc Natl Acad Sci U S A 94, 14138 - 14143.

Giudice LC, Irwin JC, Dsupin BA, Pannier EM, Jin IH, Vu TH, Hoffman AR (1993): Insulin-like growth factor (IGF), IGF binding protein (IGFBP), IGF receptor gene expression and IGFBP synthesis in human uterine leiomyomata.

Hum Reprod 8, 1796 - 1806.

Goetz RM, Thatte HS, Prabhakar P, Cho MR, Michel T, Golan DE (1999): Estradiol induces the calcium-dependent translocation of endothelial nitric oxide synthase. Proc Natl Acad Sci U S A 96, 2788-2793.

Greendale GA, Reboussin BA, Sie A (1999): Effects of estrogen and estrogenprogestin on mammographic parenchymal density. Ann Intern Med 130, 262-268. 
Gu Q, Moss RL (1996): 17 beta-Estradiol potentiates kainate-induced currents via activation of the cAMP cascade. J Neurosci 16, 3620-3629.

Guo Z, Benten WP, Kruchen J, Wunderlich F (2002): Nongenomic testosterone calcium signalling: Genotropic actions in androgen receptor-free macrophages. J Biol Chem 277, 29600-07.

Gustafsson JA (2000): Novel aspects of estrogen action. J Soc Gynecol Investig 7, 8-9.

Hajjar RR, Kaiser FE, Morley JE (1997): Outcomes of long-term testosterone replacement in older hypogonadal males: A retrospective analysis. J Clin Endocrinol Metab 82, 3793-6.

Hanke H, Tosch A, Lenz Ch, Finking G, Weidemann W (2002): Wirkung von Östrogenen und Androgenen im arteriellen Gefäßsystem - Stellenwert in der Primärund Sekundärprävention der koronaren Herzerkrankung. Dtsch Sportmed 53 ( 2), 3844.

Harper MJ, Walpole AE (1967): A new derivative of triphenylethylene: effect on implantation and mode of action in rats. J Reprod Fertil 13, 101-119.

Hartmann SH, Talbart GB: Reproductive aging. In: Handbook of the biology of aging, $2^{\text {nd }}$; Finch CE, Hanflicks L editors, van Nostrand Reinhold, New York 1985, 457-510.

Higami Y, Tsuchiya T, Chiba T, Yamaza H, Muraoka I, Hirose M, Komatsu T, Shimokawa I (2006): Hepatic gene expression profile of lipid metabolism in rats: Impact of caloric restriction and growth hormone/insulin-like growth factor-1 suppression. J Gerontol A Biol Sci Med Sci 61(11), 1099-110.

Hiort O, Holterhus PM, Nitsche EM (1998): Physiologie and pathophysiologie of androgen action. Bailliers Clin Endocrinol Metab 12, 115.

Ho KJ, Liao JK (2002): Nonnuclear actions of estrogen. Arterioscler Thromb Vasc Biol 22, 1952-1961.

Hofbauer LC, Hicok KC, Khosla S (1998): Effects of gonadal and adrenal androgens in a novel androgen-responsive human osteoblastic cell line. J Cell Biochem 71, 96-108.

Hostanska K, Nisslein T, Freudenstein J, Reichling J, Saller R (2005):

Apoptosis of human prostate androgen-dependent and -independent carcinoma cells induced by an isopropanolic extract of black cohosh involves degradation of cytokeratin (CK) 18. Anticancer Res 25(1A), 139-47.

Houser BB (1979): An investigation of the correlation between hormonal levels in males and mood, behavior and physical discomfort. Horm Behav 12, 185. 
Hughes DE, Jilka RL, Manolagas SC (1995): Sex steroids promote osteoclast apoptosis in vitro and in vivo. J B M R 10 (S1), 150.

Hulley S, Grady D, Bush T, Furberg C, Herrington D, Riggs B, Vittinghoff E (1998): For the Heart and Estrogen/progestin Replacement Study (HERS) Research Group: Randomized trial of estrogen plus progestin for secondary prevention of coronary heart disease in postmenopausal women. J A M A 280, 605-613.

Hyde JS, Fennema E, Lamon SJ (1990): Gender differences in mathematics performance: a meta-analysis. Psychol Bull 107, 139.

Improta-Brears T, Whorton AR, Codazzi F, York JD, Meyer T, McDonnell D P (1999): Estrogen-induced activation of mitogen-activated protein kinase requires mobilization of intracellular calcium. Proc Natl Acad Sci U S A 96, 4686-4691.

Jarry H, Metten M, Spengler B, Christoffel V, Wuttke W (2003): In vitro effects of the Cimicifuga racemosa extract BNO 1055. Maturitas 44, $31-38$.

Jarry H, Stromeier S, Wuttke W, Nahrstedt A (2007): Petasiphenone, a phenol isolated from Cimicifuga racemosa, in vitro inhibits proliferation of the human prostate cancer cell line LNCaP. Planta Med 73(2), 184-7.

Jung SH, Lee YS, Lim SS, Lee S, Shin KH, Kim YS (2004): Antioxidant activities of isoflavones from the rhizomes of Belamcanda chinensis on carbon tetrachlorideinduced hepatic injury in rats. Arch Pharm Res 27(2), 184-8.

Kaiser FE, Kies N, Maas G, Schmid H, Beach RC, Bormacher K, Horrmann WM, Richle $E$ (1978): The measurement of the psychotropic effects of an androgen in the aging male with psychovegetative symptomatology: a controlled double blind study mesterolone versus placebo. Progr Neurol Psychopharmacol 2, 505-15.

Kallen CB, Billheimer JT, Summers SA, Stayrook SE, Lewis M, Strauss JF (1998): Steroidogenic acute regulatory protein (StAR) is a sterol transfer protein. J Biol Chem 273, 26285-26288.

Kasperk CH, Wergedal JE, Farley JR, Linkhart TA, Turner RT, Baylink DJ (1989): Androgens directly stimulate proliferation of bone cells in vitro. Endocrinology 124, 1576-1578.

Kastelan D (2007): Osteoporosis in men. Arh Hig Rada Toksikol 58(1), 25-32.

Kauffman RF, Bensch WR, Roudebush RE, Cole HW, Bean JS, Phillips DL, Monroe A, Cullinan GJ, Glasebrook AL, Bryant HU (1997): Hypocholesterolemic activity of raloxifene (LY139481): pharmacological characterization as a selective estrogen receptor modulator. J Pharmacol Exp Ther 280, 146-153. 
Kiess W, Höflich A: Endokrines System: Insulin-like Growth Factors (IGFs)/Somatomedine. In: Lehrbuch der Klinischen Chemie und Pathobiochemie, 3. Auflage; hrsg. v. Greiling H, Gressner AM, Schattauer-Verlag, Stuttgart 1995, 984 - 988.

Kim JG, Shin CS, Choi YM, Moon SY, Kim SY, Lee JY (1999): The relationship among circulating insulin-like growth factor components, biochemical markers of bone turnover and bone mineral density in postmenopausal women under the age of 60. Clin Endocrinol (Oxf) 51(3), 301-7.

Kommission E Monographie (1989): Cimicifuga. Bundesanzeiger 41, 1070.

Kruse SO: Phytochemische Arbeiten zu Cimicifuga racemosa (L.) Nutt. - Gewinnung und Analytik wirksamer Fraktionen und Inhaltsstoffe. Biol. Diss. Münster, 35-50.

Kuiper GG, Enmark E, Pelto-Huikko M, Nilsson S, Gustafsson JA (1996): Cloning of a novel receptor in rat prostate and ovary. Proc Natl Acad Sci U S A 92, 5925-5930.

Kuiper GG, Lemmen JG, Carlsson B, Corton JC, Safe SH, Van Der Saag PT, Van Der BB, Gustafsson JA (1998): Interaction of estrogenic chemicals and phytoestrogens with estrogen receptor beta. Endocrinology 139, 4252 - 4263.

Kumar V, Chambon P (1988): The estrogen receptor binds tightly to its responsive element as a ligand-induced homodimer. Cell 55, 145-156.

Lamartiniere CA (2000): Protection against breast cancer with genistein: a component of soy. Am J Clin Nutr 71, 1705-7.

Lampit M, Hochberg Z (2003): Androgen therapy in constitutional delay of growth. Horm Res 59(6), 270-5.

Lang F: Wasser- und Elektrolythaushalt: Kalzium- und Phosphathaushalt.In: Physiologie des Menschen, 28. Auflage; hrsg. V. Schmidt RF, Thews G, Lang F, Springer-Verlag, Heidelberg 2000, 786 - 788.

Lazkowski DA, Fraher LJ, Hodsman A, Steer B, Modrowski D, Han VK (1994): Regional variation of insulin-like growth factor I gene expression in mature rat bone and cartilage. Bone 15, 563-576.

Le Mellay V, Grosse B, Lieberherr M (1997): Phospholipase C beta and membrane action of calcitriol and estradiol. J Biol Chem 272, 11902-11907.

LeRoith D, Werner H, Beitner-Johnson D, Roberts CT Jr (1995):

Molecular and cellular aspects of the insulin-like growth factor I receptor.

Endocr Rev 16(2), 143-163. 
Lodish H, Baltimore D, Berk A, Zipursky SL, Matsudaira P, Darnell J: Integrative und spezielle Zellaktivitäten, Signalübertragung zwischen Zellen: Hormone und Rezeptoren. In: Molekulare Zellbiologie, 2. Auflage; Lodish H, Baltimore D editors, de Gruyter-Verlag, Berlin 1996, 887.

Löhning AM (1999) : Beitrag zur pharmakologischen Charakterisierung von Zubereitungen aus Cimicifuga racemosa Nutt., Ranunculaceae. Biol. Diss. Münster, 15-35.

Loomis AK, Thomas $P$ (1999): Binding characteristics of estrogen receptor (ER) in Atlantic croaker (Micropogonias undulatus) testis: different affinity for estrogens and xenobiotics from that of hepatic ER. Biol Reprod 61, 51-60.

Love RR, Mazess RB, Barden HS, Epstein S, Newcomb PA, Jordan VC, Carbone PP, DeMets DL (1992): effects of tamoxifen on bone mineral density in postmenopausal women with breast cancer. N Engl J Med 326, 852-856.

Mahavni V, Sood AK (2001): Hormone replacement therapy and cancer risk. Curr Opin Oncol 13, $384-389$.

Mangelsdorf DJ, Thummel C, Beato M, Herrlich P, Schutz G, Umesono K, Blumberg B, Kastner P, Mark M, Chambon P (1995): The nuclear receptor superfamily: the second decade. Cell 83, 835-839.

Manolagas SC (2000): Birth and death of bone cells: basic regulatory mechanisms and implications for the pathogenesis and treatment of osteoporosis. Endocr Rev 21, 115-137.

Manolagas SC, Kousteni S, Jilka RL (2002): Sex steroids and bone.

Recent Prog Horm Res 57, 385-409.

Marttunen MB, Hietanen P, Tiitinen A, Ylikorkala O (1998): Comparison of effects of tamoxifen and toremifene on bone biochemistry and bone mineral density in postmenopausal breast cancer patients. J Clin Endocrinol Metab 83, 1158-1162.

Mauras N, Rogol AD, Haymond MW, Veldhuis JD (1996): Sex steroids, growth hormone, insulin-like growth factor-1: neuroendocrine and metabolic regulation in puberty. Horm Res 45(1-2), 74-80.

McCarty MF (2001): Androgenic progestins amplify the breast cancer risk associated with hormone replacement therapy by boosting IGF-I activity. Med Hypotheses 56(2), 213-6.

McCarty MF (2004): Chronic activation of AMP-activated kinase as a strategy for slowing aging. Med Hypotheses 63(2), 334-9.

McMichael-Phillips DF, Harding C, Morton M, Roberts SA, Howell A, Potten CS, Bundred NJ (1998): Effects of soy-protein supplementation on epithelial proliferation in the histologically normal human breast. Am J Clin Nutr 68, 1431-6. 
Melmed S (1990): Acromegaly. N Engl J Med 322, 966.

Migliaccio A., Di Domenico M, Castoria G, de Falco A, Bontempo P, Nola E, Auricchio F (1996): Tyrosine kinase/ p21ras/ MAP-kinase pathway activation by estradiol-receptor complex in MCF-7 cells. E M B O J 15, 1292-1300.

Morishima A, Grumbach MM, Simpson ER, Fisher C, Qin K (1995): Aromatase deficiency in male and female siblings caused by a novel mutation and the physiological role of estrogens. J Clin Endocrinol Metab 80, 3689-3698.

Morley P, Whitfield JF, Vanderhyden BC, Tsang BK, Schwartz JL (1992): A new, nongenomic estrogen action: the rapid release of intracellular calcium. Endocrinology 131, $1305-1312$.

Mosselman S, Polman J, Dijkema R (1996): ER beta: identification and characterization of a novel human estrogen receptor. F E B S Lett 392, 49-53.

Mullis K, Faloona F, Scharf S, Saiki R, Horn G, Erlich H (1986):

Specific enzymatic amplification of DNA in vitro: the polymerase chain reaction. Cold Spring Harb Symp Quant Biol 51, 263-273.

Mundy GR (1993): Role of cytokines in bone resorption. J Cell Biochem 53, 296-300.

Nesselhut T, Schellhase C, Dietrich R, Kuhn W (1993): Untersuchungen zur proliferativen Potenz von Phytopharmaka mit östrogenähnlicher Wirkung bei Mammakarzinomzellen. Arch Gynecol Obstet 254, 817-818.

Nikov GN, Hopkins NE, Boue S, Alworth WL (2000):

Interactions of dietary estrogens with human estrogen receptors and the effect on estrogen receptor-estrogen response element complex formation.

Environ Health Perspect 108, 867 - 872.

Nisslein T, Freudenstein J (2003): Effects of an isopropanolic extract of Cimicifuga racemosa on urinary crosslinks and other parameters of bone quality in an ovariectomized rat model of osteoporosis. J Bone Miner Metab 21(6), 370-6.

Nugent AG, Leung KC, Sullivan D, Reutens AT, Ho KK (2003): Modulation by progestogens of the effects of oestrogen on hepatic endocrine function in postmenopausal women. Clin Endocrinol (Oxf) 59(6), 690-8.

Pacifici R, Rifas L, McCracken R (1989): Ovarian steroid treatment blocks a postmenopausal increase in blood monocyte interleukin-1 release. Proc Natl Acad Sci U S A 86, 2398-402.

Passarge E: Genetik, spezielle Pathologie, Proto-Onkogene (Onkogene).In: Klinische Pathophysiologie, 8. Auflage; hrsg. v. Siegenthaler, W, Thieme-Verlag, Stuttgart 2000, 47.

Petrakis NL (1993): Nipple aspirate fluid in epidemiologic studies of breast disease. Epidemiol Rev 15, 188-195. 
Petrakis NL, Barnes S, King EB (1996): Stimulatory influence of soy protein isolate on breast secretion in pre- and postmenopausal women. Cancer Epidemiol Biomarkers Prev 5, 785-794.

Petrides PE: Endokrines Gewebe III: Hypothalamisch-hypophysäres System und Zielgewebe. In: Biochemie und Pathobiochemie, 6. Auflage; hrsg. v. Löffler G, Petrides PE, Springer-Verlag, Berlin 1998 a, 836 - 852.

Petrides PE: Tumorgewebe, Onkogene. In: Biochemie und Pathobiochemie, 6. Auflage; hrsg. v. Löffler G, Petrides PE, Springer-Verlag, Berlin 1998 b, 1092.

Picherit C, Coxam V, Bennetau-Pelissero C, Kati-Coulibali S, Davicco MJ, Lebecque $P$, Barlet JP (2000): Daidzein is more efficient than genistein in preventing ovarectomie-induced bone loss in rats. J Nutr 130, 1675-1681.

Pietschmann P, Skalicky M, Kneissel M, Rauner M, Hofbauer G, Stupphann D, Viidik A (2007): Bone structure and metabolism in a rodent model of male senile osteoporosis. Exp Gerontol 42(11):1099-108.

Plas E, Riedl CR, Pflüger H (2001): Männergesundheit, „Andropause“. Ärzte Woche, 15. Jg 12, 1-4.

Randall VA (1994): Role of 5- $\alpha-$ Reductase in health and disease. Bailliers Clin Endocrinol Metab 8, 405.

Raz R, Stamm WE (1993): A controlled trial of intravaginal estriol in postmenopausal women with recurent urinary tract infection. N Engl J Med 329, 753.

Reiss SE, Gloth ST, Blumenthal RS, Resar JR, Zacur HA, Gerstenblith G, Brinker JA (1994): Ethinyl estradiol acutely attenuates abnormal coronary vasomotor responses to acetylcholine in postmenopausal women. Circulation 89, 52-60.

Robinson E, Kimmick GG, Muss HB (1996): Tamoxifen in postmenopausal women a safety perspective. Drugs \& Aging 8, 329-337.

Robinson JA, Riggs BL, Spelsberg TC (1996): Osteoclasts and transforming growth factor- $ß$ : estrogen mediated isoform-specific regulation of production. Endocrinology 137, 615-21.

Rosen CJ, Donahue LR (1998): Insulin-like growth factors and bone: the osteoporosis connection revisited. Proc Soc Exp Biol Med 219, 1-7.

Rosen CJ, Glowacki J, Craig W (1998): Sex steroids, the insulin-like growth factor regulatory system and aging: implications for the management of older postmenopausal women. J Nutr Health Aging 2, 39-44.

Rubin R, Baserga R (1995): Biology of disease. Insulin-like growth factor-I receptor. Its role in cell proliferation, apoptosis, and tumorigenicity. Lab Invest 73(3), 311-331. 
Runnebaum B, von Holst TH, Rabe T: Klimakterium der Frau. In: Gynäkologische Endokrinologie; Runnebaum B, Rabe T editors, Springer Verlag, Berlin- HeidelbergNew York- London- Paris-Tokyo 1987, 679-99.

Saile B, DiRocco P, Dudas J, El-Armouche H, Sebb H, Eisenbach C, Neubauer K, Ramadori G (2004): IGF-I induces DNA synthesis and apoptosis in rat liver hepatic stellate cells (HSC) but DNA synthesis and proliferation in rat liver myofibroblasts (rMF). Lab Invest 84 (8), 1037-49.

Salmon WD Jr, Daughaday WH (1957): A hormonally controlled serum factor which stimulates sulfate incorporation by cartilage in vitro. J Lab Clin Med 49, 825-836.

Scheiber MD, Liu JH, Subbiah MT, Rebar RW, Setchell KD (2001): Dietary inclusion of whole soy foods result in significant reductions in clinical risk factors for osteoporosis and cardiovascular disease in normal postmenopausal women. Menopause 9, 392-394.

Scheidegger KJ, Cenni B, Picard D, Delafontaine P (2000): Estradiol decreases IGF1 and IGF-1 receptor expression in rat aortic smooth muscle cells: mechanisms for its atheroprotective effects. J Biol Chem 10, 1074.

Schill WB (2001): Fertility and sexual life of men after their forties and in older age. Asian J Androl 3, 1-7.

Schopohl J: Testis: physiologische Grundlagen und allgemeine Pathophysiologie. In: Klinische Pathophysiologie, 8. Auflage; hrsg. v. Siegenthaler W, Thieme-Verlag, Stuttgart 2000 a, $353-357$.

Schopohl J: Testis: Spezielle Pathophysiologie: Hypergonadotroper Hypogonadismus. In: Klinische Pathophysiologie, 8. Auflage; hrsg. v. Siegenthaler W, Thieme-Verlag, Stuttgart 2000 b, 362.

Seidlova-Wuttke D, Christoffel V, Heiden I, Jarry H, Spengler B, Wuttke W (2000): Die Wirkung von Belamcanda chinensis abstammenden Phytoöstrogenen auf die Serum-LH-Spiegel und auf die Expression von östrogenregulierten Genen im Uterus und im Knochen der ovarektomierten Ratte. J Menopause 7 (2, Ausgabe für Deutschland) 28-31.

Seidlova-Wuttke D, Hesse O, Jarry H, Christoffel V, Spengler B, Becker T, Wuttke W (2003): Evidence for selective estrogen receptor modulator activity in a black cohosh (Cimicifuga racemosa) extract: comparison with estradiol-17ß. Eur J Endocrinol 149, 351-362.

Seidlova-Wuttke D, Hesse O, Jarry H, Rimoldi G, Thelen P, Christoffel V, Wuttke W (2004): Belamcanda chiensis and the therof purified tectorigenin have selective estrogen receptor modulator activities. Phytomedicine 11 (5), 392-403.

Seidlova-Wuttke D, Jarry H, Pitzel L, Wuttke W (2005): Effects of estradiol-17beta, testosterone and a black cohosh preparation on bone and prostate in orchidectomized rats. Maturitas 51(2), 177-86. 
Seidlova-Wuttke D, Thelen P, Wuttke W (2006): Inhibitory effects of a black cohosh (Cimicifuga racemosa) extract on prostate cancer. Planta Med 72 (6), 521-6.

Sell C, Rubini M, Rubin R, Liu JP, Efstratiadis A, Baserga R (1993):

Simian virus 40 large tumor antigen is unable to transform mouse embryonic fibroblasts lacking type-I IGF receptor. P N A S 90, 11217-11221.

Selye H (1942): Correlations between the chemical structures and the pharmacological actions of the steroids. Endocrinology 30, 437-453.

Sepp-Lorenzino L (1998):Structure and function of the insulin-like growth factor I receptor. Breast Cancer Res Treat 47, 235-253.

Setchell KD, Gosselin SJ, Welsh MB, Johnston JO, Balistreri WF, Kramer LW, Dresser BL, Tarr MJ (1987): Dietary estrogens--a probable cause of infertility and liver disease in captive cheetahs. Gastroenterology 93 (2), 225-33.

Setchell KD, Brown NM, Desai P, Zimmer-Nechemias L, Wolfe BE, Brashear WT, Kirschner AS, Cassidy A, Heubi JE (2001): Bioavailability of pure isoflavones in healthy humans and analysis of commercial soy isoflavone supplements. J Nutr 131, 1362-1375.

Shapiro J, Christiana J, Frishman WH (1999): Testosterone and other anabolic steroids as cardiovascular drugs. Am J Therapeut 6, 167-174.

Shi-Juan C, Huaibin L, Durand J, Oparil S, Yui-Fai C (1999): Estrogen reduces myointimal proliferation after balloon injury of rat carotid artery. Circulation 93, 577584.

Simoncini T, Varone G, Fornari L, Mannella P, Luisi M, Labrie F, Genazzani AR (2002): Genomic and nongenomic mechanisms of nitric oxide synthesis induction in human endothelial cells by a fourth generation selective estrogen receptor modulator. Endocrinology 143, 2052-2061.

Smith EP, Boyd J, Frank GR, Takahashi H, Cohen RM, Specker B, Williams TC, Lubahn DB, Korach KS (1994): Estrogen resistance caused by a mutation in the estrogen-receptor gene in a man. N Engl J Med 331, 1056-1061.

Spelsberg TC, Subramaniam M, Riggs BL, Khosla S (1999): The actions and interactions of sex steroids and growth factors/cytokines on the skeleton. Mol Endocrinol 13: 819-828.

Stewart CEH, Rotwein P (1996): Growth, differentiation, and survival: multiple physiological functions for insulin-like growth factors. Physiol Rev 76 (4), 1005-1026.

St Germain A, Peterson CT, Robinson JG, Alekel DL (2001): Isoflavone-rich or isoflavone-poor soy protein does not reduce menopausal symptoms during 24 weeks of treatment. Menopause 8, 17-26. 
Stürmer EK, Seidlova-Wuttke D, Sehmisch S, RackT, Wille J, Frosch KH, Wuttke W, Stürmer KM (2006): Standardized bending and breaking test for the normal and osteoporotic metaphyseal tibias of the rat: effect of estradiol, testosterone and raloxifene. J Bone Miner Res 21(1), 89-96.

Tenover JS, Dahl KD, Vale WW, Rivier JE, Bremner WJ (1990): Hormonal responses to a potent gonadotropin hormone-releasing hormone antagonist in normal elderly men. J Clin Endocrinol Metab 71, 881-8.

Thelen P, Scharf JG, Burfeind P, Hemmerlein B, Wuttke W, Spengler B, Christoffel V, Ringert RH, Seidlova-Wuttke D (2005): Tectorigenin and other phytochemicals extracted from leopard lily Belamcanda chinensis affect new and established targets for therapies in prostate cancer. Carcinogenesis 26 (8), 1360-7.

Tremblay RR, Morales A (1998): Canadian practice recommendations for screening, monitoring and treating men affected by andropause or partial androgen deficiency. The Aging Male 1, 213-8.

Tse WT, Forget BG (1990): Reverse transcription and direct amplification of cellular RNA transcripts by Taq polymerase. Gene 88: 293 - 296.

Urban RJ, Bodenburg YH, Gilkison C, Foxworth J, Coggan AR, Wolfe RR, Ferrando A (1995): Testosterone administration to elderly men increases sklettal muscle strength and protein synthesis. Am J Physiol 269, 820.

Vargas R, Wroblewska B, Rego A, Hatch J, Ramwell PW (1993): Estradiol inhibits smooth muscle cell proliferation of pig coronary artery. B J P 109, 612-617.

Venken K, Schuit F, Van Lommel L, Tsukamoto K, Kopchick JJ, Coschigano K, Ohlsson C, Movérare S, Boonen S, Bouillon R, Vanderschueren D (2005): Growth without growth hormone receptor: estradiol is a major growth hormone-independent regulator of hepatic IGF-I synthesis. J Bone Miner Res 20 (12), 2138-49.

Venken K, Movérare-Skrtic S, Kopchick JJ, Coschigano KT, Ohlsson C, Boonen S, Bouillon R, Vanderschueren D (2007): Impact of androgens, growth hormone and IGF-I on bone and muscle in male mice during puberty. J Bone Miner Res 22 (1), 72-82.

Vermeulen A: Alteration of Leydig cell function and its mechanism in the aging male. In: Carl Schirren-Symposium: Advances in Andrology; Holstein AF, Leidenberger F, Hölzer KH, Bettendorf G editors, Diesbach, Berlin 1988, 82-5.

Vermeulen A: Androgens and male senescence. In: Testosterone; Nieschlag E, Behre HM editors, Springer, Berlin-Heidelberg 1990, 261-76.

Vetter W, Bachmann LM: Nebennierenrinde, Allgemeine und spezielle Pathophysiologie, Androgene. In: Klinische Pathophysiologie, 8. Auflage; hrsg. v. Siegenthaler W, Thieme-Verlag, Stuttgart 2000, 343. 
Viereck V, Gründker C, Friess SC, Frosch KH, Raddatz D, Schoppet M, Nisslein T, Emons G, Hofbauer LC (2005): Isopropanolic extract of black cohosh stimulates osteoprotegerin production by human osteoblasts. J Bone Miner Res 20 (11), 2036-43.

Wagner JD, Clarkson TB, St Clair RW, Schwenke DC, Shively CA, Adams MR (1991): Estrogen and progesterone replacement therapy reduces low density lipoprotein accumulation in the coronary arteries of surgically postmenopausal Cynomolgus monkeys. J Clin Invest 88, 1995-2002.

Wagner H, Bauer R, Xiao PG, Chen JM, Nenninger A: Rhizoma Belamcandae sinensis. In: Chinese Drug Monographs and Analysis 2 [11]; hrsg. v. Dr. Erich Wühr, Verlag für Ganzheitliche Medizin, Kötzting 1999, 1-13.

Wakisaka A, Tanaka H, Barnes J, Liang CT (1998): Effect of locally infused IGF-I on femoral gene expression and bone turnover activity in old rats. J Bone Miner Res $13(1), 13-9$.

Webb CM, McNeill JG, Hayward CS, de Zeigler D, Collins P (1999): Effects of testosterone on coronary vasomotor regulation in men with coronary heart disease. Circulation 100, 1690-1696.

Wermer AA (1939): The male climacteric. J A M A 119, 1441-3.

Werner H, Le Roith D (1997) : The Insulin-Like Growth Factor-I Receptor - Signaling Pathways Are Important for Tumorgenesis and Inhibition of Apoptosis.

Crit Rev Oncog 8 (1), 71-92.

Wide L (1985): Median charge and charge heterogeneity of human pituitary FSH, LH and TSH: II. Relationship to sex and age. Acta Endocrinol (Copenh) 109, 190-7.

Williams JK, Honore EK, Washburn SA, Clarkson TB (1994): Effects of hormone replacement therapy on reactivity of atherosclerotic coronary arteries in Cynomolgus monkeys. J Am Coll Cardiol 24, 1757-1761.

Wu S, Wenig X (1992): Therapeutic effects of andriol on serum lipids and apolipoproteins in elderly male coronary heart disease patients. Chin Med Sci 7, 137-141.

Wuttke W: Endokrinologie: Regulation der Gonadenfunktion. In: Physiologie des Menschen, 28. Auflage; hrsg. v. Schmidt RF, Thews G, Lang F, Springer-Verlag, Heidelberg 2000 a, 380.

Wuttke W: Endokrinologie: Wachstumshormon. In: Physiologie des Menschen, 28. Auflage; hrsg. v. Schmidt RF, Thews G, Lang F, Springer-Verlag, Heidelberg 2000 b, 398.

Wuttke W, Jarry H, Becker T, Schultens A, Christoffel V, Gorkow C, Seidlova-Wuttke D (2002a): Phytoestrogens: endocrine disrupters or replacement for hormone replacement therapy? Maturitas 44 (1), 9-20. 
Wuttke W, Seidlova-Wuttke D, Gorkow C (2002b): The Cimicifuga preparation BNO 1055 vs. conjugated estrogens in a double-blind placebo-controlled study: effects on menopause symptoms and bone markers. Maturitas 44 (1), 67-77.

Yakar S, Liu JL, Stannard B, Butler A, Accili D, Sauer B, Leroith D (1999):

Normal growth and development in the absence of hepatic insulin-like growth factor I. Proc Natl Acad Sci U S A 96, 7324-7329.

Yasuda H, Shima N, Nakagawa N, Mochizuki SI, Yano K, Fujise N, Sato Y, Goto M, Yamaguchi K, Kuriyama M (1999): Identity of osteoclastogenesis inhibitory factor (OCIF) and osteoprotegerin (OPG): a mechanism by which OPG/OCIF inhibits osteoclastogenesis in vitro. Endocrinology 139, 1329 - 1337.

Zanker CL, Swaine IL (2000): Responses of bone turnover markers to repeated endurance running in humans under conditions of energy balance or energy restriction. Eur J Appl Physiol 83, $434-440$.

Zapf J (1995): Physiological role of the insulin-like growth factor binding proteins. Eur J Endocrinol 132, 645-654.

Ziegler R: Calcium- und Knochenstoffwechsel : Allgemeine und spezielle Pathologie. In: Klinische Pathophysiologie, 8. Auflage; hrsg. v. Siegenthaler, W., Thieme-Verlag, Stuttgart 2000, 319.

Zmuda JM, Thompson PD, Dickenson R (1996): Testosterone decreases lipoprotein a in men. Am J Cardiol 77, 1244-1247. 


\section{Danksagung}

Ich möchte mich herzlich bei Herrn Prof. Dr. Wolfgang Wuttke für die Überlassung des Themas sowie für das damit vebundene Vertrauen und seine Betreuung bedanken.

Besonders danken möchte ich Frau Dr. Dana Seidlova-Wuttke für ihre großartige Betreuung während der gesamten Dauer der Doktorarbeit sowie für ihre freundliche Art.

Mein Dank gilt ferner Frau Sabine Lüdemann, unter deren Anleitung ein großer Teil der experimentellen Arbeit erfolgt ist, sowie allen Mitarbeiterinnen und Mitarbeitern aus dem Department für Endokrinologie der Medizinischen Fakultät der Universität Göttingen. 


\section{Lebenslauf}

Ich bin am 09.04.1975 in Teheran / Iran geboren. Die Grundschule besuchte ich in Teheran, die Orientierungsstufe und das Gymnasium jedoch in Göttingen.

05/1995 konnte ich die allgemeine Hochschulreife am Felix-Klein-Gymnasium erlangen.

04/1996 begann ich den Studiengang Humanmedizin an der Universität Göttingen. Ich legte die ärztliche Vorprüfung 09/1998, den ersten Abschnitt der ärztlichen Prüfung 03/2000 und den zweiten Abschnitt 09/2001 ab. Während des Praktischen Jahres durfte ich für zwei Monate in der Notaufnahme eines Teheraner Krankenhauses (Tehran-Hospital) arbeiten. Den dritten Abschnitt der ärztlichen Prüfung konnte ich am 10.12.2002 in Göttingen erfolgreich bestehen. 04/2003 begann ich meine berufliche Tätigkeit als Arzt im Praktikum im Zentrum Innere Medizin, Abteilung Nephrologie und Rheumatologie des Universitätsklinikums Göttingen.

Am 07.05.2004 heiratete ich meine Ehefrau Parisa, geborene Memarmoshrefi.

Seit 10/2004 bin ich als Assistenzarzt in der Abteilung Gastroenterologie und Endokrinologie tätig. 